Extended Plate and Beam Wall System: Concept Investigation and Initial Evaluation

J. Wiehagen and V. Kochkin Partnership for Home Innovation

August 2015 


\section{NOTICE}

This report was prepared as an account of work sponsored by an agency of the United States government. Neither the United States government nor any agency thereof, nor any of their employees, subcontractors, or affiliated partners makes any warranty, express or implied, or assumes any legal liability or responsibility for the accuracy, completeness, or usefulness of any information, apparatus, product, or process disclosed, or represents that its use would not infringe privately owned rights. Reference herein to any specific commercial product, process, or service by trade name, trademark, manufacturer, or otherwise does not necessarily constitute or imply its endorsement, recommendation, or favoring by the United States government or any agency thereof. The views and opinions of authors expressed herein do not necessarily state or reflect those of the United States government or any agency thereof.

Available electronically at SciTech Connect http:/www.osti.gov/scitech

Available for a processing fee to U.S. Department of Energy

and its contractors, in paper, from:

U.S. Department of Energy

Office of Scientific and Technical Information

P.O. Box 62

Oak Ridge, TN 37831-0062

OSTI http://www.osti.gov

Phone: 865.576.8401

Fax: 865.576.5728

Email: reports@osti.gov

Available for sale to the public, in paper, from:

U.S. Department of Commerce

National Technical Information Service

5301 Shawnee Road

Alexandria, VA 22312

NTIS http://www.ntis.gov

Phone: 800.553 .6847 or 703.605 .6000

Fax: 703.605.6900

Email: orders@ntis.gov 


\title{
Extended Plate and Beam Wall System: Concept Investigation and Initial Evaluation
}

\author{
Prepared for: \\ The National Renewable Energy Laboratory \\ On behalf of the U.S. Department of Energy's Building America Program \\ Office of Energy Efficiency and Renewable Energy \\ 15013 Denver West Parkway \\ Golden, CO 80401 \\ NREL Contract No. DE-AC36-08GO28308 \\ Prepared by: \\ J. Wiehagen and V. Kochkin \\ Home Innovation Research Labs \\ Partnership for Home Innovation \\ 400 Prince George's Blvd. \\ Upper Marlboro, MD 20774 \\ NREL Technical Monitor: Stacey Rothgeb \\ Prepared under Subcontract No. KNDJ-0-40335-05
}

August 2015 
The work presented in this report does not represent performance of any product relative to regulated minimum efficiency requirements.

The laboratory and/or field sites used for this work are not certified rating test facilities. The conditions and methods under which products were characterized for this work differ from standard rating conditions, as described.

Because the methods and conditions differ, the reported results are not comparable to rated product performance and should only be used to estimate performance under the measured conditions. 


\section{Contents}

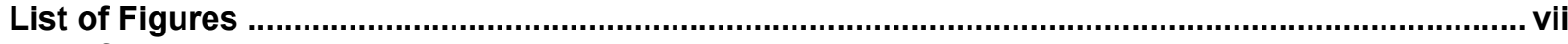

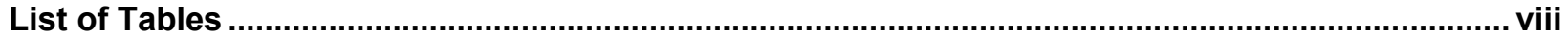

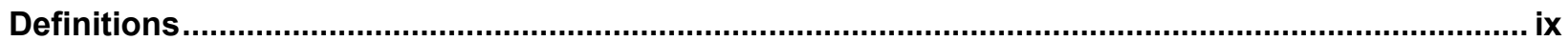

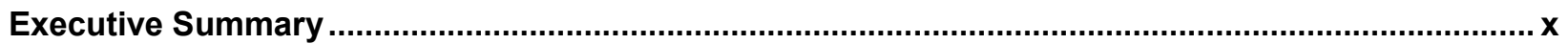

1 Problem Statement

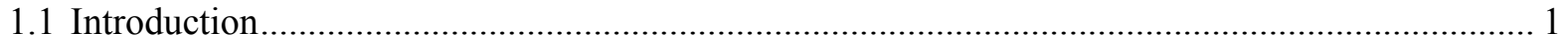

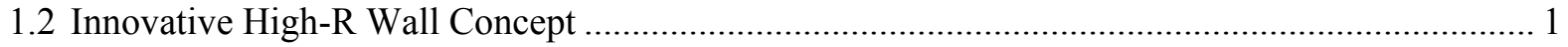

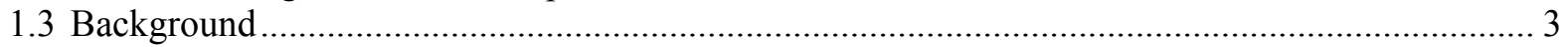

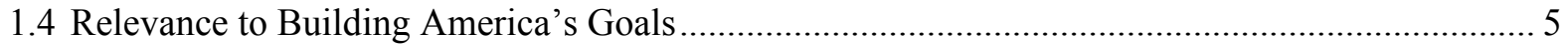

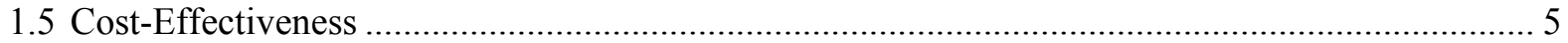

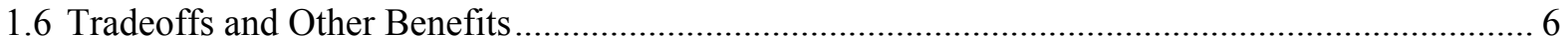

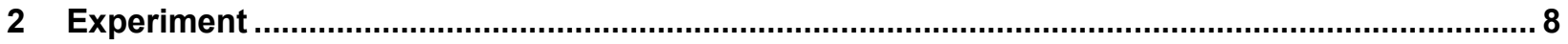

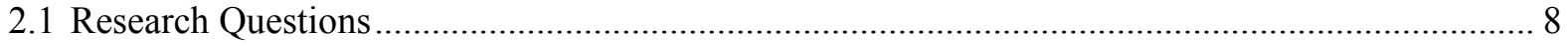

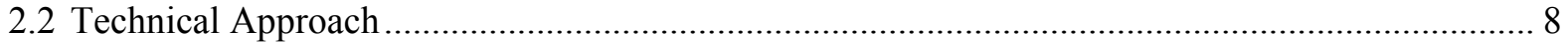

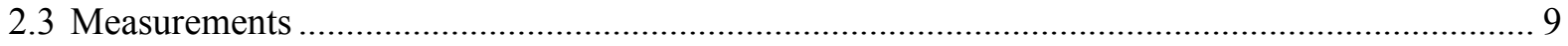

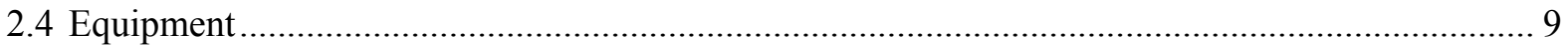

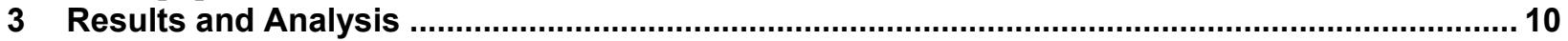

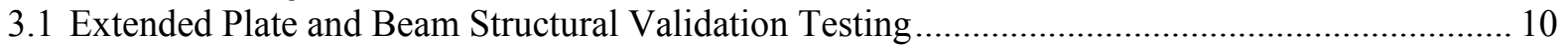

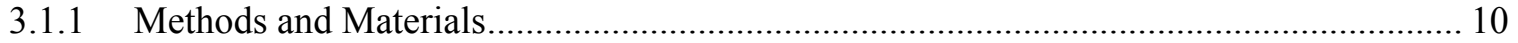

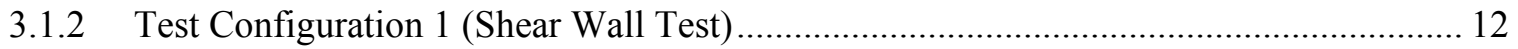

3.1.3 Test Configuration 2 (Shear Wall Test) .................................................................... 13

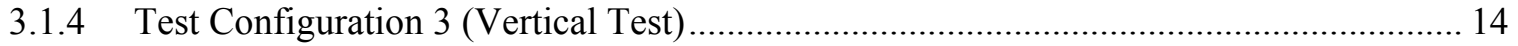

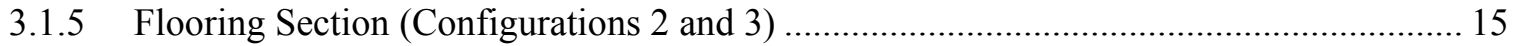

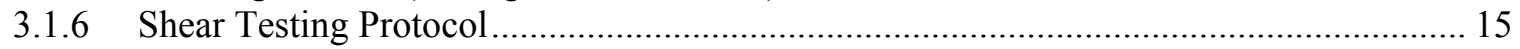

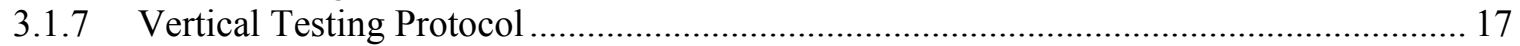

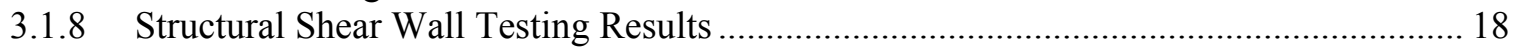

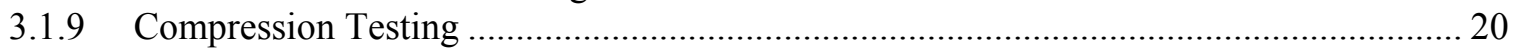

3.1.10 Extended Plate and Beam Wall System Structural Testing Summary Analysis.............. 21

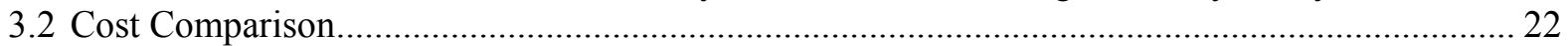

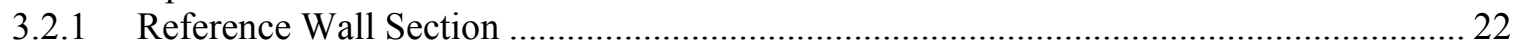

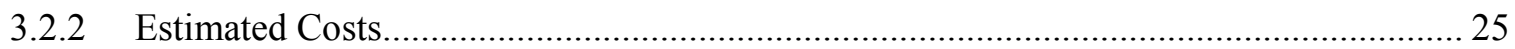

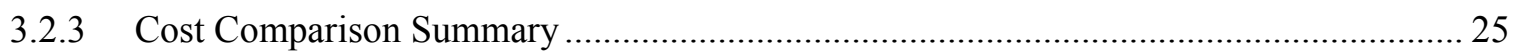

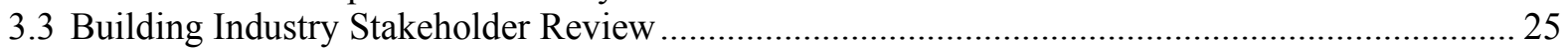

3.3.1 Extended Plate and Beam Constructability Evaluation Based on Stakeholder Discussion26

3.3.2 Stakeholder Review-Extended Plate and Beam Design and Construction

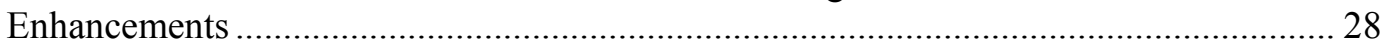

3.3.3 Extended Plate and Beam Building Code Review ......................................................... 29

3.3.4 Summary of Extended Plate and Beam Building Code Applicability ............................. 30

3.4 Extended Plate and Beam Construction Details ..................................................................... 30

3.4.1 Extended Plate and Beam Construction Detail Set........................................................ 31

3.4.2 Summary of Extended Plate and Beam Wall Detail Development................................... 32

3.5 Extended Plate and Beam Example Scope of Work (Framing) ................................................. 33

3.6 Example International Residential Code Prescriptive Requirements for the Extended Plate and

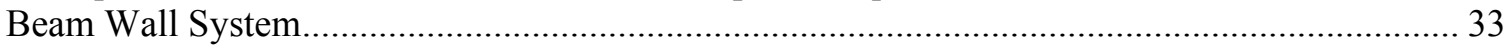

3.6.1 Example International Residential Code Provisions Applicable to the Extended Plate and

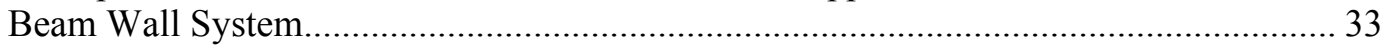




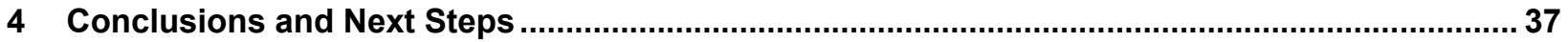

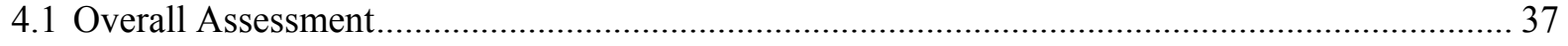

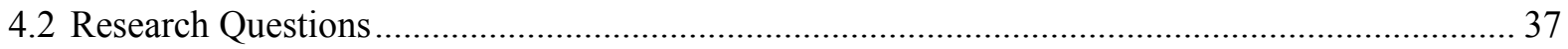

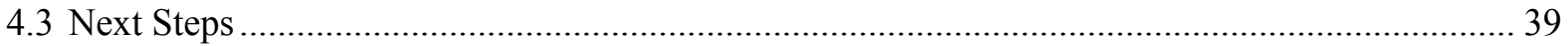

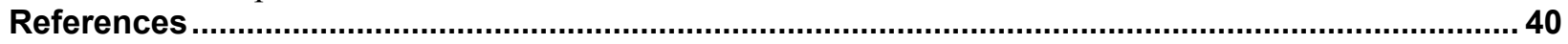

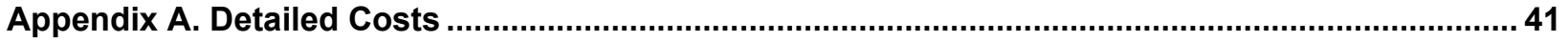

Appendix B. Reference Wall Details and Individual Cost Summary ................................................ 43

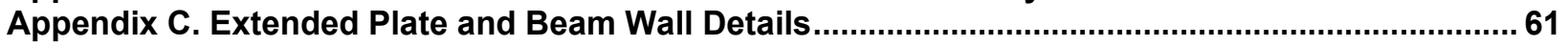

Appendix D. Scope of Work, Field Framing of Extended Plate and Beam Walls .............................. 73

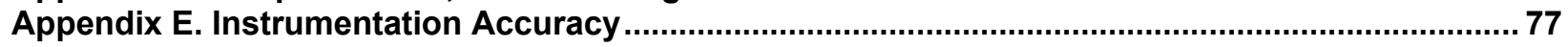




\section{List of Figures}

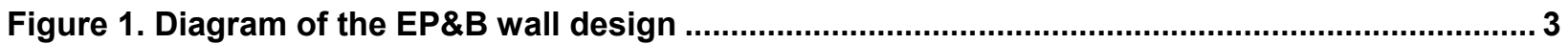

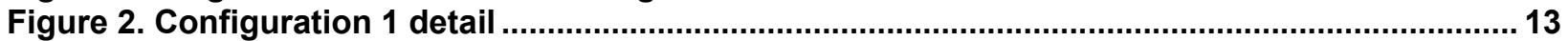

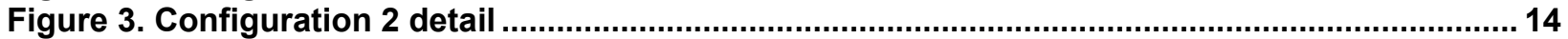

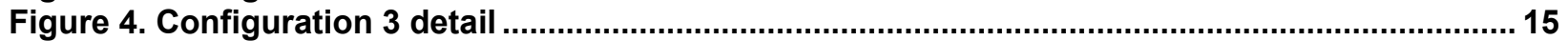

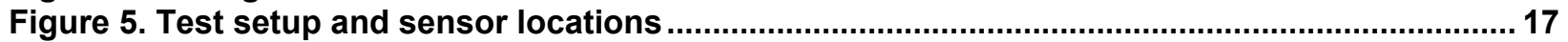

Figure 6. Specimen in test setup with and without floor platform ........................................... 17

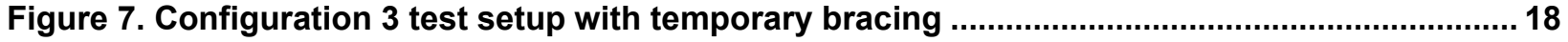

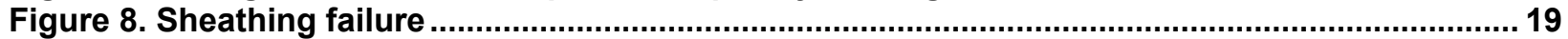

Figure 9. Shear load versus deflection comparison .................................................................. 20

Figure 10. Primary failure mode of compression test.................................................................... 21

Figure 11. Example gypsum board damage

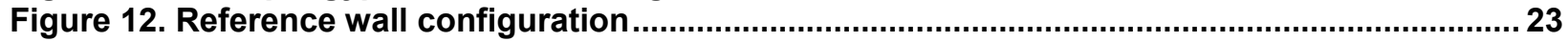

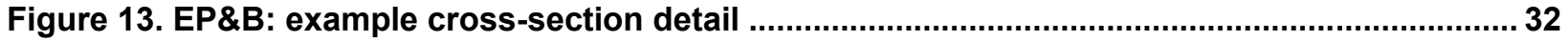

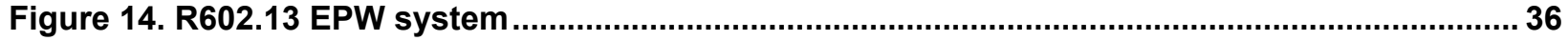

Figure 15. R602.13.7 Full-width studs (bucks) at door openings................................................... 36

Figure B1. Configurations VS1 and FCS1-2 × 4 studs @ 16 in. o.c.............................................. 43

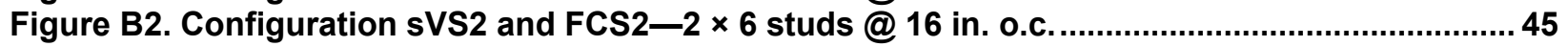

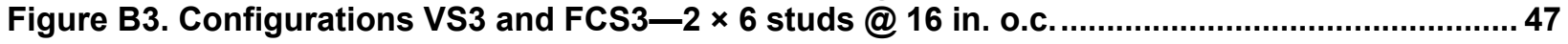

Figure B4. Configurations VS4 and FCS4-2 × 6 EP\&B................................................................... 49

Figure B5. Configurations VS5 and FCS5-2 $\times 4$ stud @16 in. o.c. with 2 in. $+1 / 2$ in. exterior XPS . 51

Figure B6. Configurations VS6 and FCS6-2 $\times 6$ stud @16 in. o.c. with 2 in. $+1 / 2$ in. exterior XPS .53

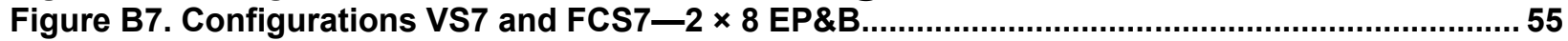

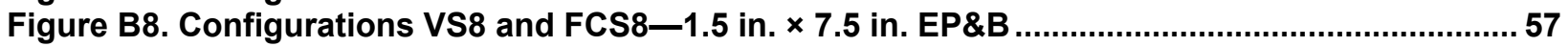

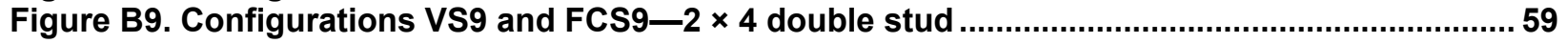

Unless otherwise noted, all figures were created by Home Innovation Research Labs. 


\section{List of Tables}

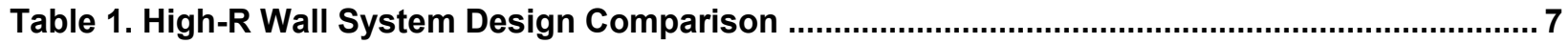

Table 2. High-R Wall Cost and Construction Tradeoffs ............................................................... 7

Table 3. EP\&B Wall Test Methodologies ….................................................................................... 9

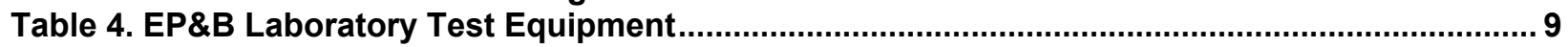

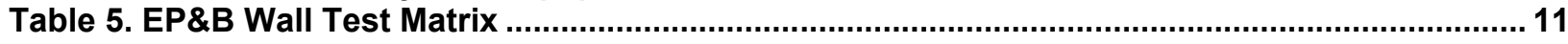

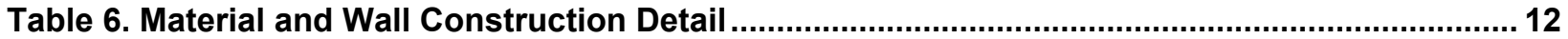

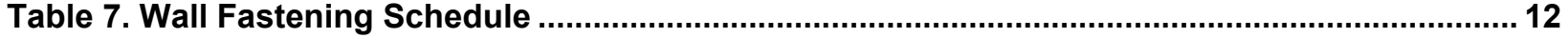

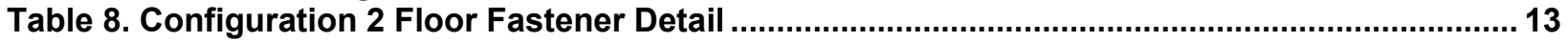

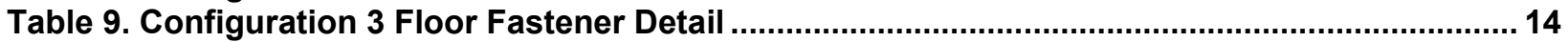

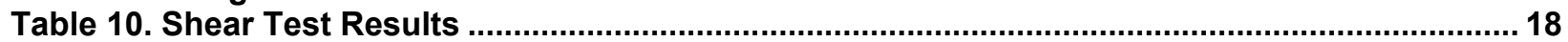

Table 11. Residual Deflections at Three Reloading Stages (ASTM E72) .......................................... 19

Table 12. Representative Wall Section Configuration Cost Estimates ............................................. 24

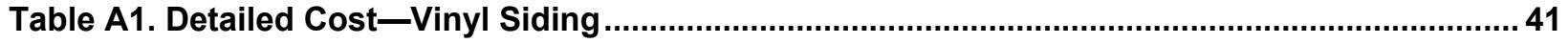

Table A2. Detailed Cost-Fiber Cement Siding ....................................................................... 42

Table B1. Costs for Configurations VS1 and FCS1-2 × 4 Studs @ 16 in. o.c. ............................... 44

Table B2. Costs for Configurations VS2 and FCS2-2 $\times 6$ Studs @ 16 in. o.c. ...............................46

Table B3. Costs for Configurations VS3 and FCS3-2 $\times 6$ studs @ 24 in. 0.c................................... 48

Table B4. Costs for Configurations VS4 and FCS4-2 × 6 EP\&B …................................................. 50

Table B5. Costs for Configuration VS5 andFCS5-2 × 4 Stud @16 in. o.c. With 2 in. + 1/2 in. Exterior XPS

Table B6. Costs for Configurations VS6 and FCS6-2 × 6 Stud @16 in. o.c. With 2 in. + 1/2 in.

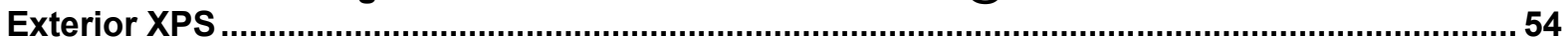

Table B7. Costs for Configurations VS7 and FCS7-2 × 8 EP\&B …......................................... 56

Table B8. Costs for Configurations VS8 and FCS8-1.5 in. $\times 7.5$ in. EP\&B .................................58

Table B9. Costs for Configurations VS9 and FCS9-2 $\times 4$ Double Stud ........................................60

Unless otherwise noted, all tables were created by Home Innovation Research Labs. 


\section{Definitions}

$2 \times 4$

$2 \times 6$

$2 \times 8$

$2 \times 10$

BA

EP\&B

FCS

High-R

ICF

IECC

IRC

o.c.

OSB

R-value

SIP

SPF

UTM

U-value

VS

WSP

XPS
Nominal $2 \times 4$ dimensional lumber $\left(1-\frac{1}{2}\right.$ in. $\times 3-1 / 2$ in. actual $)$

Nominal $2 \times 6$ dimensional lumber $\left(1-\frac{1}{2}\right.$ in. $\times 5-1 / 2$ in. actual $)$

Nominal $2 \times 8$ dimensional lumber $(1-1 / 2$ in. $\times 7-1 / 4$ in. actual $)$

Nominal $2 \times 10$ dimensional lumber $(1-1 / 2$ in. $\times 9-1 / 4$ in. actual $)$

DOE Building America Program

Extended Plate and Beam

Fiber Cement Siding

Building America program reference to wall systems with high thermal resistance exceeding energy code minimum requirements

Insulating Concrete Form

International Energy Conservation Code

International Residential Code

On Center

Oriented Strand Board

Quantitative measure of resistance to heat flow

Structural Insulated Panel

Spray Polyurethane Foam

Universal Test Machine

Quantitative measure of heat flow $\left(\mathrm{Btu} / \mathrm{h} \cdot{ }^{\circ} \mathrm{F} \cdot \mathrm{ft}^{2}\right)$, reciprocal of R-value

Vinyl Siding

Wood Structural Panel

Extruded Polystyrene 


\section{Executive Summary}

A new and innovative high-R wall design called the extended plate and beam (EP\&B) is under development. The EP\&B system uniquely integrates foam sheathing insulation with wall framing such that wood structural panels are installed exterior to the foam sheathing. This system enables the use of standard practices for installing the drainage plane, windows and doors, claddings, cavity insulation, and interior finishes. It reduces transition risks for builders and features R-25 to R-30 thermal resistance. It also provides superior moisture performance because it maintains warmer cavity temperatures and allows uninterrupted drying of oriented strand boards to the outside. The system is equally suitable to field framing or factory panelization. The latter option has a significant advantage over the standard exterior foam sheathing installation approach, which uses prefabricated wall panels with foam that may be damaged during transport.

As part of the ongoing work, the EP\&B wall system concept underwent structural verification testing and was positively vetted by a group of industry stakeholders. After passing these initial milestone markers the system design (1) was analyzed to assess the cost implications relative to other advanced wall systems, (2) underwent design assessment to develop construction details, and (3) was evaluated to develop representative prescriptive requirements for the building code. This report summarizes the assessment steps conducted to date and provides details about the concept development. The keys results of the evaluation follow.

- The results of the overall assessment summarized in this report support the viability of the EP\&B wall system and warrant its continued refinement and the development of further substantiating documentation about the system's performance.

- The shear performance of the EP\&B walls is consistent with the capacities for the current braced wall methods in the International Residential Code.

- Results of an initial test of a shear wall specimen supported by a floor platform do not indicate a negative impact on shear capacity from insetting the rim board by 1 in.

Although further testing is needed, this finding can support a change in construction practices for insulating rim areas by enabling the installation of rigid foam sheathing products exterior to the rim. (This conclusion is equally applicable to standard $2 \times 6$ wall systems with cavity insulation.)

- Vertical load testing indicates that the floor rim joist detail can carry story-to-story forces that exceed loads that apply to typical low-rise residential construction.

- The cost of the EP\&B system is comparable to - and in some cases lower than - that of other walls with the same R-value. The cost normalized by the R-value is also similar between wall types in the same R-value range. Therefore, the added benefits of the EP\&B system do not come with an extra price; in some cases they result in a moderate cost savings relative to comparable R-value alternatives.

- The stakeholder review and a similar review by building code officials indicate that continued development of the EP\&B system is warranted and will be beneficial to the residential building industry. 
- A comprehensive set of framing details and options for the EP\&B was developed and refined as part of the stakeholder review process and as part of demonstration site activities. A complementary scope of work was developed to support the implementation of the construction details and to help integrate quality assurance measures. An example set of International Residential Code provisions was developed to demonstrate the system's applicability within the code format.

- The EP\&B wall system enables construction with R-values at least 50\% higher than standard code requirements. The major advantage of the EP\&B system is that its straightforward approach uses methods and materials that are common to the industry.

- A set of next steps is mapped out to help accelerate market adoption of the EP\&B system. 


\section{Problem Statement}

\subsection{Introduction}

Fueled by above-code programs such as the U.S. Department of Energy's Zero Energy Ready Home program, various green building programs, and new building code requirements, the demand for higher performing wall systems is greater than ever. Numerous concepts for higher R-value walls have emerged primarily in custom homes and in small well-defined projects. Examples include double-wall framing, thick rigid exterior foam panels over standard framing, closed-cell foam-filled cavity framing, oriented strand board (OSB) thicker than 1 in., wall structural insulated panels (SIPs), and $2 \times 8$ or $2 \times 10$ dimensional wall framing systems. Monolithic wall systems such as SIPs, insulated concrete forms (ICFs), and other versions of these technology approaches are available now with prescriptive design requirements that can help enable the use of the technology. However, to date they have combined for less than $5 \%$ of the above-grade wall residential construction market. ${ }^{1}$

These systems are designed primarily to achieve nominal R-values of R-20 to R-30; the higher R levels add more cost and complexity. Most of the wall system designs that achieve R-value levels higher than R-30 have a significant learning curve and require the addition of mostly unfamiliar structural and flashing details compared to typical construction methodologies currently used by the trades. Many of these newer systems do not yet lend themselves to adoption by production builders because of limited availability of design and material integration details, lack of trade contractor training and work scopes, quality assurance processes that are geared toward standard construction processes, and a lack of field experience that has prevented the construction industry from working through the inevitable problems when a new structural technology is used.

The scope of this study includes walls of R-25 to R-30 that are intended to support zero energy ready homes in climate zones 4 and higher. The study focuses primarily on finding practical methods for incorporating more than $1-1 / 2$ in. of rigid foam sheathing. The objective is to conduct an initial set of evaluations to advance the development effort to the next stage gate before embarking on an in-depth assessment for achieving code compliance and broader market acceptance.

\subsection{Innovative High-R Wall Concept}

A unique wall design that is under development features a simple and clear innovation-a framing system that can achieve a nominal R-25 or R-30 thermal performance (R-20 or R-25 whole-wall) level with installation details that are much more common to the standard framing details used in most residential framing today. Any investigation of a new wall design concept must analyze the innovative system in light of the advanced framing designs already in use to determine the structural, thermal, moisture, economic, and installation factors that have the greatest potential to limit adoption of the concept. The overall concept selected for investigation was developed from current construction experience, hybrid concepts of various commercially available approaches, and new concepts based on discussions with industry professionals. The investigation into developing an adaptable high- $\mathrm{R}$ wall system design will be guided by an

\footnotetext{
${ }^{1}$ Based on the Home Innovation Research Labs' Builder Practices Survey.
} 
overall principle for balancing the cost and complexity of shifting to a high-R wall system with a focus on builders of noncustom homes.

One such concept under investigation and reported here is the extended plate and beam (EP\&B) wall framing design. EP\&B is an advanced wall system design that incorporates foam sheathing integrated with a framing system that allows the structural sheathing panels to be mounted exterior to the foam insulation. The key design and performance features of the EP\&B design include:

- $\quad$ Reduced thermal bridging from framing members

- Structural sheathing installed on the exterior for siding attachment and nailed directly to the extended top and bottom plates to provide shear load resistance

- A single drainage plane and flashing surface for window and door openings at the exterior structural sheathing

- Structural sheathing that can dry directly to the exterior and has limited exposure to interior moisture diffusion

- Flexibility in the selection of wall cavity and foam sheathing materials

- Flexibility in the use of framing combinations for optimum overall wall thermal resistance

- A rim beam design that eliminates standard headers in most wall sections spanned by the beam.

This proposed EP\&B advanced wall design is diagramed in Figure 1. The design relies on common construction methods and materials. However, extended top and bottom plates enable the integration of foam sheathing into a conventional wall system in a manner that continues to provide structural backing for siding attachment and relies on wood structural panels (WSPs) that are nailed directly to the framing for shear resistance. The rim beam ensures the continuity of the vertical load path. Complementing these innovations is the development of a complete design solution that may be readily standardized into prescriptive procedures so that the wall system may be constructed and approved with as little transition cost as possible.

This report summarizes the results of an initial evaluation of the following aspects of the EP\&B system:

- Shear wall performance

- Vertical load capacity

- Cost

- Constructability

- Feasibility of some of the specific elements. 


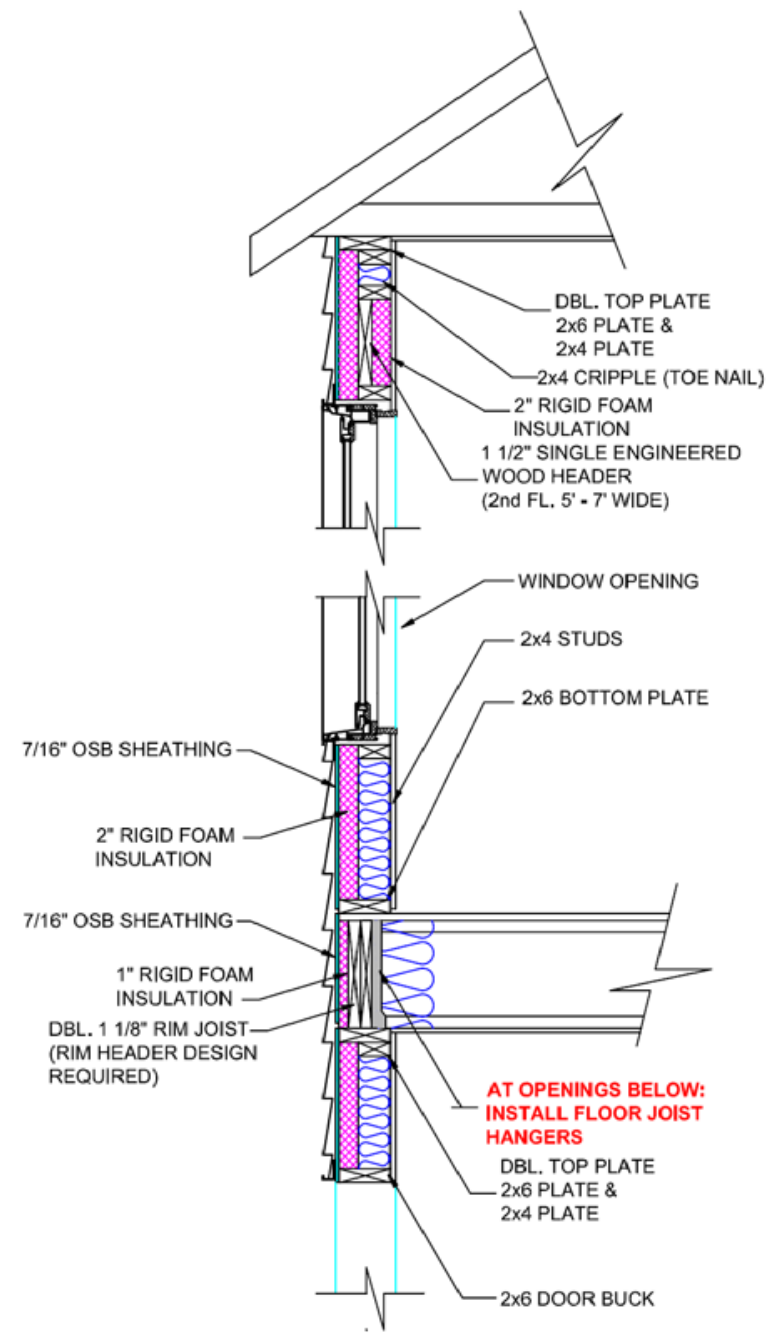

Figure 1. Diagram of the EP\&B wall design

\subsection{Background}

Multiple approaches to higher R-value walls have been demonstrated since the attention to building energy efficiency became more prominent in the 1970s and with the development of building energy codes in the 1990s. The development of the building codes along with the emergence of energy programs such as ENERGY STAR ${ }^{\circledR}$ and those on a local or state level have continually increased the minimum requirements for the wall insulation levels. In the past 10 years, multiple organizations have performed analyses to evaluate high- $\mathrm{R}$ wall systems. These evaluations have combined the thermal, moisture, cost, and constructability aspects of the wall system.

For this research, light frame wall system designs ${ }^{2}$ that have a nominal wall ${ }^{3} \mathrm{R}$-value of 25 $\mathrm{h} \cdot{ }^{\circ} \mathrm{F} \cdot \mathrm{ft}^{2} / \mathrm{Btu}$ are considered. Most recent research into high-R wall systems as part of the

\footnotetext{
${ }^{2}$ This work focuses solely on wood frame wall systems, particularly framing systems that use nominal $2 \mathrm{x}$ lumber stock (excluding SIP, log, and heavy timber) because this residential construction method remains about $90 \%$ of the market.
} 
Building America program and from other similar research efforts has generally taken two distinct paths:

- Increase the thickness of the wall system so that the structural framing incorporates higher levels of insulation.

- Add insulation to the exterior of the structural framing.

Common goals for these wall system designs include higher thermal resistance, reduced thermal bridging through framing members, resistance to moisture diffusion, drying capability when wetted, constructability, and cost containment. Both approaches to nominal R-30 and higher wall systems have been analyzed extensively by industry experts with similar conclusions (Straube and Smegal 2009; Straube et al. 2010; Aldrich et al. 2010; Minnesota Sustainable Housing Initiative 2012; Cold Climate Housing Research Center 2010):

- For thick wall systems, the double-wall design can provide the highest performance with a combination of insulation and air sealing materials and maintain constructability and "marketable" construction costs. ${ }^{4}$ Other thick wall systems include the truss wall design that has been demonstrated, but limited details are available about constructability and actual costs.

- For exterior insulated systems to achieve whole-wall R-values higher than 30, use of either $2 \times 6$ or $2 \times 4$ framing has been analyzed. The necessary exterior insulation is typically a foam board product that is at least 2 in. thick; it is coupled with some type of supplemental framing that is required for finish attachment. A growing experience base that includes constructability and costs is developing for wall systems that employ thick exterior insulation.

Although these approaches have been successful in some demonstrations and projects, each system is hindered by significant trade contractor learning curves (driven in large part by uncommon framing and attachment details), higher cost premiums over standard framing practices, and in some cases complex finishing details (Straube et al. 2010). Furthermore, neither system lends itself to factory panelization; however, fabrication and transportation mechanisms can certainly be developed. However, in the development of construction details and in field demonstrations these systems have been successfully employed. Projects include multiple homes in the same development. Widespread deployment of these framing and insulation systems appears slow to gain traction especially for use in production home designs. Longer-term performance analysis is yet to be performed.

This focused research effort on the EP\&B wall design seeks to merge these two leading paths to high-R wall system designs, incorporate features of each, and provide a path to a standardized approach that allows for construction flexibility in the materials used for framing and insulation

\footnotetext{
${ }^{3}$ Nominal wall R-value is cavity + sheathing insulation only. Whole-wall R-value is defined as R-value estimation for the whole opaque wall including the thermal performance of not only the "clear wall" area, with insulation and structural elements, but also typical envelope interface details, including wall/wall (corners), wall /roof, wall/floor, wall/door, and wall/window connections.

${ }^{4}$ Marketable construction costs have been vetted through actual bid/sales agreements in multiple projects.
} 
and use of common details for other building elements. This report summarizes the initial design and proof-of-concept testing and evaluation.

\subsection{Relevance to Building America's Goals}

Overall, the goal of the U.S. Department of Energy's Building America program is to "reduce home energy use by 30\%-50\% (compared to 2009 energy codes for new homes and pre-retrofit energy use for existing homes)." To this end, Building America teams conduct research to "develop market-ready energy solutions that improve efficiency of new and existing homes in each U.S. climate zone, while increasing comfort, safety, and durability." Furthermore, the Building America program has spearheaded a home design methodology to develop zero energy ready homes ${ }^{6}$ with envelope performance that exceeds the 2012 International Energy Conservation Code (IECC) insulation levels, which will necessitate the use of high-R wall systems.

The goal of this investigation is to develop a wall framing method that enables deeper wall cavities and foam sheathing. This will simplify each approach and maintain wall design and material selection flexibility to adapt to climate and cost constraints or choices. The proposed wall system can be applied to climate zones 4 through 8 where the nominal wall R-values of 25 and higher would be desired for high-performance homes and for achieving the Building America goals. Design simplification and a focus on a consistent construction methodology are expected to enable the use of much higher-performing wall systems by:

- Standardizing a framing system methodology that can be adapted to desired thermal performance of R-25 to R-30

- Minimizing transition costs including plan changes that affect interior floor space

- Maintaining flexibility in the selection of insulation materials both in and outboard of the cavity

- Providing trade contractors with a consistent approach to framing details, air sealing, insulating, and flashing that can be applied to various thermal designs.

\subsection{Cost-Effectiveness}

Even though the EP\&B concept is not sufficiently developed for a complete cost analysis, a number of cost constraints will be imposed on the concept development and the cost-benefit estimates that were developed for comparison to other high-performance wall systems. These selected cost constraints are bounded by the double-wall and thick exterior insulation methodologies that are now used as high-R wall systems, which include material and labor costs.

Cost-effective technologies that are designed to save energy have a complicated history based on the chosen analysis methodology (Straube et al. 2010). Most often, adding efficiency measures in homes is based on the cost savings in the utility bills. If the investment in efficiency is less than the cost savings in utilities, a positive cost attribute is assigned to the efficiency measure. This type of cost analysis is further complicated by the selected methodology, which includes the cost

\footnotetext{
${ }^{5}$ http://www1.eere.energy.gov/buildings/building_america/program_goals.html

${ }^{6} \mathrm{http}: / /$ www.energy.gov/eere/buildings/zero-energy-ready-home
} 
of borrowing, utility rates, utility rate escalation, life cycle of the measure, and the effects on other systems in the home.

A comparative perspective is used in response to the question of cost-effectiveness for the EP\&B advanced wall system described in this study. The cost comparison is made relative to other wall systems that are designed to achieve a similar level of energy performance - namely the doublewall and the thick exterior foam insulation systems. Specialized wall systems such as ICFs or SIPs are not included in the comparison because they represent a small and unique part of the market, require a complete change of construction practices, and are used almost exclusively by small custom builders. The cost comparison for the proposed advanced wall design must show that compared to other high- $\mathrm{R}$ wall designs it is:

- No more costly when all aspects of design and construction-field modifications, inspections, finishes, etc.- - are included

- More expedient to frame so labor costs are balanced with increased insulation materials

- Less disruptive to construction schedules when quality assurance processes are implemented at various stages of construction

- More flexible in using material combinations to optimize the overall R-value of the wall system and maintain the same construction methodology

- Equally capable of being field fabricated, panelized, and shipped

- Applicable to prescriptive design methodologies to simplify design and inspection processes.

Other aspects of a detailed cost analysis that can be considered later in the concept development include costs to ensure satisfactory moisture performance, costs associated with trim finishes, the construction schedule to close in the envelope, and costs associated with field changes to the framing system.

\subsection{Tradeoffs and Other Benefits}

The EP\&B advanced wall concept discussed here is compared to the leading options most often discussed for high-R wall systems. ${ }^{7}$ As such, the evaluation of the overall performance benefit for a home in terms of simple payback, annualized mortgage and utility costs, or a life-cycle cost analysis is not complete at this point but will become important once the viability of the system is demonstrated. However, as a justification for this investigation the performance constraint is that the energy savings attributed to the advanced wall design are at least as significant as the other frame high-R wall system designs currently being implemented, albeit in small numbers.

An initial parallel-path performance estimation of three high- $\mathrm{R}$ wall systems was conducted to roughly compare the nominal and overall wall R-values. Table 1 summarizes three wall system designs of a nominal R-30 to compare the whole-wall R-value, framing factor, and resultant wall

\footnotetext{
${ }^{7}$ Other wall systems such as SIPs, ICFs, and other monolithic systems can be designed as high-R wall systems; however, the light frame wall system designs have more than $90 \%$ of the market and as such will be the focus of this investigation.
} 
depth. Two other wall systems are included for reference. (Refer to Figure 1 for the EP\&B wall configuration.)

Table 1. High-R Wall System Design Comparison

\begin{tabular}{|c|c|c|c|c|}
\hline \multirow[b]{2}{*}{ Wall System } & \multicolumn{2}{|c|}{ R-Value ${ }^{\text {a }}$} & \multirow[b]{2}{*}{$\begin{array}{c}\text { Framing } \\
\text { Factor }\end{array}$} & \multirow[b]{2}{*}{$\begin{array}{c}\text { Wall } \\
\text { Depth }^{c}\end{array}$} \\
\hline & Nominal $^{b}$ & $\begin{array}{l}\text { Whole- } \\
\text { Wall }^{\mathrm{c}}\end{array}$ & & \\
\hline $2 \times 4$ Double Wall, 1 in. Separation & 30 & 23 & $20 \%$ & 8.50 \\
\hline $2 \times 4$ Wall $+3-1 / 4$ in. Exterior Foam & 30 & 27 & $23 \%$ & 7.50 \\
\hline $2 \times 6$ EP\&B (with $2 \times 8$ plates) & 30 & 24 & $18 \%$ & 7.75 \\
\hline $2 \times 4 \mathrm{EP} \& B$ (with $2 \times 6$ plates) ${ }^{d}$ & 25 & 21 & $23 \%$ & 6.00 \\
\hline $2 \times 4$ Wall +1.0 in. Exterior Foam ${ }^{d}$ & 18 & 15 & $23 \%$ & 5.00 \\
\hline
\end{tabular}

${ }^{\mathrm{a}} \mathrm{R}$-value in $\mathrm{h} \cdot{ }^{\circ} \mathrm{F} \cdot \mathrm{ft}^{2} / \mathrm{Btu}$

${ }^{\mathrm{b}}$ Sum of cavity (R3.7/in. fiberglass) plus exterior (R5.0/in. extruded polystyrene [XPS])

${ }^{\mathrm{c}}$ Framing and sheathing only, no interior/exterior finishes or film factors

${ }^{\mathrm{d}}$ Included as a reference point for comparison

The primary tradeoff that leads to the viability of this investigation is the cost savings over both alternative framing systems to achieve R-25 or R-30 walls. To be sure, the cost of the wall system will be higher relative to code-minimum systems; however, this design effort focuses on minimizing the cost differences and enabling the use of the system on a much broader scale than has thus far been successful with other systems. This assumption is made because of the construction changes that are generally consistent with construction details that are already common in light wood framing. The major cost and construction tradeoffs between the approaches are summarized in Table 2 for R-30 wall options.

Table 2. High-R Wall Cost and Construction Tradeoffs

\begin{tabular}{|c|c|c|c|}
\hline & Double Wall & Exterior Foam & EP\&B ( $2 \times 6$ studs $)$ \\
\hline $\begin{array}{l}\text { Wall System } \\
\text { Summary }\end{array}$ & $\begin{array}{c}\text { Double } 2 \times 4 \text { wall } \\
\text { with } 1 \text {-in. separation }\end{array}$ & $\begin{array}{l}2 \times 4 \text { with } 3-1 / 4 \text { in. } \\
\text { exterior foam }\end{array}$ & $2 \times 6 \mathrm{EP} \& \mathrm{~B}$ \\
\hline Framing & $\begin{array}{l}\text { Additional interior } \\
2 \times 4 \text { framed wall }\end{array}$ & Standard $2 \times 4$ & $\begin{array}{c}\text { Standard } 2 \times 6 \text { studs with } 2 \times 8 \\
\text { top/bottom plates } \\
\text { Double rim (or recessed single } \\
\text { rim) }\end{array}$ \\
\hline Headers & Standard & Standard & Rim header \\
\hline Cavity Insulation & 8-in. loose fill & Batt or loose fill & Batt or loose fill \\
\hline $\begin{array}{l}\text { Structural } \\
\text { Sheathing }\end{array}$ & OSB, exterior & $\begin{array}{l}\text { OSB, behind exterior } \\
\text { foam }\end{array}$ & OSB, exterior \\
\hline $\begin{array}{c}\text { Exterior Framing } \\
\text { Insulation }\end{array}$ & None & 3-1/4-in. XPS & $1-3 / 4-$ in. or 2 -in. XPS \\
\hline $\begin{array}{c}\text { Exterior Insulation } \\
\text { Attachment }\end{array}$ & N/A & $\begin{array}{l}\text { 3/4-in. furring strips } \\
\text { through foam to studs }\end{array}$ & Cap nail to studs \\
\hline Siding Attachment & Sheathing/studs & Furring strips & Sheathing \\
\hline $\begin{array}{c}\text { Primary Moisture } \\
\text { Risk }\end{array}$ & $\begin{array}{l}\text { Condensation at } \\
\text { sheathing }\end{array}$ & $\begin{array}{l}\text { Drying if leakage behind } \\
\text { foam }\end{array}$ & Condensation at plates \\
\hline $\begin{array}{l}\text { Panelization } \\
\text { Opportunity }\end{array}$ & $\begin{array}{l}\text { Minimal benefit over } \\
\text { site-built }\end{array}$ & $\begin{array}{l}\text { Shipping and handling } \\
\text { problematic because of } \\
\text { potential damage to foam }\end{array}$ & $\begin{array}{l}\text { Similar to current wall panelizing } \\
\text { practices }\end{array}$ \\
\hline
\end{tabular}




\section{Experiment}

\subsection{Research Questions}

The goal of this work is to develop an initial design and conduct a proof-of-concept evaluation for the EP\&B high-R wall system. In that context the advanced wall system designs developed in this investigation will provide answers to the following questions:

- Which primary details are necessary to construct the wall framing and plates, rim beam, wall corners, and structural sheathing attachment?

- Which connection options are most advantageous to attach the foam to the framing and the structural sheathing to the plates and framing?

- What is the design unit shear for resisting lateral loads that use the recommended attachment methodology?

- What is the vertical capacity of the wall-floor-wall assembly given the offset location of the rim joist relative to the studs above and below?

- Do fabrication issues limit the panelization potential of the wall system design?

- What are the air sealing requirements for the wall system to effectively limit wall air leakage from the interior to the exterior?

- Which framing and flashing details are needed for openings?

- Which prescriptive details are necessary to use the rim beam as a rim header?

- Will the beam header bearing be sufficient for prescriptive installation requirements?

- What is the moisture performance of the wall system by climate zone?

- How does the cost of the EP\&B system compare to other high-R walls?

- For which range of wall framing configurations (framing and plates) will the design be suitable and practical?

This question set focuses on determining the structural, thermal, and moisture capabilities of the design and the construction details needed to implement the system in the field with minimal additional training of trade contractors.

The scope of the evaluation addressed by this report is limited to only several aspects as outlined in Section 2.2. The remaining aspects including moisture testing are parts of an ongoing evaluation and will be reported in the future.

\subsection{Technical Approach}

This report focuses on evaluating the following:

1. Initial structural evaluation using racking and compression tests on full-scale wall assemblies $(8 \mathrm{ft} \times 8 \mathrm{ft})$ in the laboratory.

Initial structural testing of full-size wall specimens was performed at the accredited laboratory of Home Innovation to evaluate the shear and gravity capacity of the EP\&B system. 
2. Comparative cost analysis of the EP\&B system and other commercially available wall systems with a comparable thermal performance (R-value).

Cost analysis of materials and labor was performed by Home Innovation to compare the $E P \& B$ system with other high-R walls.

3. Constructability analysis based on a review of industry stakeholders and development of initial building code requirements for a prescriptive approach.

A group of stakeholders was assembled to discuss the system and obtain feedback about the initial set of designs.

4. Development of construction approaches and details, including fabrication, structural and insulation attachments, and window and door installation and flashing.

Home Innovation staff worked with an architectural design firm from Pennsylvania and with an experienced structural engineer to develop a set of details. To demonstrate how the EP\&B system can be integrated into the design and construction process, an example framing scope of work and an example set of prescriptive provisions (International Residential Code [IRC] format) are developed.

\subsection{Measurements}

Table 3 outlines the test methodologies selected for analysis of the EP\&B wall system design.

Table 3. EP\&B Wall Test Methodologies

\begin{tabular}{|c|c|c|}
\hline Test Description & Test Method & Parameter of Interest \\
\hline $\begin{array}{c}\text { Shear Resistance of Wall } \\
\text { Section }\end{array}$ & $\begin{array}{l}\text { ASTM E72 shear wall } \\
\text { setup and loading protc }\end{array}$ & $\begin{array}{c}\text { Capacity, stiffness, } \\
\text { deformation capacity } \\
\text { Note: Exploratory testing of } \\
\text { select wall configurations }\end{array}$ \\
\hline $\begin{array}{l}\text { Testing of the Multiple Rim } \\
\text { Assembly under Eccentric } \\
\text { Loading from the } \\
\text { Supported Walls }\end{array}$ & $\begin{array}{l}\text { Vertical compression test of a } \\
\text { wall/floor section simulating } \\
\text { gravity load transfer from the } \\
\text { upper wall through the floor } \\
\text { and into the supporting wall }\end{array}$ & $\begin{array}{c}\text { Capacity, deformation, failure } \\
\text { mode, bearing response } \\
\text { Note: This is a validation test } \\
\text { only }\end{array}$ \\
\hline
\end{tabular}

\subsection{Equipment}

Table 4 shows measurements and associated test equipment. The test equipment is calibrated based on stated procedures in standards and according to Home Innovation quality assurance procedures that are accredited by qualified agencies. Additional information about the equipment is provided in the following sections, which describe the specific testing tasks. Appendix E provides information about the accuracy of the sensors used in the laboratory testing.

Table 4. EP\&B Laboratory Test Equipment

\begin{tabular}{c|c}
\hline Measurement & Equipment Needed \\
\hline Wall System Shear Capacity & Shear wall test machine \\
\hline Wall System Dead and Live Load Capacity & Universal test machine (UTM) \\
\hline
\end{tabular}




\section{Results and Analysis}

\subsection{Extended Plate and Beam Structural Validation Testing}

The primary goal of this exploratory testing program is to understand the impacts (if any) of the framing details and sheathing attachment on the structural load-bearing capacity of the EP\&B system compared to typical prescriptive approaches for shear resistance using structural wood panels. Two objectives of the testing program are to:

- Evaluate the shear performance of an EP\&B wall supported on a rigid base or floor framing with a recessed rim joist.

- Evaluate the resistance of the wall/floor system subjected to gravity loads.

The shear wall resistance is evaluated relative to published values for standard wood-frame walls and the vertical capacity is evaluated relative to published loads for residential construction applications.

\subsubsection{Methods and Materials}

The test matrix is summarized in Table 5. Testing was performed at the Home Innovation Research Labs in Upper Marlboro, Maryland. All materials used to construct the test specimens were acquired from a local vendor. Standard pneumatic nails were used for framing and were installed using a pneumatic gun. The average specific gravity of the dimension lumber was 0.44 with a coefficient of variation of $7.4 \%$.

The testing was performed generally in accordance with ASTM 72-13a "Standard Test Methods of Conducting Strength Tests of Panels for Building Construction." Modifications to the procedure were made where appropriate to accommodate the configuration of the EP\&B wall system components.

The sheathing on each specimen was installed with a $1 / 8$-in. gap between adjacent panels. A minimum sheathing nail edge distance of $3 / 8$ in. was used.

Each test configuration includes wall configuration details and a purpose statement. Wall configurations are described in Section 3.1.2. Three configurations were tested:

- Configuration 1 (shear wall test). EP\&B wall system with a 3-in. on center (o.c.) nailing pattern at the top and bottom extended plates.

- Configuration 2 (shear wall test). EP\&B wall system supported by floor framing with a single rim joist inset by $1 \mathrm{in}$. to accommodate foam insulation to the exterior of the rim.

- Configuration 3 (vertical test). EP\&B wall assembly consisting of two wall segments separated by floor framing with a double rim joist to the exterior edge of the extended plate.

Testing was performed at the Home Innovation Research Labs in Upper Marlboro, Maryland. All materials used in the construction of the test specimens were acquired from a local vendor. Standard pneumatic nails were used for framing and were installed using a pneumatic gun. The 
average specific gravity of the dimension lumber was 0.44 with a coefficient of variation of $7.4 \%$.

The testing was performed generally in accordance with ASTM 72-13a "Standard Test Methods of Conducting Strength Tests of Panels for Building Construction." Modifications to the procedure were made where appropriate because of the configuration of the EP\&B wall system components.

The sheathing on each specimen was installed with a $1 / 8$-in. gap between adjacent panels. A minimum sheathing nail edge distance of $3 / 8$ in. was used.

Table 5. EP\&B Wall Test Matrix

\begin{tabular}{|c|c|c|c|c|c|}
\hline $\begin{array}{c}\text { Config. } \\
\#\end{array}$ & Test & Description & $\begin{array}{c}\text { Floor } \\
\text { Framing }\end{array}$ & $\begin{array}{l}\text { Sheathing } \\
\text { Fastener } \\
\text { Schedule }\end{array}$ & Purpose \\
\hline 1-A & \multirow{2}{*}{$\begin{array}{l}\text { Shear wall } \\
(\text { E 72-13a) }\end{array}$} & \multirow{2}{*}{$\begin{array}{l}\text { EP\&B wall } \\
\text { supported on } \\
\text { rigid base }\end{array}$} & \multirow{2}{*}{$\mathrm{N} / \mathrm{A}$} & $\begin{array}{l}4 \text { in. } \times 0.131 \text { in. } \\
\text { nails at } 3 \text { in. o.c. } \\
\text { on the top and } \\
\text { bottom plates and } \\
6 \text { in. in the studs }\end{array}$ & \multirow{2}{*}{$\begin{array}{l}\text { Evaluate shear } \\
\text { strength of EP\&B } \\
\text { wall with } 3 \text { in. o.c. } \\
\text { nailing at plates for } \\
\text { two nail diameters }\end{array}$} \\
\hline 1-B & & & & $\begin{array}{l}4 \text { in. } \times 0.148 \text { in. } \\
\text { nails at } 3 \text { in. o.c. } \\
\text { on the top and } \\
\text { bottom plates and } \\
6 \text { in. in the studs }\end{array}$ & \\
\hline 2 & $\begin{array}{l}\text { Shear wall } \\
\text { (E 72-13a) }\end{array}$ & $\begin{array}{c}\text { EP\&B wall } \\
\text { supported by } \\
\text { floor framing } \\
\text { with inset rim } \\
\text { joist }\end{array}$ & 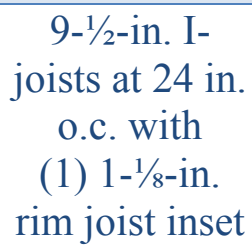 & $\begin{array}{l}4 \text { in. } \times 0.148 \text { in. } \\
\text { nails at } 3 \text { in. o.c. } \\
\text { on the top and } \\
\text { bottom plates and } \\
6 \text { in. in the studs }\end{array}$ & $\begin{array}{l}\text { Evaluate the impact of } \\
\text { floor framing with } \\
\text { inset rim joist (for } \\
\text { exterior foam) }\end{array}$ \\
\hline 3 & $\begin{array}{c}\text { Vertical } \\
\text { load } \\
\text { (E 72-13a) }\end{array}$ & $\begin{array}{l}\text { Two EP\&B } \\
\text { wall segments } \\
\text { separated by } \\
\text { floor framing }\end{array}$ & $\begin{array}{l}9-1 / 2-i n . ~ I- \\
\text { joists at } 16 \text { in. } \\
\text { o.c. with } \\
2 \times 1-1 / 8 \text {-in. } \\
\text { rim joists }\end{array}$ & $\begin{array}{l}4 \text { in. } \times 0.148 \text { in. } \\
\text { nails at } 3 \text { in. o.c. } \\
\text { on the top and } \\
\text { bottom plates and } \\
6 \text { in. in the studs }\end{array}$ & $\begin{array}{l}\text { Evaluate vertical load } \\
\text { path and compression } \\
\text { strength of EP\&B } \\
\text { wall system through } \\
\text { the floor }\end{array}$ \\
\hline
\end{tabular}

Table 6 summarizes the materials and construction details and Table 7 summarizes fastening schedules. 
Table 6. Material and Wall Construction Detail

\begin{tabular}{|c|c|}
\hline Component & Specification \\
\hline Framing Lumber & $\begin{array}{c}2 \times 4 \text { SPF }^{*} \text { stud-grade studs, } 2 \times 4 \text { SPF \#2 grade plates, } \\
2 \times 6 \text { SPF \#2 grade plates, } 9-1 / 2-\text {-in. deep I-joists, } \\
1-1 / 8 \text {-in. rim board, } 23 / 32-i n . \text { OSB subfloor }\end{array}$ \\
\hline Stud Spacing & Maximum 16 in. o.c. \\
\hline Wall Sheathing & $7 / 16$ in. thick OSB \\
\hline Wall Sheathing Fasteners & $\begin{array}{l}\text { Configuration } 1 \text {-a: } \mathrm{D}=0.131 \text { in., } \mathrm{L}=4 \mathrm{in} \text {. } \\
\text { All other configurations: } \mathrm{D}=0.148 \text { in., } \mathrm{L}=4 \mathrm{in} .\end{array}$ \\
\hline Framing Nails & $16 \mathrm{~d}(\mathrm{D}=0.131$ in., $\mathrm{L}=3-1 / 4$ in. $)$ \\
\hline Panel Joints & 1/8-in. gap \\
\hline Hold-Down (shear wall only) & ASTM E72-13a \\
\hline Anchor Bolts (shear wall only) & $\begin{array}{l}\text { (3) } 1 / 2 \text {-in.-diameter bolts } 3 \text {-in. } \times 3 \text {-in. plate washers } \\
\text { (Configuration } 1) \\
\text { (3) } 1 / 2 \text {-in.-diameter bolts with standard cut washers } \\
\text { (Configuration } 2 \text { ) }\end{array}$ \\
\hline Interior Sheathing & None \\
\hline
\end{tabular}

* Spray polyurethane foam

Table 7. Wall Fastening Schedule

\begin{tabular}{|c|c|c|}
\hline Connection & Fastener & Schedule \\
\hline $\begin{array}{c}\text { Top Plate to Top Plate (face-nailed) } \\
\text { ASTM E72 }\end{array}$ & $10 \mathrm{~d}(\mathrm{D}=0.131$ in., $\mathrm{L}=3$ in. $)$ & $\begin{array}{l}16 \text { in. o.c. } \\
\text { starting } \\
4 \text { in. from end }\end{array}$ \\
\hline Top/Bottom Plate to Stud (end-nailed) & $\begin{array}{l}2-16 \mathrm{~d}(\mathrm{D}=0.131 \text { in. } \\
\mathrm{L}=3-1 / 4 \text { in. })\end{array}$ & Per connection \\
\hline $\begin{array}{c}\text { Stud to Stud With Spacer (face-nailed) } \\
\text { ASTM E72 (shear test only) }\end{array}$ & $\begin{array}{c}3-16 \mathrm{~d}(\mathrm{D}=0.131 \text { in. } \\
\mathrm{L}=3-1 / 4 \text { in. })\end{array}$ & $\begin{array}{l}3 \text { nails per spacer } \\
\text { (total } 9 \text { nails) }\end{array}$ \\
\hline $\begin{array}{l}\text { Sheathing Panels to Framing } \\
\text { (at top and bottom plates) }\end{array}$ & $\begin{array}{c}\text { Nails }(D=0.131 \text { in., } \\
L=4 \text { in. }) \text { or } \\
(D=0.148 \text { in., } L=4 \text { in. })\end{array}$ & 3 in. o.c. \\
\hline $\begin{array}{l}\text { Sheathing Panels to Framing } \\
\text { (at studs) }\end{array}$ & $\begin{array}{l}\text { Nails }(D=0.131 \text { in., } \\
L=4 \text { in. }) \text { or } \\
(D=0.148 \text { in., } L=4 \text { in. })\end{array}$ & 6 in. o.c. \\
\hline
\end{tabular}

For the fastening schedule of the floor sections, see Sections 3.1.2-3.1.4.

\subsubsection{Test Configuration 1 (Shear Wall Test)}

Two $8 \mathrm{ft} \times 8 \mathrm{ft}$ test specimens were constructed; each had a different sheathing nail diameter. The frame for each specimen was constructed in accordance with ASTM E72, except the top and bottom plates were $2 \times 6$ (instead of $2 \times 4)$ dimension lumber. All fastener locations for the framing members conformed to ASTM E72. Details of Configuration 1 are shown in Figure 2. 


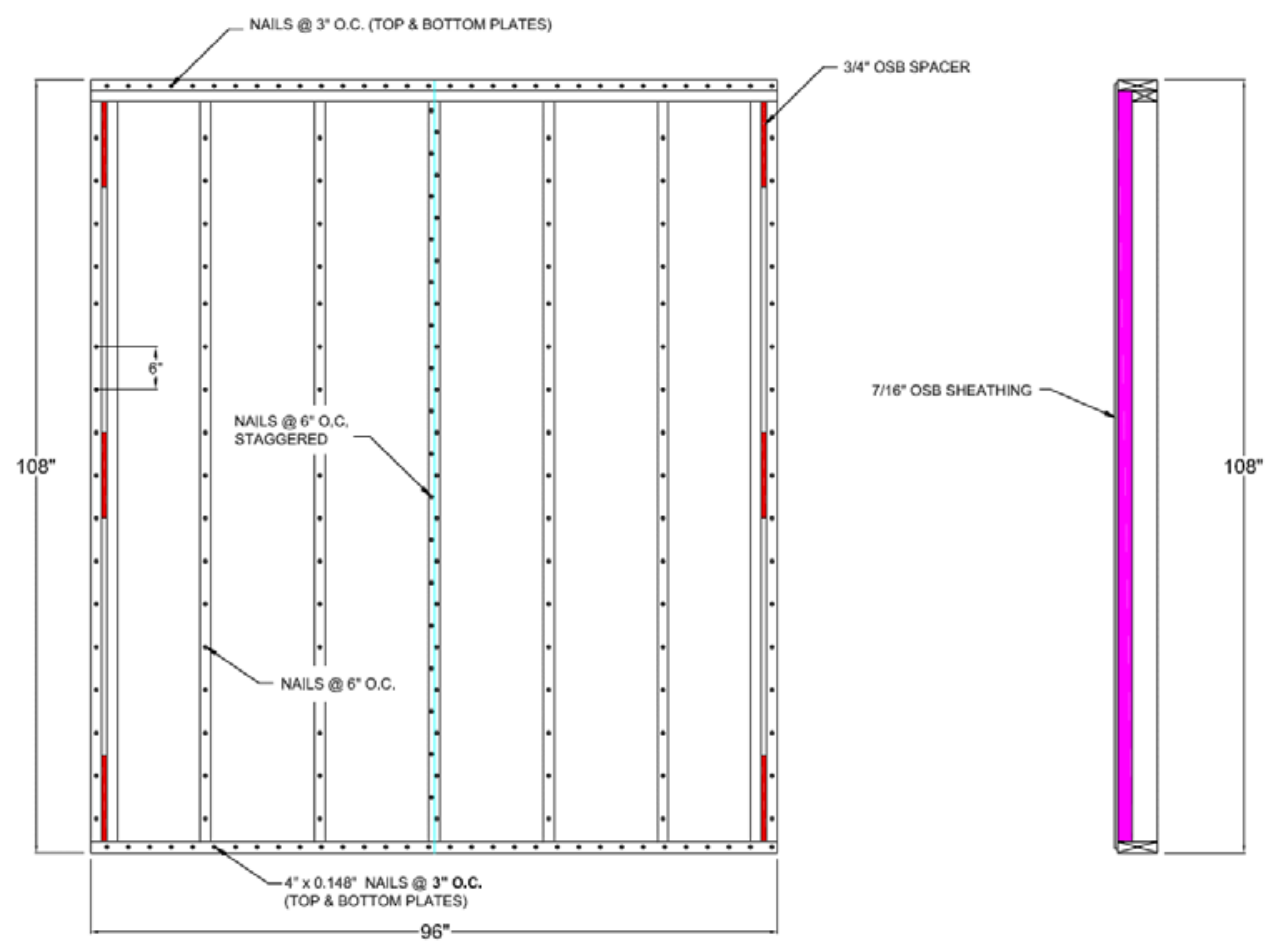

Figure 2. Configuration 1 detail

\subsubsection{Test Configuration 2 (Shear Wall Test)}

An $8 \mathrm{ft} \times 8 \mathrm{ft}$ wall was constructed in the same manner as in Configuration 1. Instead of bolting the wall to the rigid base, the wall was attached to an 8 -ft-long floor section. The entire assembly was constructed as outlined in Table 8 and Figure 3. The location of the rim was chosen as a worst-case scenario for this method of loading; the primary force went through the sheathing nails at the bottom plate.

Table 8. Configuration 2 Floor Fastener Detail

\begin{tabular}{|c|c|c|c|}
\hline Number & Description & Fastener & Schedule \\
\hline 1 & $\begin{array}{l}\text { Sheathing to studs and } \\
\text { plates }\end{array}$ & 4 in. $\times 0.148$ in. & 3 in. o.c. \\
\hline 2 & Subfloor to rim & $8 \mathrm{~d} 2.5$ in. $\times 0.131$ in. & $\begin{array}{l}6 \text { in. o.c. into rim and } 12 \text { in. o.c. } \\
\text { into joists }\end{array}$ \\
\hline 3 & Rim to joist & $10 \mathrm{~d} 3$ in. $\times 0.131$ in. & One into each flange \\
\hline 4 & Rim to sill plate & $8 \mathrm{~d} 2.5$ in. $\times 0.131$ in. & 6 in. o.c. (toe-nailed) \\
\hline 5 & Joist to sill plate & $8 \mathrm{~d} 2.5$ in. $\times 0.131$ in. & $\begin{array}{l}\text { Two nails driven at an angle into } \\
\text { bottom flange, } 1 \text { each side of web } \\
\text { at least } 1-1 / 2 \text { in. from end }\end{array}$ \\
\hline 6 & Bottom plate to rim & $16 \mathrm{~d} 3.25$ in. $\times 0.131$ in. & Three nails per 16 -in. space \\
\hline
\end{tabular}



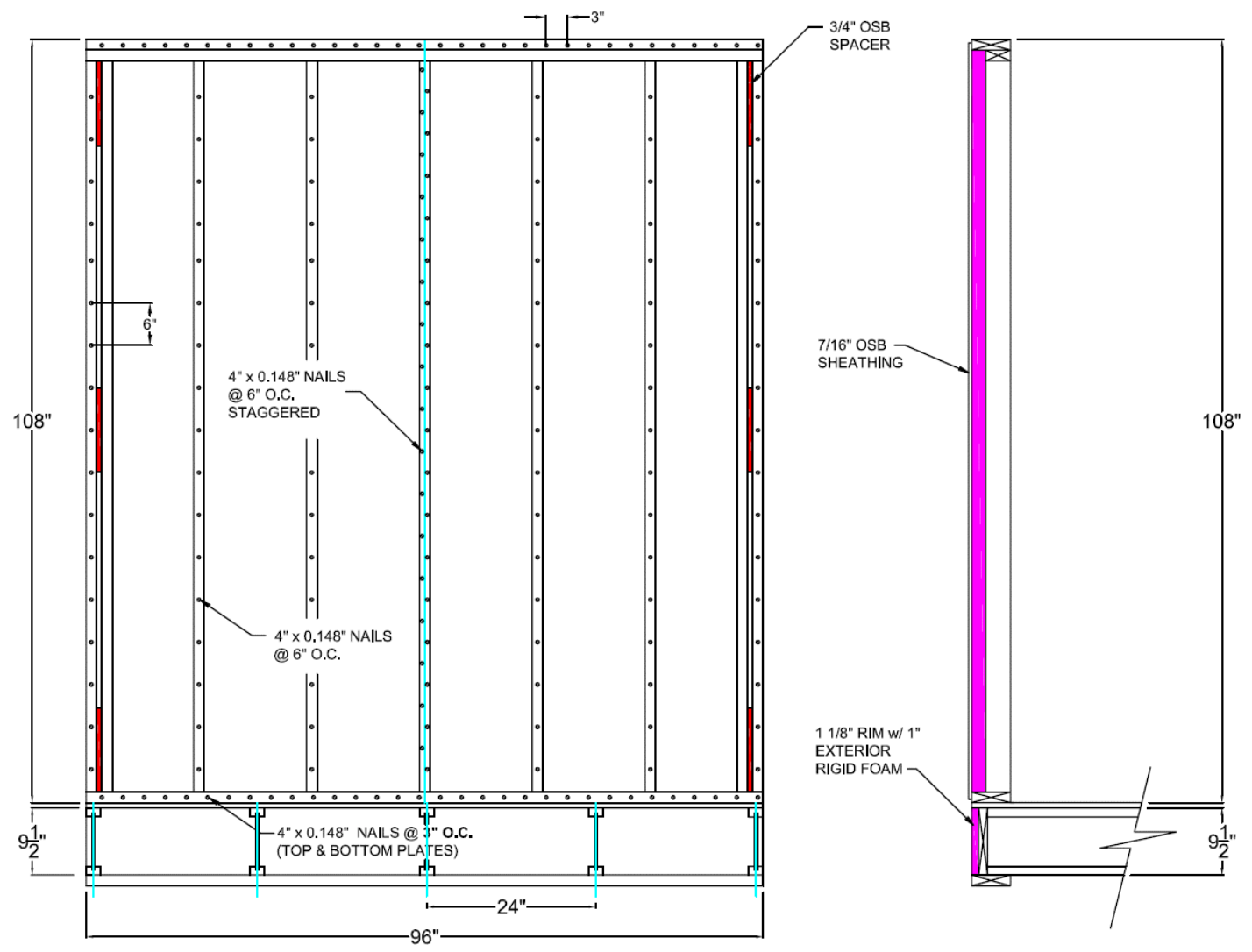

Figure 3. Configuration 2 detail

\subsubsection{Test Configuration 3 (Vertical Test)}

The specimen was constructed in accordance with Table 9 and Figure 4. The specimen width of 66.5 in. was chosen such that the tributary area for a four-stud wall would be represented. The location of the double rim was chosen as a worst-case scenario for this type of loading; the stud overlapped the rim joist by only $1 / 4$ in.

Table 9. Configuration 3 Floor Fastener Detail

\begin{tabular}{|c|c|c|c|}
\hline Number & Description & Fastener & Schedule \\
\hline 1 & $\begin{array}{c}\text { Sheathing to studs and } \\
\text { plates }\end{array}$ & 4 in. $\times 0.148$ in. & 3 in. o.c. \\
\hline 2 & Subfloor to rim & $8 \mathrm{~d} 2.5$ in. $\times 0.131$ in. & $\begin{array}{l}6 \text { in. o.c. into the rim and } \\
12 \text { in. o.c. into the joists }\end{array}$ \\
\hline 3 & Rim to rim & $8 \mathrm{~d} 2.5$ in. $\times 0.131$ in. & One row top and bottom 12 in. o.c. \\
\hline 4 & Rim to sill plate & $8 \mathrm{~d} 2.5$ in. $\times 0.131$ in. & 6 in. o.c. (toe-nailed) \\
\hline 5 & Joist to sill plate & $8 \mathrm{~d} 2.5$ in. $\times 0.131$ in. & $\begin{array}{l}2 \text { nails driven at an angle into bottom } \\
\text { flange, } 1 \text { each side of web at least } 1-1 / 2 \\
\text { in. from end }\end{array}$ \\
\hline 6 & Rim to joist & $8 \mathrm{~d} 2.5$ in. $\times 0.131$ in. & One into each flange \\
\hline 7 & Bottom plate to rim & $\begin{array}{c}16 \mathrm{~d} 3.25 \text { in. } \times 0.131 \\
\text { in. }\end{array}$ & Three nails per 16 -in. space \\
\hline
\end{tabular}

Note: The fasteners selected for the flooring section in Configuration 2 were in accordance with the joist manufacturer recommendations or the 2009 IRC provisions. 


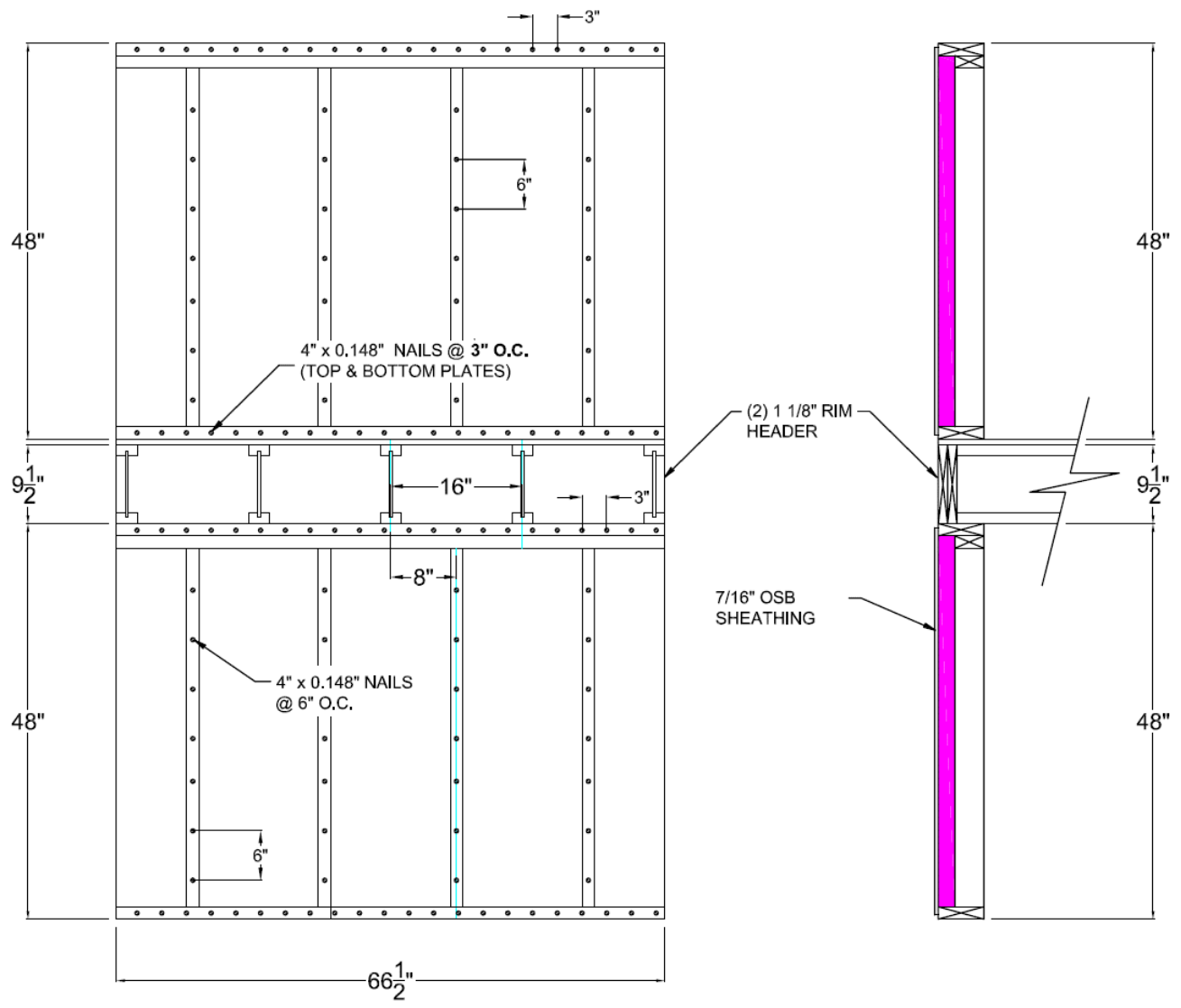

Figure 4. Configuration 3 detail

\subsubsection{Flooring Section (Configurations 2 and 3)}

The flooring sections consisted of 9-1/2-in. deep joists spaced 24 in. o.c. (Configuration 2) or 16 in. o.c. (Configuration 3). The fasteners selected for the flooring section in Configuration 2 were in accordance with the joist manufacturer recommendations or the 2009 IRC provisions.

\subsubsection{Shear Testing Protocol}

The shear testing was conducted in accordance with the general provisions of ASTM E72-13a, "Standard Test Methods of Conducting Strength Tests of Panels for Building Construction," using a racking shear test apparatus controlled via a computer-based control system. Testing in accordance with ASTM E 72 provided a consistent basis for comparing the results with historical test data. All specimens were anchored to the base of the racking apparatus using $1 / 2$-in.-diameter bolts with the end bolts located no more than $12 \mathrm{in.} \mathrm{from} \mathrm{the} \mathrm{ends.} \mathrm{The} \mathrm{wall} \mathrm{bottom} \mathrm{plate} \mathrm{in}$ Configuration 1 specimens was anchored using 3-in. $\times 3$-in. plate washers; the sill plate of Configuration 2 was anchored with standard cut washers.

The load for the shear testing was applied to the specimens with a hydraulic cylinder via a $4 \times 6$ wood beam bolted to the specimen. The load was applied at a constant rate of $0.06 \mathrm{in}$. per minute using the loading protocol outlined in Section 14.4 of ASTM E 72-13a. The specimen was displaced until an initial load of $790 \mathrm{lb}$ was reached. The specimen was then unloaded and the set deflection was recorded. This loading and unloading process was repeated for load levels of 1,570 $\mathrm{lb}$ and 2,360 lb. Finally, the specimen was displaced until it either failed or $4 \mathrm{in}$. of total 
displacement occurred. The load was measured by a 50,000-1b capacity electronic load cell located between the cylinder and the $4 \times 6$ load beam. The $4 \times 6$ beam was used to match the width of the $2 \times 6$ top plate. The load beam was placed and bolted to the specimens in such a way as to not interfere with the sheathing panel deformation during the test. Similarly, the wall was placed in the test setup and bolted down so that the test setup did not interfere with any sheathing panel deformation. Instrument readings including load and multiple deflection measurements were recorded using a computer-based data acquisition system at the locations listed here:

- Configuration 1 (Both a and b)

○ Load on wall

○ Displacement of the top plate

- Slip of the bottom plate

- Uplift deformation at the specimen corner

○ Compressive deformation at the specimen corner.

- Configuration 2

○ Load on wall

○ Displacement of the top plate

○ Displacement of the foundation sill plate

○ Uplift deformation at the specimen corner

- Compressive deformation at the specimen corner

- Relative displacement of the bottom plate versus the subfloor

- Relative uplift deformation at the specimen corner versus the subfloor.

- Configuration 3
○ Load on wall
- UTM displacement.

Figure 5 shows the schematic of the shear wall test setup that illustrates the location of the instrumentation and loading apparatus. A photograph of the test setup is shown in Figure 6. 


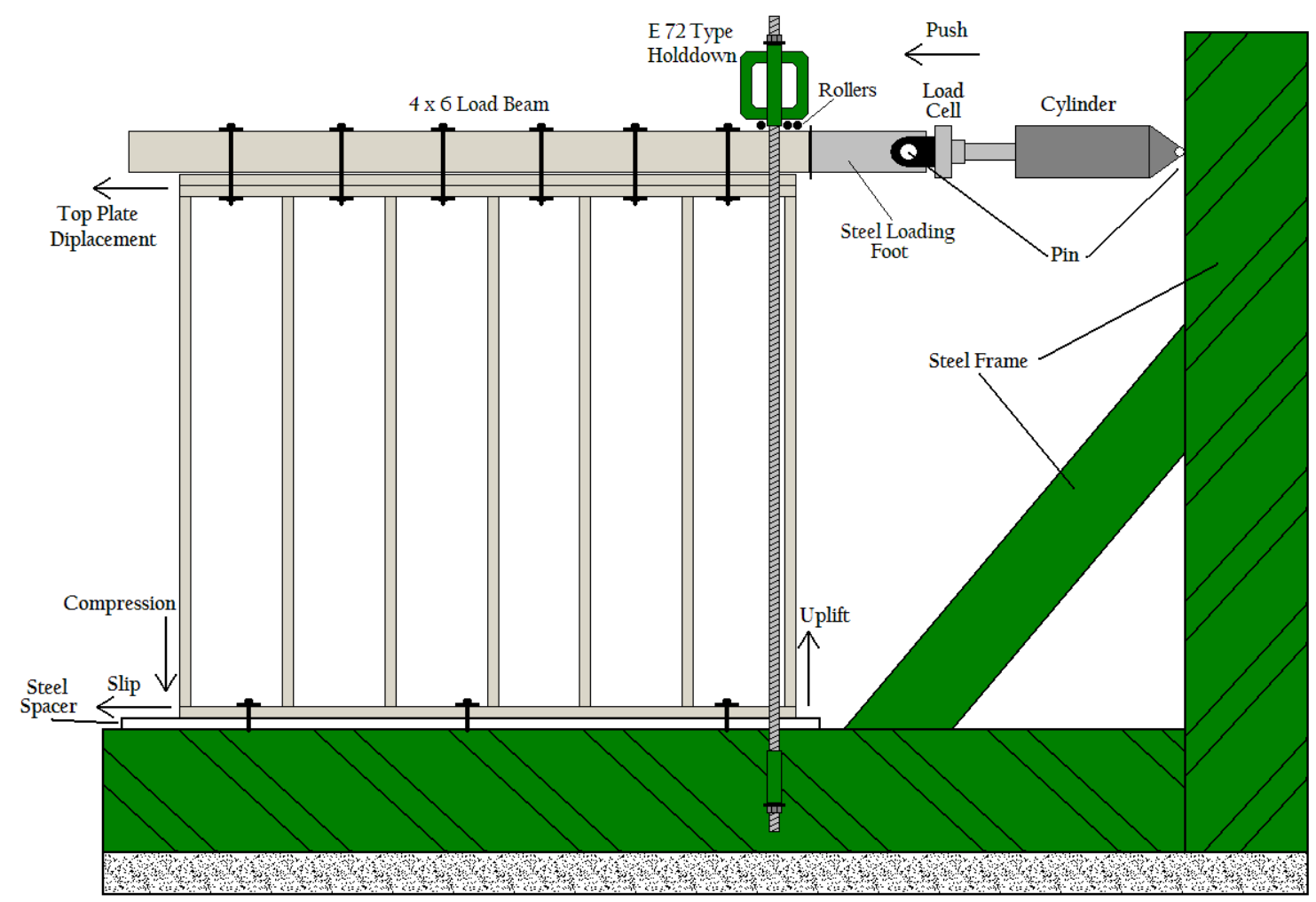

Steel/Concrete Composite Section

Figure 5. Test setup and sensor locations
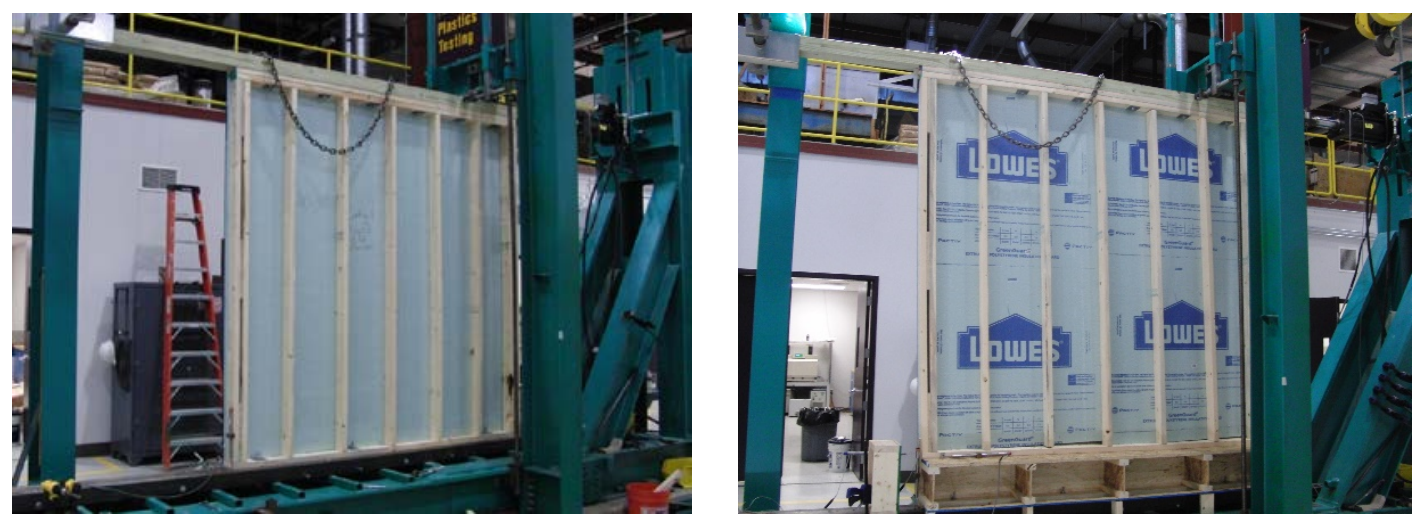

Figure 6. Specimen in test setup with and without floor platform

\subsubsection{Vertical Testing Protocol}

A two-story EP\&B wall section was constructed to test the vertical load transfer from the upper wall section through the floor to the lower story wall section. A second wall section was constructed parallel to and connected to the test wall to stabilize that section (see Figure 7). The two-story support wall section was the same dimension as the test wall but was constructed to be stronger to ensure the test-to-failure occurred in the EP\&B test wall. The two walls were spaced 26 in. apart. 
The specimen was tested in a large-scale UTM that can develop a 200,000-lb load (see Figure 7). The specimen was positioned on the support beams so that the load beam did not interfere with any potential OSB deformation during the testing. Steel beams were used to distribute the load from the UTM into the top plates of the test specimen. The assembly was also braced against the UTM with $2 \times 4$ blocks and sheets of Teflon to allow for unrestrained compressive deformation of the specimen.
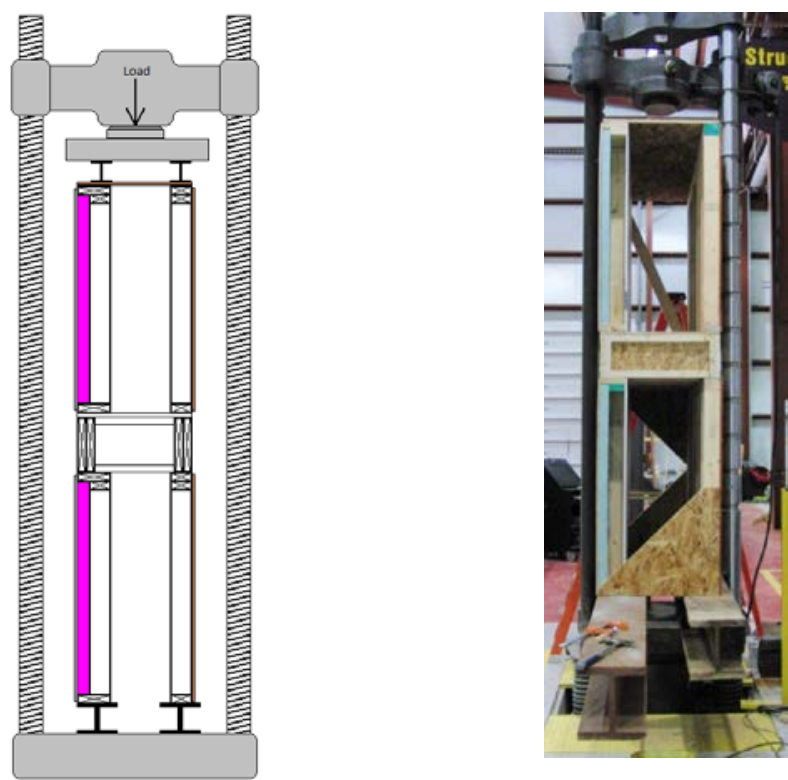

Figure 7. Configuration 3 test setup with temporary bracing

The vertical load was applied to the top of the specimen at a constant rate of 0.03 in. per minute. The loading continued until the specimen failed.

\subsubsection{Structural Shear Wall Testing Results}

The results of the shear testing are summarized in Table 10 and Table 11.

Table 10. Shear Test Results

\begin{tabular}{|c|c|c|c|c|}
\hline $\begin{array}{c}\text { Test Wall } \\
\text { Configuration }\end{array}$ & Test Specimen Description & $\begin{array}{l}\text { Peak Load } \\
\text { (lb) }\end{array}$ & $\begin{array}{l}\text { Unit Shear } \\
\text { (lb/ft) }\end{array}$ & $\begin{array}{l}\text { Deflection at } \\
\text { Peak Load } \\
\text { (in.) }\end{array}$ \\
\hline $1-\mathbf{a}$ & $\begin{array}{c}\text { EP\&B wall with } \\
\text { 4-in. } \times 0.131 \text {-in. nails }\end{array}$ & 4,876 & 610 & 2.07 \\
\hline 1-b & $\begin{array}{c}\text { EP\&B wall with } \\
4 \text {-in. } \times 0.148 \text {-in. nails }\end{array}$ & 5,764 & 721 & 2.92 \\
\hline 2 & $\begin{array}{l}\text { EP\&B wall with } \\
\text { 4-in. } \times 0.148 \text {-in. nails with } \\
\text { floor section }\end{array}$ & 6,267 & 783 & 3.52 \\
\hline
\end{tabular}


Table 11. Residual Deflections at Three Reloading Stages (ASTM E72)

\begin{tabular}{c|c|c|c|c|c|c}
\hline \multirow{2}{*}{$\begin{array}{c}\text { Test Wall } \\
\text { Configuration }\end{array}$} & \multicolumn{2}{|c|}{$\mathbf{7 9 0} \mathbf{~ l b}$} & \multicolumn{2}{c|}{$\mathbf{1 , 5 7 0 ~ l b}$} & \multicolumn{2}{c}{$\mathbf{2 , 3 6 0 ~ l b}$} \\
\cline { 2 - 7 } & Inch & $\mathbf{\%}$ & Inch & \% & Inch & \% \\
\hline 1-a & 0.018 & 22.7 & 0.062 & 31.8 & 0.159 & 41.1 \\
\hline $\mathbf{1 - b}$ & 0.018 & 22.3 & 0.079 & 34.8 & 0.158 & 40.1 \\
$\mathbf{2}$ & 0.032 & 35.1 & 0.106 & 41.4 & 0.224 & 47.6 \\
\hline
\end{tabular}

The measured shear capacities are within the range of values for standard wood-frame walls used in typical low-rise residential construction. For example, the nominal unit shear capacity for a standard wall with SPF studs spaced at 16 in. o.c. and sheathed with 7/16 in. OSB using 8d common nails at 6 in. o.c. is $671 \mathrm{lb} / \mathrm{ft}$. The nominal unit shear capacity for the same wall except with $6 \mathrm{~d}$ common nails and $3 / 8$-in. OSB is $515 \mathrm{lb} / \mathrm{ft}$. Comparing the results of Configurations 1 and 2 does not indicate a negative impact on shear capacity from insetting the rim board by $1 \mathrm{in}$.

A similar response mechanism and a failure mode were observed in all wall sections. The primary failure modes included degradation of the sheathing nail connections and rotation of the OSB panels. The loss of strength was caused by the nail deforming and pulling through the OSB panel edge at the top and bottom plates. The observed failure modes are consistent with those of standard wood-frame shear walls. Figure 8 and Figure 9 show the response mechanism for Configurations 1 and 2, respectively.

Figure 9 shows load-deformation relationships for all the shear tests (including data from a previously tested EP\&B wall section; see the green line on the chart). The slip of the test specimen relative to the rigid base was removed from the deflection shown in Figure 9. In the previously tested EP\&B wall, studs were spaced at 24 in. o.c. (compared to 16 in. o.c. used in this testing program). The sheathing fasteners ( $D=0.131 \mathrm{in}$., $\mathrm{L}=4 \mathrm{in}$.) were spaced at 2 in. o.c. at the top and bottom plates and 4 in. o.c. at the studs.
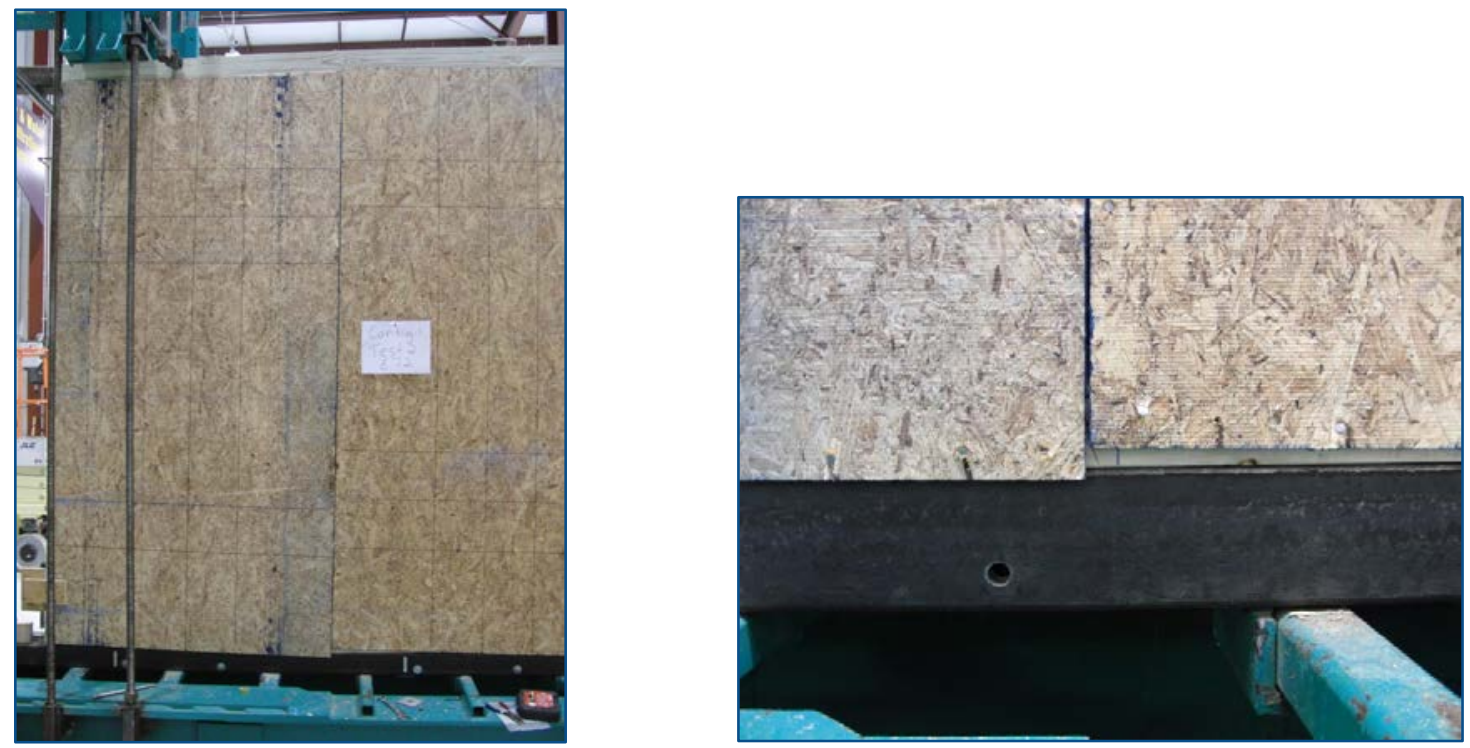

Figure 8. Sheathing failure 


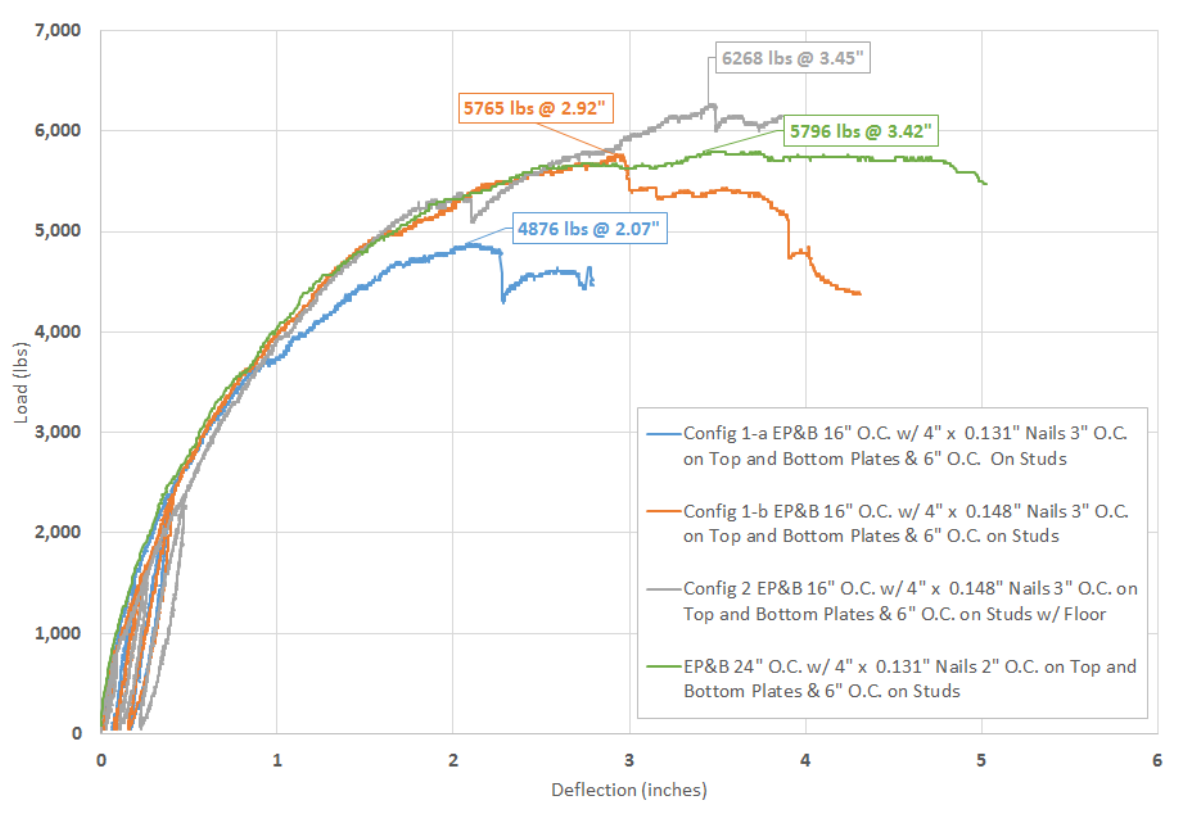

Figure 9. Shear load versus deflection comparison

Figure 9 indicates a consistent overall response between the tested specimens. The shape of the curves is also consistent with the response of standard wood-frame walls.

\subsubsection{Compression Testing}

The maximum load at failure applied to the entire specimen measured 102,360 lb. Because the specimen consisted of two parallel wall sections, the load was shared between the two walls. Therefore, the EP\&B wall section carried a maximum of 51,180 lb at failure, which corresponds to approximately $9,600 \mathrm{lb} / \mathrm{ft}$. As a point of comparison, unit load on the bottom story of a threestory house with clear-span floors, roof span of $36 \mathrm{ft}$, and ground snow load of $70 \mathrm{lb} / \mathrm{ft}^{2}$ is 2,791 $\mathrm{lb} / \mathrm{ft}$, which corresponds to a safety factor of 3.4. Therefore, the vertical capacity of the tested EP\&B detail is applicable to most typical low-rise residential buildings.

The main failure mode of the specimen under compressive load was at the bottom plate on the second story (top) wall section at the subfloor. A stud in the top wall crushed the bottom plate and forced its way through the subfloor into the floor joist bay. This response mode is shown in Figure 10. 

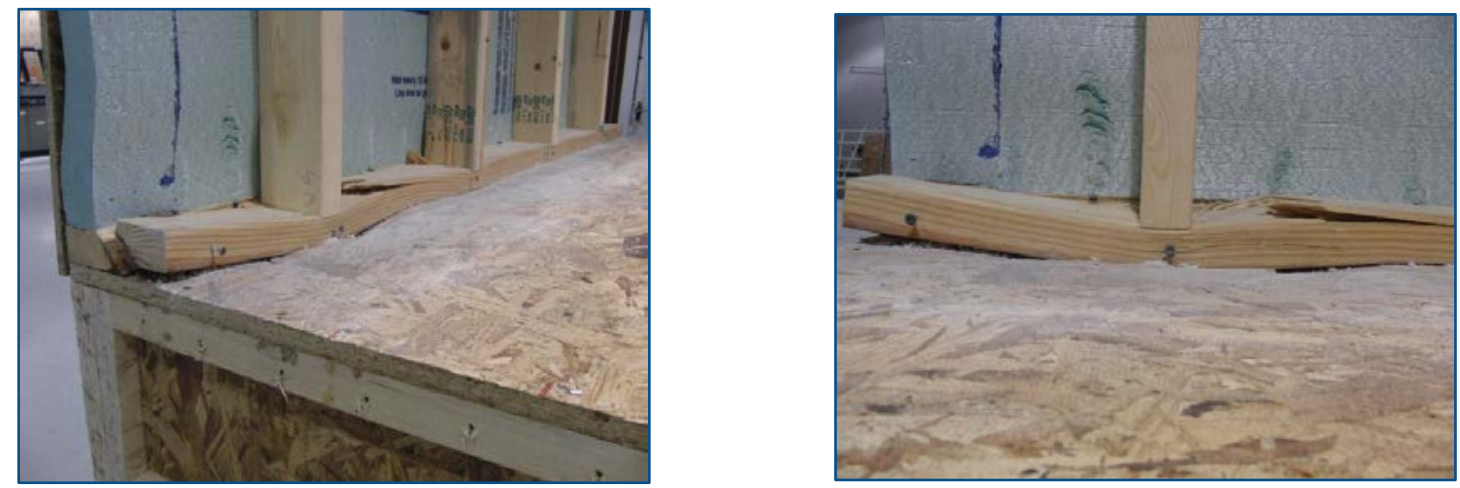

Figure 10. Primary failure mode of compression test

The gypsum board edges were damaged from being crushed into the floor at a lower load than the subfloor failure. Depending on the location, the gypsum was crushed and the screws were pulled through the gypsum as it separated from the wall. An example of the damage can be seen in Figure 11. The damage was the result of wood plates crushing and compressing under the high vertical loads.

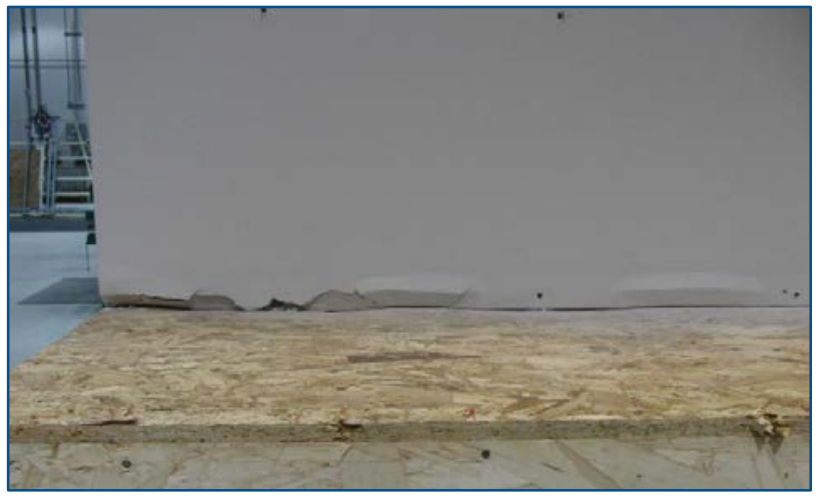

Figure 11. Example gypsum board damage

\subsubsection{Extended Plate and Beam Wall System Structural Testing Summary Analysis}

The reported testing represents an exploratory phase of evaluating the structural performance of the EP\&B system. The results provide a basis for initial observations:

- The nail spacing increase from 2 in. o.c. to 3 in. o.c. can be offset by an increase in the nail diameter from 0.131 in. to 0.148 in., which results in a similar shear capacity for both systems.

- When maintaining the 2-in. o.c. nail spacing, larger diameter nails of 0.148 in. showed an increased capacity of $18.2 \%$ over the smaller 0.131 -in.-diameter nails.

- Shear wall tests performed with the specimen attached to a rigid base (Configuration 1) and with the specimen attached to a wood floor with an inset rim joint (Configuration 2) result in similar shear capacity. Therefore, insetting the rim by 1 in. to accommodate exterior foam insulation did not appear to have a significant effect on shear capacity. 
- The measured shear capacities are within the range of values for standard wood-frame walls used in typical low-rise residential construction in low-hazard areas (nonhurricane and nonseismic areas).

- Vertical load testing indicates that the floor rim joist detail can carry story-to-story loads that exceed loads that are applicable to typical low-rise residential construction.

\subsection{Cost Comparison}

An important aspect of the assessment was to analyze the cost of the EP\&B wall design compared with other high-performance wall systems. Estimated costs for materials and labor and a defined wall section were used to develop this comparison.

\subsubsection{Reference Wall Section}

A reference wall section size and configuration were developed for the analysis. The reference wall section included the supported rim to address all cost implications on analyzed systems. The wall section was $20 \mathrm{ft}$ wide $\times 10 \mathrm{ft}$ high (9-ft wall and 1 - $\mathrm{ft}$ rim) and included a 6 - $\mathrm{ft} \times 5$ - $\mathrm{ft}$ window (3050 twin) to capture the cost impact on framing and detailing of openings. The window opening represented $15 \%$ of the total wall area - a typical ratio for residential construction. Each wall had all components, including interior and exterior finishes. Figure 12 shows the reference wall configuration.

Two types of claddings were analyzed: vinyl siding and fiber cement siding. These were selected for their difference in price and installation requirements. Nine wall types were analyzed with each cladding for a total of 18 unique wall assemblies. Table 12 summarizes the wall assemblies and estimated costs. Key variables between wall assemblies included framing $(2 \times 4$ versus $2 \times 6$ versus double wall versus EP\&B), stud spacing (16 in. versus 24 in. o.c.), framing at openings (standard versus rim header), XPS foam (no foam, 2 -in. foam, 1 -in. + 3/4-in. foam), and other derivative details. For walls with 2 in. of exterior rigid foam insulation, furring strips were used for siding attachment. Where vinyl siding was attached to furring strips, a $1 \frac{1}{2}$-in. rigid foam backer was installed between the furring strips to comply with wind rating requirements for a solid backer behind vinyl siding. Boutique wall systems such as SIPs and ICFs are not included in this cost comparison because they represent a different type of wall assembly that requires a complete change of enclosure construction practices. This study focuses on systems that build upon conventional framing techniques that are familiar to builders. 

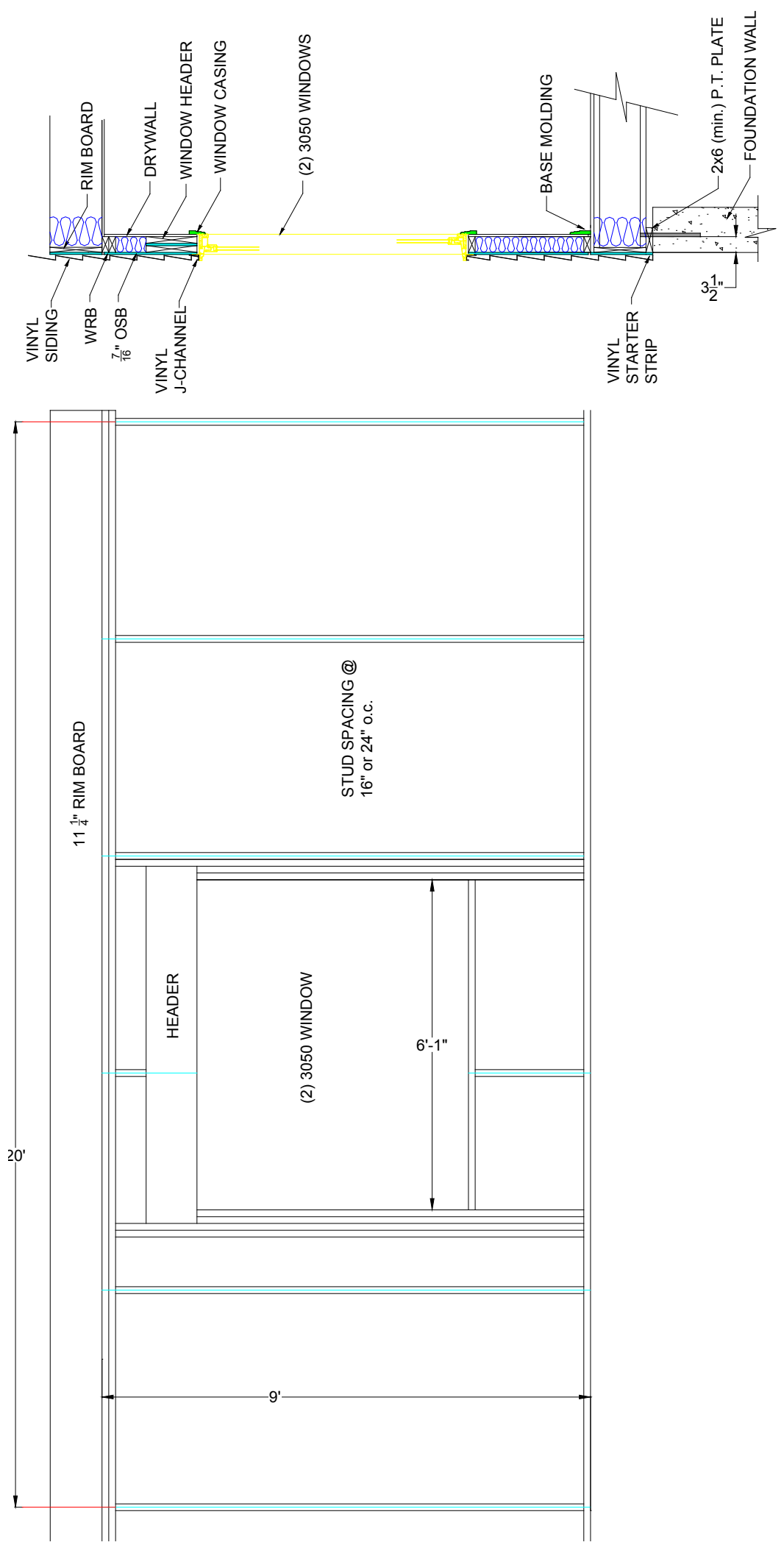

Figure 12. Reference wall configuration 
Table 12. Representative Wall Section Configuration Cost Estimates

\begin{tabular}{|c|c|c|c|c|c|c|c|c|}
\hline $\begin{array}{l}\text { Wall } \\
\text { Code }\end{array}$ & Wall Configuration & Fig $\#^{\mathrm{a}}$ & $\begin{array}{l}\text { R-Value } \\
\text { Nominal }\end{array}$ & $\begin{array}{r}\text { Total } \\
\text { Width }\end{array}$ & $\begin{array}{l}\text { Total } \\
\text { Cost }\end{array}$ & $\operatorname{Cost} / \mathrm{ft}^{2}$ & $\begin{array}{c}\operatorname{Cost} / \mathbf{f t}^{2} \\
\text { Increase }\end{array}$ & $\begin{array}{c}\text { Cost per } \\
\text { R-Value/ft }\end{array}$ \\
\hline 1VS & $2 \times 4 @ 16$ in.o.c. & 1 & 13 & 4.4 & $\$ 3,499.48$ & $\$ 17.50$ & $\mathrm{~N} / \mathrm{A}$ & $\$ 1.35$ \\
\hline $2 \mathrm{VS}$ & $2 \times 6 @ 24$ in. o.c. & 2 & 20 & 6.4 & $\$ 3,509.98$ & $\$ 17.55$ & ref & $\$ 0.89$ \\
\hline 3VS & $2 \times 6 @ 16$ in. o.c. & 3 & 20 & 6.4 & $\$ 3,576.98$ & $\$ 17.88$ & $\$ 0.34$ & $\$ 0.90$ \\
\hline 4VS & $\mathrm{EP} \& \mathrm{~B} 2 \times 4 / 2 \times 6$ & 4 & 23 & 4.4 & $\$ 3,935.18$ & $\$ 19.68$ & $\$ 2.13$ & $\$ 0.87$ \\
\hline $5 \mathrm{VS}$ & $2 \times 4$ with 2 -in. $+1 / 2$-in. exterior foam & 5 & 25 & 6.9 & $\$ 4,305.02$ & $\$ 21.53$ & $\$ 3.98$ & $\$ 0.86$ \\
\hline 6VS & $2 \times 6$ with 2 -in. $+1 / 2$-in. exterior foam & 6 & 32 & 8.9 & $\$ 4,435.72$ & $\$ 22.18$ & $\$ 4.63$ & $\$ 0.69$ \\
\hline $7 \mathrm{VS}$ & $\mathrm{EP} \& \mathrm{~B} 2 \times 6 / 2 \times 8$ & 7 & 29 & 6.4 & $\$ 4,147.68$ & $\$ 20.74$ & $\$ 3.19$ & $\$ 0.73$ \\
\hline $8 \mathrm{VS}^{\mathrm{a}}$ & $E P \& B 2 \times 6 / 1-1 / 2 \times 7-1 / 2^{a}$ & 8 & 30 & 6.4 & $\$ 4,043.38$ & $\$ 20.22$ & $\$ 2.67$ & $\$ 0.68$ \\
\hline 9VS & $2 \times 4$ double-stud with 1-in. gap & 9 & 29 & 8.9 & $\$ 3,994.43$ & $\$ 19.97$ & $\$ 2.42$ & $\$ 0.69$ \\
\hline $1 F C S$ & $2 \times 4 @ 16$ in. o.c. & 1 & 13 & 4.4 & $\$ 3,788.30$ & $\$ 18.94$ & $\mathrm{n} / \mathrm{a}$ & $\$ 1.46$ \\
\hline 2FCS & 2×6@24 in. o.c. & 3 & 20 & 6.4 & $\$ 3,798.80$ & $\$ 18.99$ & ref & $\$ 0.96$ \\
\hline 3FCS & $2 \times 6 @ 16$ in. o.c. & 2 & 20 & 6.4 & $\$ 3,865.80$ & $\$ 19.33$ & $\$ 0.34$ & $\$ 0.98$ \\
\hline 4FCS & $\mathrm{EP} \& \mathrm{~B} 2 \times 4 / 2 \times 6$ & 4 & 23 & 4.4 & $\$ 4,224.00$ & $\$ 21.12$ & $\$ 2.13$ & $\$ 0.93$ \\
\hline 5FCS & $2 \times 4$ with 2 -in. exterior foam & 5 & 23 & 6.4 & $\$ 4,333.64$ & $\$ 21.67$ & $\$ 2.67$ & $\$ 0.96$ \\
\hline 6FCS & $2 \times 6$ with 2 -in. exterior foam & 6 & 30 & 8.4 & $\$ 4,464.34$ & $\$ 22.32$ & $\$ 3.33$ & $\$ 0.75$ \\
\hline 7FCS & $\mathrm{EP} \& \mathrm{~B} 2 \times 6 / 2 \times 8$ & 7 & 29 & 6.4 & $\$ 4,436.50$ & $\$ 22.18$ & $\$ 3.19$ & $\$ 0.78$ \\
\hline $8 F C S^{a}$ & EP\&B $2 \times 6 / 1-1 / 2 \times 7-1 / 2$ & 8 & 30 & 6.4 & $\$ 4,332.20$ & $\$ 21.66$ & $\$ 2.67$ & $\$ 0.73$ \\
\hline 9FCS & $2 \times 4$ double-stud with 1 -in. gap & 9 & 29 & 8.9 & $\$ 4,283.25$ & $\$ 21.42$ & $\$ 2.42$ & $\$ 0.74$ \\
\hline
\end{tabular}

${ }^{a}$ EP\&B wall configurations with $2 \times 6$ studs were analyzed using both $2 \times 8$ plates ( $7-1 / 4$ in. width) and ripped plates to a $7 \frac{1}{2}$ in. dimension. The added cost of ripping plates is included as well as the added cost of installing a 1 -in. layer and a $3 / 4-$ in. layer of foam sheathing for the $2 \times 8$ plates.

${ }^{\mathrm{b}}$ See Appendices A and B. 


\subsubsection{Estimated Costs}

Costs were developed and represented at the national level from three primary sources:

- Home Innovation Research Labs' database, which was originally compiled in 2008 and has been updated and expanded over the ensuing 5 years

- RSMeans Residential Cost Data 2014

- Websites for major national manufacturers and retailers.

When additional labor time was needed for specific tasks that were not directly addressed by standard cost guides the labor rate from RSM 2014 was used. The reported costs contained overhead and profit, which were expected to be charged by trades and suppliers (i.e., builder's costs). No builder overhead and profit were added.

The costs were evaluated for the entire wall system to capture the interaction effects (e.g., impact of the header type on the number of supporting studs and impact of the cladding type of the backing material). The system approach also allows for evaluating the cost impact of increasing the wall's R-value relative to the cost of the entire wall system.

Each wall configuration and a detail of the estimated costs summarized in Table 12 are available in Appendix A and Appendix B. The representative wall sections show vinyl siding only. The estimated costs apply to the representative $200-\mathrm{ft}^{2}$ wall section, including finishes and a double 3050 window.

\subsubsection{Cost Comparison Summary}

The results indicate that the cost of the EP\&B system is comparable to-and in some cases lower than - walls with the same R-value. The cost normalized by the R-value is also similar between wall types in the same R-value range. Therefore, the added benefits of the EP\&B system do not come with an extra price and in some cases result in a moderate cost saving relative to comparable R-value alternatives.

\subsection{Building Industry Stakeholder Review}

A stakeholder group was convened to review the design details for the EP\&B wall system and independently assess its constructability based on the initial proposed construction approach. The range of stakeholder backgrounds allowed for various perspectives on the EP\&B wall construction and encouraged identification of specific details that might alter standard construction or fabrication processes.

Stakeholders represented various sectors of the residential construction industry and possessed expertise in home construction, framing, factory panelizing, modular construction, architectural design, and building code enforcement.

The stakeholders were shown a PowerPoint presentation that outlined the EP\&B wall system design as currently envisioned, structural testing to date, and an initial field fabrication example. The participants were asked to identify construction issues that might require changes to the initial wall design or that would require changes to typical construction practices. 


\subsubsection{Extended Plate and Beam Constructability Evaluation Based on Stakeholder Discussion}

Various aspects of the EP\&B wall system design and construction including an overall discussion of higher R-value walls are highlighted in the following summary points:

- Twenty-four inches o.c. framing (applicable to the $2 \times 6$ advanced framing option only). Issues identified included problems with gypsum installation on bowed framing members and subsequent framer resistance — nonalignment between wall framing at 24 in. o.c. and floor joist framing that is 16 in. or 19.2 in. o.c. The alignment was seen as necessary for installing ducts in the exterior walls.

- Increasing wall insulation. Significant time was taken on the best methods and options to increase wall insulation. The discussion encompassed the barriers to adopting higher R-value walls; approaches currently known to the participants such as SPF and exterior foam sheathing are used less often than $2 \times 6$ framing. Insulated vinyl siding was raised as one option for increasing the R-value. Use of SPF in modular construction was less common because of shipping concerns.

- Wall moisture performance. This was viewed as an important issue that must be considered in any higher R-value wall design. More research is likely needed.

- Cavity dew point temperature. Concerns arose about the location of the dew point temperature sensor in the EP\&B system and whether field data were available for $2 \times 4$ and $2 \times 6$ stud systems.

- Sheathing attachment. Details about the EP\&B sheathing attachment were presented and discussed at length. Structural shear nailing solely at the extended plates was viewed as a limitation in hurricane zones in the southern part of New York State. The use of nonstandard nail guns to handle the 4-in.-long nails in the sheathing was seen as an extra cost that would need to be considered.

- Sheathing attachment. A close 2 in. o.c. nailing pattern was viewed as a potential difficulty for framers and potentially a problem for the sheathing if the nail spacing were less than 2 in. o.c.

- Shear resistance. As one means to alleviate the reliance on the sheathing for shear resistance, one participant suggested using diagonal cross bracing located on the framing studs with 2-in. or longer nails as an alternative design.

- Sheathing attachment. Sheathing installation is often overlapped to the rim/sill plate. The EP\&B may need to accommodate the connection to the extended plate and include an overlap of the rim board.

- Rough opening. Use of a double sill/top rough window opening framing is common; this practice conflicts with some advanced framing methodologies.

- Nonstandard nail length. A participant suggested approaching a nail gun supplier to retrofit a cartridge for larger 4-in. nails for use with a standard gun. The discussion revealed that the nail size is an issue. However, if a builder is committed to raising the energy-efficiency standards - and to this system - this is part of the tradeoff. If 
manufacturers see a growing market for this system they will create a 4-in. nail gun. However, retooling for contractors can be expensive and must be considered.

- Nailing accuracy. One potentially problematic detail of nailing through the sheathing and 2-in. foam to the stud is that framers have difficulty reliably hitting the studs.

- Nailing accuracy. One builder suggested using screws rather than nails, acknowledging this would slow installation but had other advantages such as improved shear load capability.

- Design detail. Use of the wall system in wall designs higher than $10 \mathrm{ft}$ (e.g., an 18-ft wall in an atrium) may be a limitation to use of the EP\&B system without a more complete set of design details.

- Design detail. Use of the double- or triple-rim board was viewed as a detrimental cost implication. One suggestion was made to use squash blocks at each joist.

- Modular construction. Based on the presentation of the initial shear wall testing, the discussion centered on the use of sheathing panels that are required to span the extended plates. The perspective of modular construction experts was that vertical sheathing and gypsum drywall at the bottom of the wall are needed to securely transport walls that are connected to the floors and ceiling. Horizontal rather than vertical sheathing is used for this purpose. Vertically installed sheathing could be feasible if an 8-ft wall were designed and built with a 10-ft panel or a 9-ft wall with an 11-ft panel.

- Modular construction. Concerns were expressed about sheathing attachment. In modular construction, horizontal sheathing is more advantageous for transport security. Sheathing, however, could be modified and still be applicable to the production process. Use of new nailing guns and nails is not a major issue for modular manufacturers.

- Roof truss. One builder raised a concern about the truss attachment to the extended plate at the top of the wall.

- Air sealing. Concerns were raised about creating increased air sealing requirements because multiple rim joists were placed all around the building, which increased the potential for more air infiltration at sills. However, all these infiltration passages can be addressed with a continuous air barrier and proper use of sealants and caulks at strategic locations.

- Learning curve. Associated constructability issues included the cost of retraining for the framer, which was viewed as a liability and may include other "nuisance costs" (e.g., sheathing orientation and length).

- Factory panelization. Fabrication of EP\&B panels would require modified equipment to accommodate the nails and nailing pattern. Shipping EP\&B panels would be easier than shipping with exterior foam because the outboard wood structural sheathing offers protection during shipping and handling. Site installation of EP\&B panels would require modified corner details. Likewise, use of the continuous rim may add complications and unnecessary cost. 


\subsubsection{Stakeholder Review-Extended Plate and Beam Design and Construction Enhancements}

Based on the stakeholder review and discussion of the EP\&B proposed wall system, the following enhancements are either planned for future design iterations or have been included in design changes:

- Multiple rim components. The added cost and complexity of installing multiple rim members are considered important design details for improvement. Subsequent laboratory structural testing demonstrated that a double-rim member would be sufficient for shear and gravity loads. The double member could also serve as a header in most standard-sized window openings. Future shear testing will include designs that use a single standard rim member.

- Siting and insulating the rim member. Multiple discussions demonstrated the need for "design consistency" when a layer of rigid insulation is installed to the exterior of the rim board. The exterior insulation of the rim is less critical because the interior insulation options for the rim area exceed the limitations of the cavity. Subsequent laboratory structural testing has demonstrated sufficient structural performance when the rim member is installed 1 in. inside from the outer edge of the plate. The structural performance is sufficient for shear and gravity loads.

- Sheathing attachment using 4-in.-long nails. The EP\&B wall system uses 2-in.-thick foam between the structural sheathing and the studs. To develop a $1 \frac{1}{2}$-in. nail penetration, 4-in. nails are required, longer than the standard 3 to $3 \frac{1}{2}$ in. nails. Most standard nail guns are designed for nails as long as $3 \frac{1}{2} \mathrm{in}$. Longer nails require fastener devices that are somewhat larger and heavier so the trade contractors must invest in another tool set. At least one manufacturer designs a nail gun that can accommodate nails as long as $4 \mathrm{in}$. The primary limitation of standard nail guns is the nail cartridge, which is a relatively inexpensive component. Given sufficient demand, tool design modifications to accept nails as long as 4-in. would appear to be reasonable.

- Wall moisture management. Concerns about wall moisture were expressedspecifically, the condensation potential in the sheathing in higher efficiency walls. The concerns stem from the reduced drying potential in the wall cavity that is caused by higher levels of insulation and lower air infiltration rates. Also, material combinations that have lower perm ratings can slow drying. In some homes where infiltration rates have been reduced without ventilation for introducing sufficient makeup air the indoor humidity levels may increase and cause a higher outward vapor pressure in winter. Home Innovation has instrumented one home in climate zone 5 to measure the changes in sheathing moisture content in the EP\&B system. (EP\&B wall systems were also installed in a test hut in climate zone 4 to obtain similar data.) An initial set of simulations using WUFI software has shown typical cyclic moisture content in the sheathing for the EP\&B system under assumed conditions. Other Building America reviews of the system have not raised any particular moisture management concerns for the EP\&B system that are caused by the configuration of materials.

- Air sealing. Because of the way the materials are configured, the infiltration performance of the wall system including the rim area requires investigation. To this end, a test house 
is planned such that the ceiling drywall will be installed before the wall insulation and drywall. With the ceiling air sealed, the building infiltration rate can be measured, particularly during various stages of air sealing. The infiltration test will use standard diagnostic tools to investigate the air leakage pathways.

- Complex framing variations. As experience with the EP\&B wall system expands, variations in wall layouts will be encountered. For example, wall sections that frame atria may be 12 to $16 \mathrm{ft}$ higher and will require unique framing details for the EP\&B system. This is consistent with any wall framing system; however, for the EP\&B system the unbroken structural sheathing span between the plates may limit the section height for tall walls. Likewise, oblique angle walls such as those at bay windows will require slight variations in the wall section attachment, although these differences will be minor. Variations in framing details will be developed based on actual field experience and unique home designs.

\subsubsection{Extended Plate and Beam Building Code Review}

A meeting with New York State Codes Division staff was held on March 6, 2014, in Albany, New York, at the New York State Department of State Codes Division.

The meeting was attended by Joseph Hill, R.A., assistant director for Energy Services, and Mike Burnetter, P.E., senior engineer for Energy Services, New York State Codes Division. The EP\&B wall system background and justification were presented by Vladimir Kochkin and Joe Wiehagen of the Home Innovation Research Labs and Philip LaRocque of the LaRocque Business Management Services, LLC.

The primary purposes of the meeting were to review the design details for the EP\&B wall system, independently assess its constructability (based on the initial proposed construction approach), and identify specific building code or inspection issues that might be anticipated as the EP\&B system gains traction in new residential construction. One specific outcome from the meeting was to determine whether the EP\&B wall system meets current New York State codes (IRC and IECC) and if it would be expected to meet the new New York State codes, which are to be finalized in early 2015. If the EP\&B wall system had been determined to not meet current building code requirements, the additional purpose of the meeting would have been to identify design changes necessary to have the wall system accepted for these codes.

Acknowledged early on was one limitation of the wall design - its unsuitability in hurricane zones. Because New York State has hurricane zones along the coast, further design and engineering - which would likely include testing — would be necessary if the EP\&B system were to be used in these high-wind areas.

Outside the high-wind areas, no impediments to the use of the EP\&B system in New York State were identified. Seismic hazard in New York State is limited to low and moderate zones.

Requirements for siding attachment were discussed. Given the current 2010 New York State Energy Conservation Code changes that provide prescriptive attachment of siding through foam (Section 402.1 .5 of the 2010 NYSECC), the participants determined that the EP\&B system would not present any complications. (Similar siding attachment prescriptive requirements for attaching siding through foam are included in the 2015 IRC.) 
Home Innovation staff raised the concern that had been expressed by builders about moisture management in high-performance (energy-efficient) wall systems. Ongoing moisture studies by Home Innovation were of interest to the meeting participants; forthcoming reports will be provided when complete. The New York State Codes Division staff identified concerns from the Wood Council about the moisture handling capability of the OSB sheathing when it is overlaid with foam sheathing products. Participants noted that the EP\&B wall system design mitigates this concern. Though not specifically related to the EP\&B system, Class I vapor retarders will be disallowed in the upcoming code changes.

When discussing parallel changes to the IRC, participants noted that state code modifications to date are based on the 2012 IECC documents. Even though the timeframe for adopting the new code is unknown, the 2012 IECC may not be superseded immediately by the 2015 IECC (which was just recently published) as the baseline code reference. Also, because New York State now uses the IECC as a basis (with state modifications), it has always lagged behind the IECC updates by at least a year to allow for other states to experience the IECC latest changes first.

Finally, the code officials did not see any problem (except in high-wind areas) at this time in having the EP\&B wall system used under the current code and the New York State modifications coming in the near future.

\subsubsection{Summary of Extended Plate and Beam Building Code Applicability}

The stakeholder review and a similar review by building code officials indicate that continued development of the EP\&B system is warranted and beneficial to the residential building industry. Based on these reviews, further laboratory testing was performed and various detailsparticularly in the rim design - were modified and resulted in improved thermal performance and simplified installation.

Thus far, the EP\&B system may be used in residential construction that is allowed by the IRC. However, the EP\&B system must be engineered at this time using the requirements of the IRC, because prescriptive requirements have yet to be developed and submitted for approval through the IECC code-making process.

\subsection{Extended Plate and Beam Construction Details}

An initial step in the assessment was to develop a set of EP\&B construction example details and provide them to a stakeholder group for evaluation. Based on the evaluation a revised set of construction details was developed for both EP\&B wall configurations. The example details are included for two EP\&B wall configurations:

- $2 \times 4$ framing with $2 \times 6$ plates

- $2 \times 6$ framing with 7-1/2-in. (ripped) plates. ${ }^{8}$

\footnotetext{
${ }^{8}$ Based on the cost analysis and reported inconsistency of the $2 \times 8$ milled dimension, use of ripped plates to a $7-1 / 2-$ in. dimension is recommended at this time.
} 


\subsubsection{Extended Plate and Beam Construction Detail Set}

For each wall configuration listed, a set of details and options for specific details was developed:

- Wall header options

- Rim header options

- Foundation rim

- Window framing

- Door framing

- Structural sheathing nailing pattern

- Outside corner framing and insulation options

- Outside corner structural sheathing options

- Inside corner framing options.

Figure 13 shows a cross-section view of a $2 \times 4 \mathrm{EP} \& \mathrm{~B}$ wall with $2 \times 6$ plates. A full set of other details is included in Appendix C. 


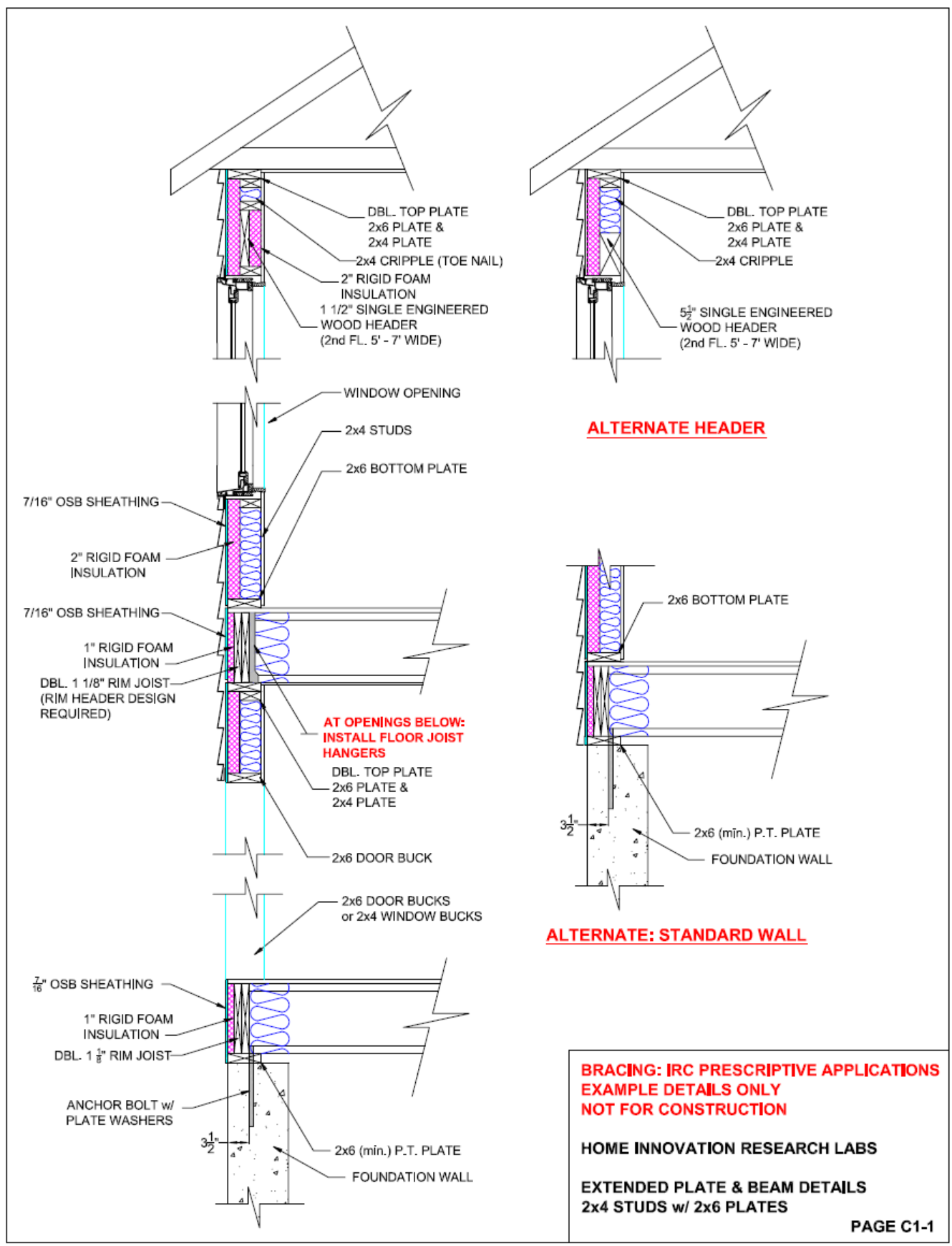

Figure 13. EP\&B: example cross-section detail

\subsubsection{Summary of Extended Plate and Beam Wall Detail Development}

The wall design modifications developed through stakeholder reviews and laboratory testing provide a more robust set of EP\&B details. These detail changes enhance the constructability; however, additional improvements are intended based on a wider range of laboratory testing. Furthermore, the intended outcome of the research, development, and testing is a set of code change proposals that are applicable to the IRC. Approval for prescriptive approaches in the IRC will facilitate a much greater diffusion of this efficient wall system design. 


\subsection{Extended Plate and Beam Example Scope of Work (Framing)}

An example scope of work was developed to support the implementation of construction details. The authors recommend that a scope of work be included with construction documentation and distributed to the framing trades. The presented scope of work is limited to framing practices. Other trades that may be affected by the EP\&B framing include those responsible for air sealing and cladding installation. Cavity insulation is installed in a manner consistent with the standard light frame construction, so it is not included in this sample scope.

The example scope of work is attached in Appendix D. An outline of the scope of work includes the following sections:

1. Introduction

2. Material List

3. Field-Framing Guidelines
A. Sill plate and First Floor Construction
B. Wall Construction
C. First Floor Openings
D. Rim Headers and Second Floor Construction
E. Top Floor Openings
F. Corner Details (Exterior Walls).

\subsection{Example International Residential Code Prescriptive Requirements for the Extended Plate and Beam Wall System}

A draft example set of prescriptive IRC provisions for the EP\&B wall system, based on the 2015 IRC, are outlined here to demonstrate how the EP\&B wall system might be incorporated into the IRC. Although these example provisions are based on current laboratory testing and field implementation, they are for demonstration purposes only. The example provisions indicate where the prescriptive requirements would fit into the current IRC code and how the provisions might modify other sections of the IRC. Repetitive testing results will be required for any building code change proposal to be submitted for the EP\&B system..

\subsubsection{Example International Residential Code Provisions Applicable to the Extended Plate and Beam Wall System}

Add a new definition to Section R202.

EXTENDED PLATE WALL (EPW). A wood-framing method for constructing exterior walls using the top and bottom plates wider than the width of the studs such that rigid foam sheathing can be inset between the studs and the exterior wood structural panel sheathing.

(Note - the name of the wall system has been modified from the EP\&B to the EPW system. This was done to avoid confusion between a beam design and a beam requirement. Further laboratory testing has shown that the original beam concept is a less critical part of the system design and thus is not required as part of the definition or code requirements.) 
Add a new section to IRC Chapter 6.

602.13 Extended plate wall (EPW). Framing, wood structural panel (WSP) sheathing, connections, wall bracing, and anchorage for the EPW shall be in accordance with all applicable provisions of Sections R602.1 through R602.12 as modified by the provisions of Section R602.13.

602.13.1 Plates. The bottom plate and the upper top plate shall be of equal width and shall be wider than the width of the studs by not more than 2 in., in accordance with Figure R602.13.1. Where a double plate is used, the plate directly attached to the stud shall be the same width as the stud width.

602.13.2 WSP sheathing attachment. WSP sheathing shall be attached to wall plates and studs at the panel perimeter and to studs in the panel field with nails providing a minimum penetration of 1-1/2 in. into plates and studs. Different nail sizes are permitted to be used at plates and studs.

602.13.3 Horizontal joints in WSPs. Where used as part of wall bracing, each WSP shall be continuous between the extended top and bottom plates. Blocking of panel edges shall not be an acceptable alternative to continuous WSPs.

602.13.4 Wall bracing. Wall bracing shall be in accordance with the WSP Bracing Method in Table R602.10.4 except the fasteners' diameters and spacing shall be in accordance with Table R602.13.4. All provisions applicable to the use of the WSP Bracing Method including provisions for mixing bracing methods shall be applicable to EPW.

Table R602.13.4 Braced Wall Fastener Requirements

\begin{tabular}{c|c|c}
\hline \multirow{2}{*}{ Minimum Nail Diameter } & \multicolumn{2}{|c}{ Fastener Spacing } \\
\cline { 2 - 3 } & At Top and Bottom Plates & At Studs \\
\hline 0.131 in. & 3 in. o.c. & 6 in. o.c. \\
\hline
\end{tabular}

602.13.4.1 Simplified wall bracing. With the exceptions of Section R602.12.2 Item 2 and Section R602.12.3 Item 1, provisions of Section R602.12 shall be applicable to the EPW. The fastening schedule for WSPs shall be in accordance with the additional requirements of Table R602.13.4.

602.13.5 Rim joist. Rim joists (band joists) installed above an EPW or supporting an EPW shall be a minimum 1-1/8-in. double member or minimum 2-1/4-in. single rim member. Rim joists are permitted to be inset by 1 in. from the exterior framing surface to provide space for exterior rigid insulation. The minimum bearing length requirements for the floor joists shall be satisfied or joists shall be supported with metal hangers.

602.13.6 Headers. When the rim joist framing and supporting full-height studs are constructed in accordance with Section R602.7.2 or an equivalent alternative, no additional headers are required at openings.

602.13.7 Door bucks. On each side of door openings, door frames shall include a stud with the width equal to the width of the top and bottom plates (Figure R602.13.7). 
602.13.8 Foam plastic sheathing. Foam plastic sheathing with a maximum total thickness of 2 in. shall be installed between the studs and the exterior WSPs. The foam plastic sheathing shall be extruded polystyrene in accordance with ASTM C 578 or polyisocyanurate in accordance with C1289. It is permitted to apply spray foam with maximum permeance of 1.5 perms to the interior cavity side of the foam plastic.

602.13.9 Vapor retarder. A vapor retarder on the interior side of the frame shall be in accordance with Section R702.7 except:

1. A Class I vapor retarder shall not be permitted.

2. A Class II vapor retarder shall be kraft paper or an approved equivalent.

3. When a Class III vapor retarder is installed in accordance with Section R702.7.1, the requirements for walls with continuous insulation shall be followed.

4. When spray foam is installed to the interior cavity side of the foam plastic sheathing, it is permitted to use combined through-the-cavity insulation R-value for use with Section R702.7.1. 


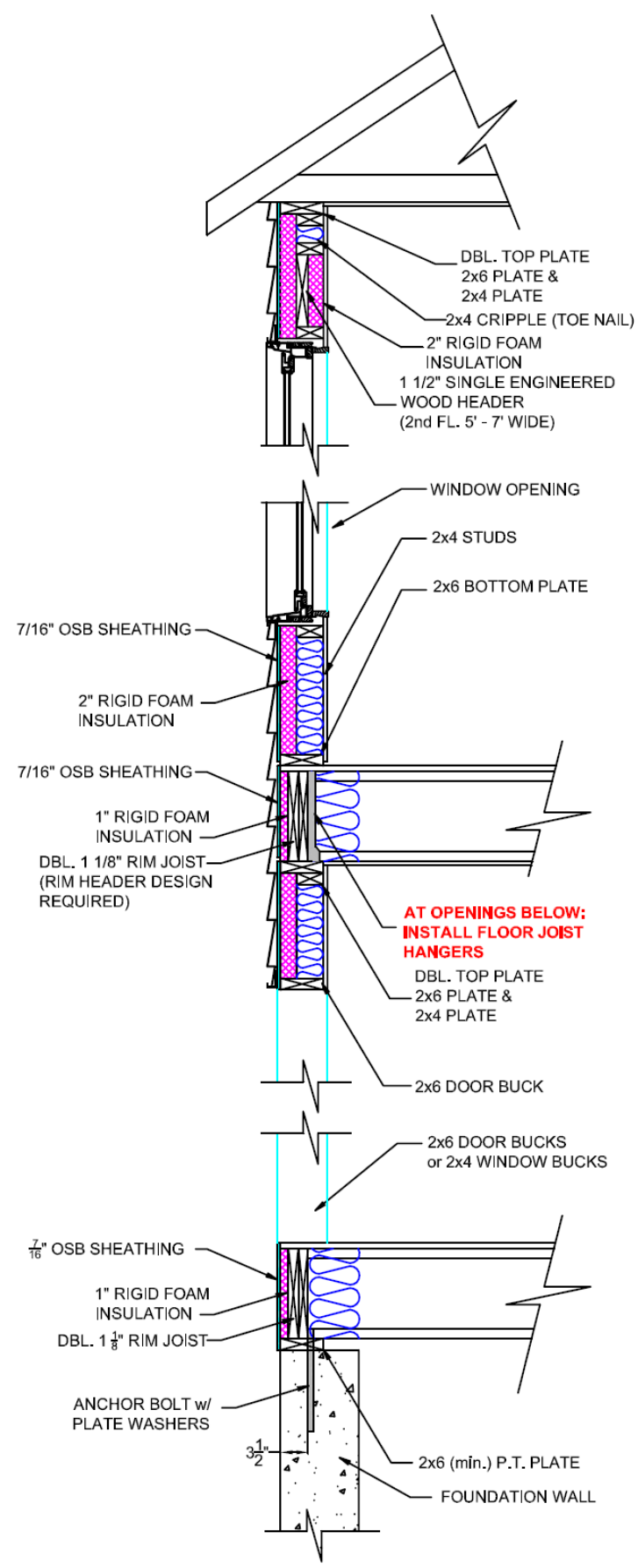

Figure 14. R602.13 EPW system

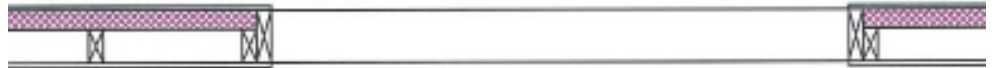

Figure 15. R602.13.7 Full-width studs (bucks) at door openings 


\section{Conclusions and Next Steps}

\subsection{Overall Assessment}

The results of the overall assessment summarized in this report support the viability of the EP\&B wall system and warrant its continued refinement and the development of further substantiating documentation about its performance.

The EP\&B wall system enables wall system construction with R-values $50 \%$ or more above standard code requirements. The major advantage of the EP\&B system is its straightforward approach, which uses common methods and materials used by the industry today. Widespread application of the wall system in new residential construction will be encouraged through the development of a design guide. The development of such a guide is planned as a final step in the maturation of the EP\&B system.

\subsection{Research Questions}

- What are the primary details necessary for constructing the wall framing and plates, rim beam, wall corners, and structural sheathing attachment?

A set of details was developed for the EP\&B wall system; some details resulted from a stakeholder review of the system and others were a result of the wall structural testing. Based on ongoing field experience with the wall system further revisions are expected to optimize the construction process.

- Which connection options are most advantageous for attaching the foam to the framing and the structural sheathing to the plates and framing?

Based on the general assessment the foam attachment requirement is simply to secure the foam before the wood sheathing is installed. Nailing patterns for the sheathing, which were originally tested at 2 in. o.c., were also tested at 3 in. o.c. at the plates and 6 in. o.c. in the field. Further structural testing is planned to refine and establish the nail spacing and specifications.

- What is the design unit shear for resisting lateral loads using the recommended attachment methodology?

Based on the initial evaluation the measured unit shear is dependent on the fastening schedule and is consistent with the capacities for the current braced walls in the IRC. Additional testing is planned to conduct multiple replicates of the same configuration needed to develop the final design values.

- Do fabrication issues limit the panelization potential of the wall system design?

Thus far manufacturers consider panelizing of the EP\&B system to be feasible; however, no system has yet been implemented in a factory. Specific issues raised by panelizers include conversion of equipment to fire 4-in.-long nails and automated equipment processes to set up close nail spacing at the plates. 
- What are the air sealing requirements for the wall system to effectively limit wall air leakage from the interior to the exterior?

Air sealing of the EP\&B wall system has been viewed generally in the same way that a standard light frame wall system is considered. Specific options included taping the foam joints before the structural sheathing is installed, a picture-frame air seal in the inside of the cavity, and a flash SPF coat over the foam. A test house is being planned that will help quantify the air infiltration changes based on various air sealing approaches.

- Which framing and flashing details are needed for openings?

The set of framing details is provided in this report. A notable difference in the opening framing is to frame the door openings the same as the plate dimension to provide a more secure locking detail. The window framing would use the stud size that accommodates longer nails or screws used to attach the window flange through the sheathing and foam to the stud.

- Which prescriptive details are necessary to use the rim beam as a rim header? Will the beam header bearing be sufficient for prescriptive installation requirements?

The EP\&B design uses a rim header design that was developed by the Home Innovation Research Labs (DeRenzis et al. 2013). The rim header is now prescriptively available in the 2015 IRC. Structural testing outlined in this report confirmed that the rim header design can support vertical loads and resist shear loads when it is inset to accommodate a 1-in. layer of exterior foam.

- What is the moisture performance of the wall system by climate zone?

EP\&B wall system designs are currently being tested in climate zones 4 and 5. A preliminary review of winter data from controlled outdoor buildings in climate zone 4 (to be published in 2015) revealed excellent performance of the system with the OSB moisture content at $13 \%$ or lower over a 12-month period. Also, a preliminary internal simulation using WUFI software for the EP\&B system in cold climates indicated no moisture issues with the wood structural sheathing. Testing and simulation analysis will be conducted as the EP\&B system is developed.

- How does the cost of the EP\&B system compare to other high-R walls?

A detailed cost analysis that incorporates both labor and material estimates shows that the EP\&B system is well within the range of costs for similarly insulated wall systems. Planned field studies will help to support these estimates and demonstrate other practical benefits to using the EP\&B system that are not captured in this analysis.

- At which range of wall framing configurations (framing/plates) will the design be suitable and practical?

As currently envisioned the EP\&B system can be practically constructed using either $2 \times 4$ studs with $2 \times 6$ plates ( 2 -in. insulating sheathing), or $2 \times 6$ studs with either $2 \times 8$ plates ( 1 $3 / 4$-in. insulating sheathing), or $2 \times 6$ studs with ripped 7-1/2-in. plates (2-in. insulating sheathing). The added cost of ripping plates to the $7-1 / 2-$ in. dimension is less than the added 
cost of two separate sheets of foam insulation ( 1 in. and $3 / 4$ in.). One-and-3/4-in. insulated sheathing is not readily available.

\subsection{Next Steps}

In a parallel effort a house is under construction that uses the EP\&B wall system. Results of that project will be summarized in a future report. Additional testing and evaluation are needed in the following key areas:

- Repetitive shear walls testing to finalize design values

- Shear wall testing to investigate the applicability of the continuous wall sheathing method in the IRC

- Moisture management based on test hut testing, whole-house monitoring, and computer simulations

- Whole-wall R-value evaluation through hotbox testing

- Air sealing testing of wall sections to evaluate the performance of the exterior insulation as a gasket between the framing and the sheathing

- Development of a guide for builders. 


\section{References}

Aldrich, R.A., Arena, L., and Zoeller, W. 2010. Practical Residential Wall Systems: R-30 and Beyond. Stephen Winter Associates, Inc. BEST2 Conference 2010.

Cold Climate Housing Research Center. 2010. CCHRC Snapshot RS 2007-03, updated February 2010 .

DeRenzis, A., Kochkin, V., and Wiehagen, J. 2013. High-R Walls for New Construction Structural Performance: Integrated Rim Header Testing. NAHB Research Center. Accessed April 16, 2015: http://apps1.eere.energy.gov/buildings/publications/pdfs/building_america/highr_walls_ne W construction.pdf.

Minnesota Sustainable Housing Initiative. 2012. Wall Section. Accessed April 16, 2015: http://www.mnshi.umn.edu/kb/scale/wall.html.

NYSECC. 2010. New York State Energy Conservation Code. Accessed July 8, 2015: http://publicecodes.cyberregs.com/st/ny/st/b1200v10/index.htm.

Straube, J., and Smegal, J. 2009. Building America Special Research Project: High-R Walls Case Study Analysis, Research Report 0903. Building Science Corporation. Somerville, MA. March 11, 2009, Rev. June 8, 2011.

Straube, J., Lstiburek, J., Pettit, B., Rudd, A., Schumacher, C., Baker, P., Ueno, K., Lukachko, A., Smegal, J., Grin, A., Neuhauser, K., and Gates, C. 2010. Building America Special Research Project: High R-Value Enclosures for High Performance Residential Buildings in All Climate Zones, Research Report-1005. Building Science Corporation. Somerville, MA. October 2010, Rev. February 2011. 


\section{Appendix A. Detailed Costs}

Table A1. Detailed Cost_Vinyl Siding

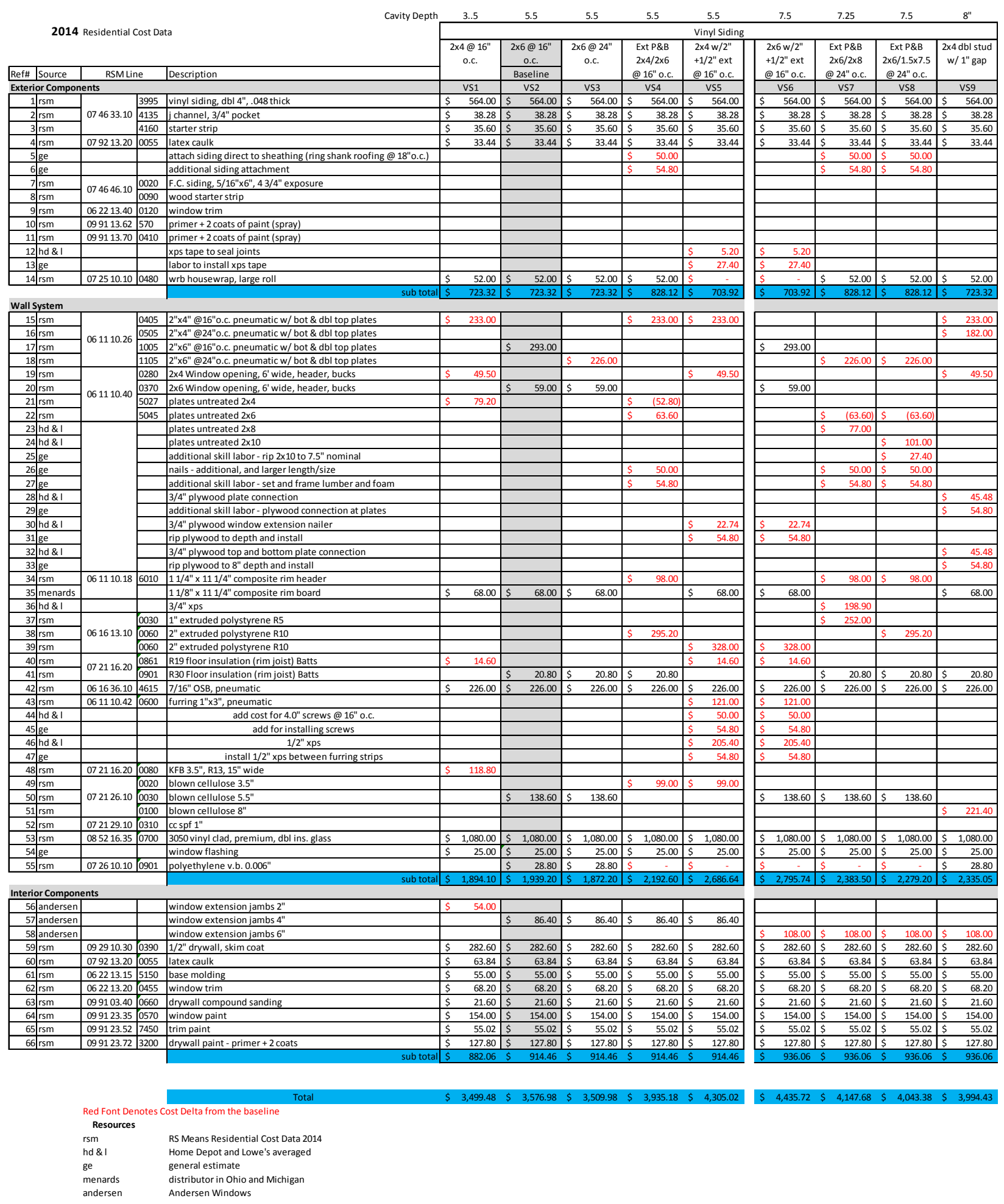




\section{Table A2. Detailed Cost-Fiber Cement Siding}

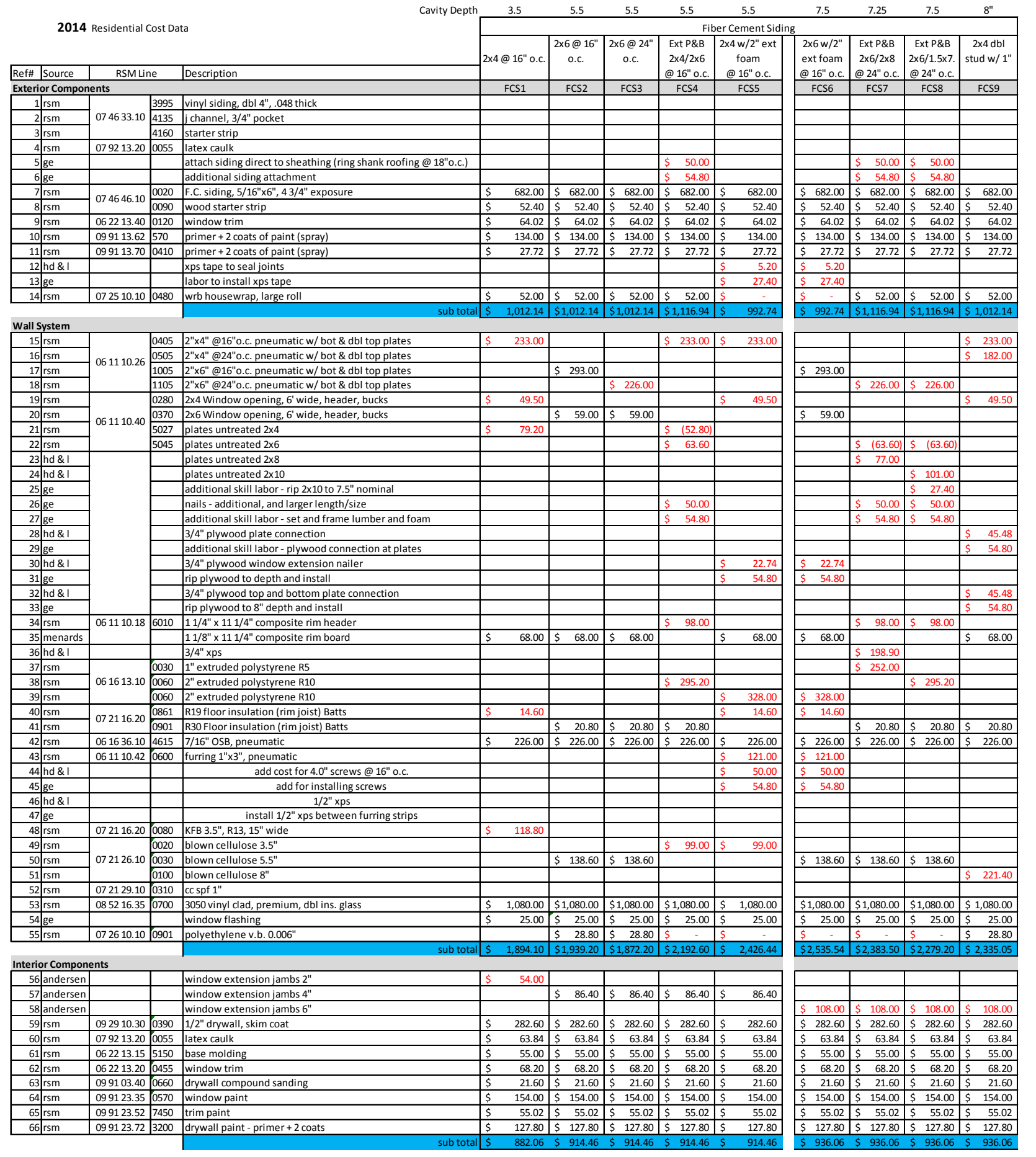




\section{Appendix B. Reference Wall Details and Individual Cost Summary}

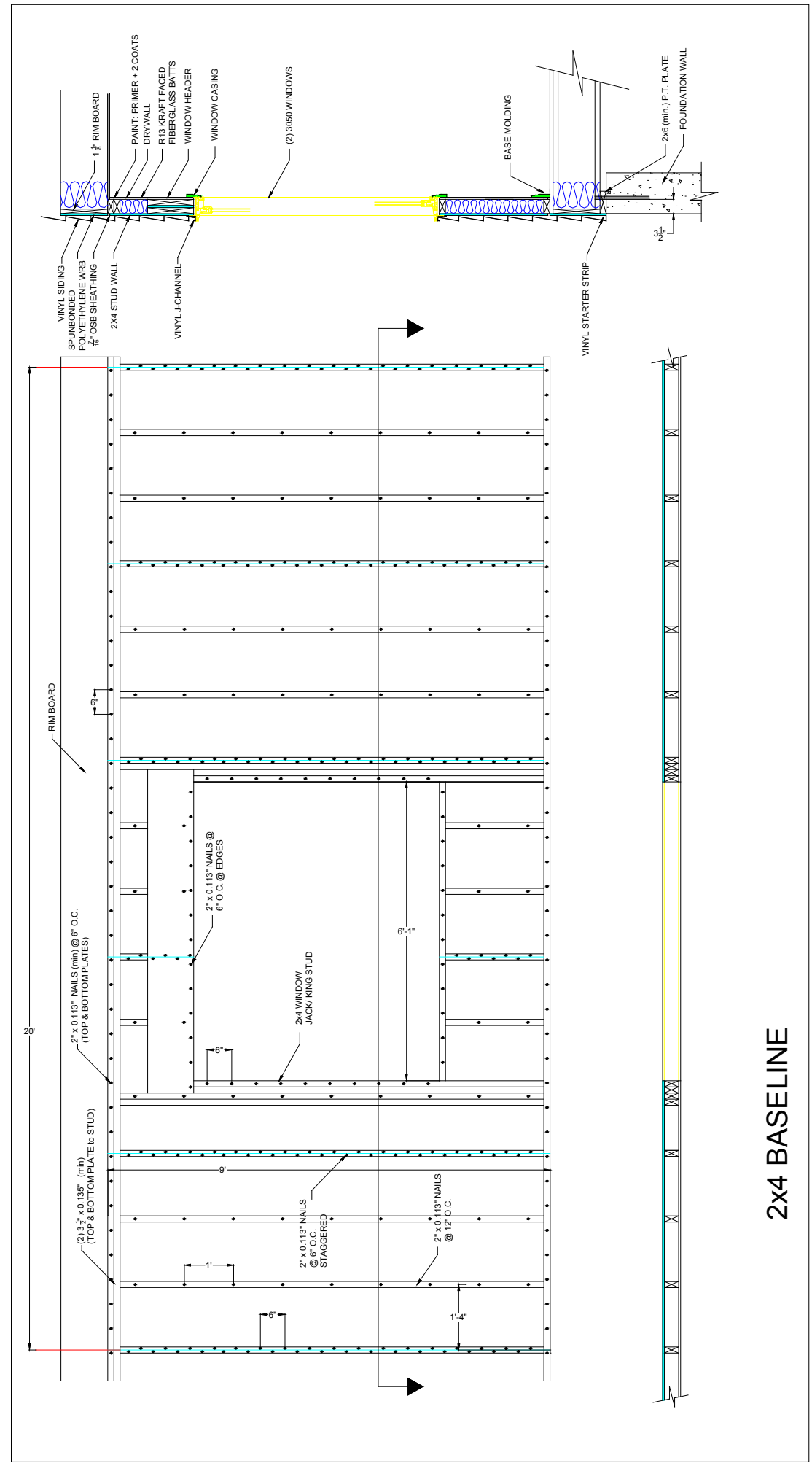

Figure B1. Configurations VS1 and FCS1-2 × 4 studs @ 16 in. o.c. 
Table B1. Costs for Configurations VS1 and FCS1-2 × 4 Studs @ 16 in. o.c.

2x4 Studs @ 16" o.c.

\begin{tabular}{|c|c|c|c|c|}
\hline & \multirow{3}{*}{\begin{tabular}{|r|} 
Ref $^{1}$ \\
1 \\
\end{tabular}} & \multirow{3}{*}{$\begin{array}{l}\text { Component } \\
\text { vinvl siding dbl } 4^{\prime \prime} \quad 048 \text { thick }\end{array}$} & \multirow{2}{*}{\multicolumn{2}{|c|}{ Installed Cost }} \\
\hline & & & & \\
\hline \multirow{6}{*}{$\begin{array}{c}\text { Exterior } \\
\text { Components }\end{array}$} & & & $\$$ & 564.00 \\
\hline & 2 & j channel, 3/4" pocket & $\$$ & 38.28 \\
\hline & 3 & starter strip & $\$$ & 35.60 \\
\hline & 4 & latex caulk & $\$$ & 33.44 \\
\hline & 14 & wrb housewrap, large roll & $\$$ & 52.00 \\
\hline & & sub total & $\$$ & 723.32 \\
\hline \multirow{10}{*}{ Wall System } & 15 & 2"x4" @16"o.c. pneumatic w/ bot \& dbl top plates & $\$$ & 233.00 \\
\hline & 19 & $2 \times 4$ Window opening, 6 ' wide, header, bucks & $\$$ & 49.50 \\
\hline & 21 & plates untreated $2 \times 4$ & $\$$ & 79.20 \\
\hline & 35 & $11 / 8^{\prime \prime}$ x $111 / 4 "$ composite rim board & $\$$ & 68.00 \\
\hline & 40 & R19 floor insulation (rim joist) Batts & $\$$ & 14.60 \\
\hline & 42 & 7/16" OSB, pneumatic & $\$$ & 226.00 \\
\hline & 48 & KFB 3.5", R13, 15" wide & $\$$ & 118.80 \\
\hline & 53 & 3050 vinyl clad, premium, dbl ins. glass & $\$$ & $1,080.00$ \\
\hline & 54 & window flashing & $\$$ & 25.00 \\
\hline & & sub total & $\$$ & $1,894.10$ \\
\hline \multirow{12}{*}{$\begin{array}{l}\text { Interior } \\
\text { Components }\end{array}$} & 56 & window extension jambs $2 "$ & $\$$ & 54.00 \\
\hline & 59 & 1/2" drywall, skim coat & $\$$ & 282.60 \\
\hline & 60 & Iatex caulk & $\$$ & 63.84 \\
\hline & 61 & base molding & $\$$ & 55.00 \\
\hline & 62 & window trim & $\$$ & 68.20 \\
\hline & 63 & drywall compound sanding & $\$$ & 21.60 \\
\hline & 64 & window paint & $\$$ & 154.00 \\
\hline & 65 & trim paint & $\$$ & 55.02 \\
\hline & 66 & drywall paint - primer +2 coats & $\$$ & 127.80 \\
\hline & & sub total & $\$$ & 882.06 \\
\hline & & & & \\
\hline & & Total & $\$$ & $3,499.48$ \\
\hline
\end{tabular}

1. See Tables A1 and A2 "Detailed Cost" for the reference number. 


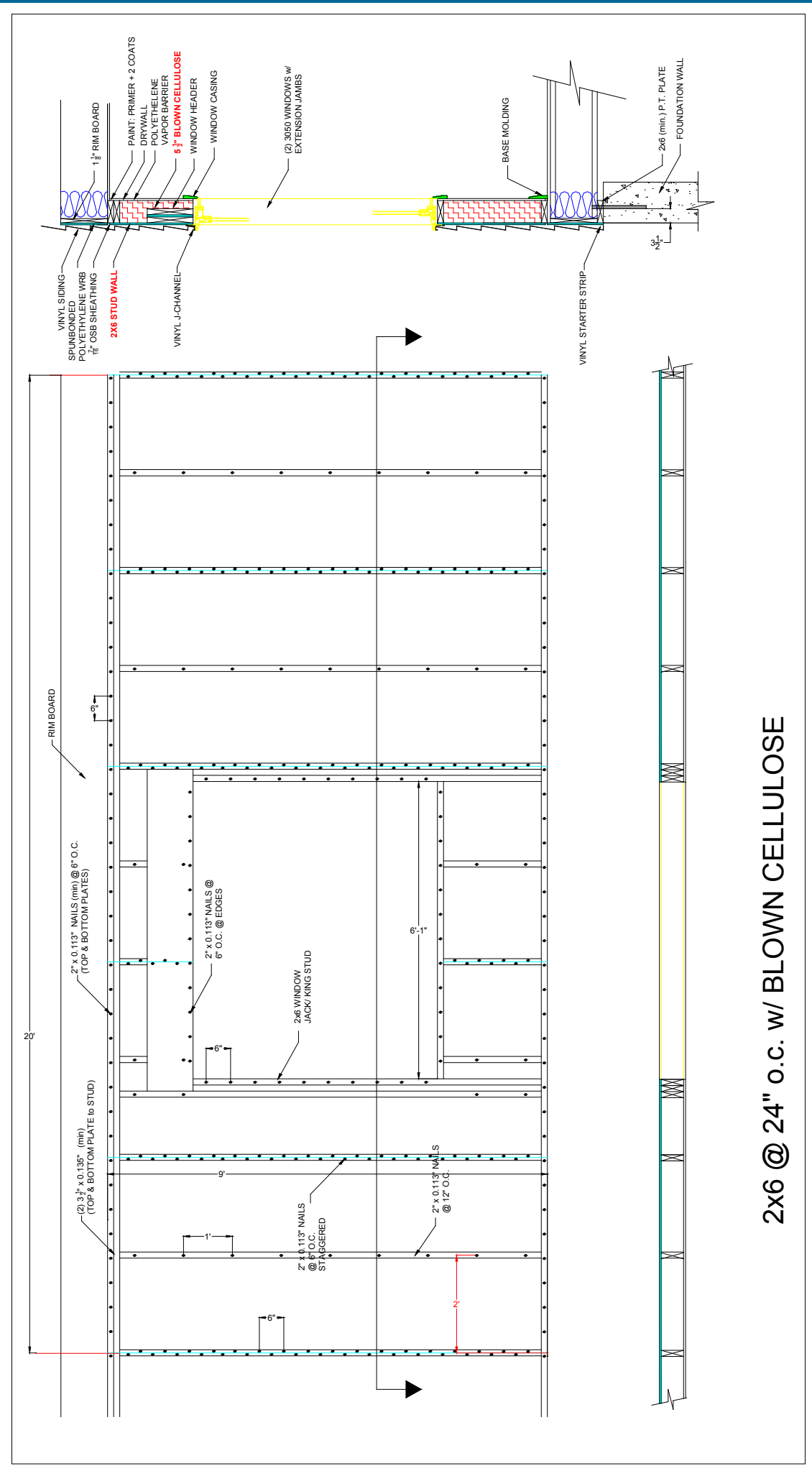

Figure B2. Configuration sVS2 and FCS2-2 × 6 studs @ 24 in. o.c. 
Table B2. Costs for Configurations VS2 and FCS2-2 × 6 Studs @ 24 in. o.c.

2x6 Studs@ @24" o.c.

\begin{tabular}{|c|c|c|c|c|}
\hline & \multirow{3}{*}{\begin{tabular}{|r|} 
Ref\# $^{1}$ \\
1
\end{tabular}} & \multirow{3}{*}{\begin{tabular}{|l} 
Component \\
vinvl siding, dbl 4", .048 thick
\end{tabular}} & \multirow{2}{*}{\multicolumn{2}{|c|}{ Installed Cost }} \\
\hline & & & & \\
\hline \multirow{6}{*}{$\begin{array}{c}\text { Exterior } \\
\text { Components }\end{array}$} & & & $\$$ & 564.00 \\
\hline & 2 & j channel, 3/4" pocket & $\$$ & 38.28 \\
\hline & 3 & starter strip & $\$$ & 35.60 \\
\hline & 4 & latex caulk & $\$$ & 33.44 \\
\hline & 14 & wrb housewrap, large roll & $\$$ & 52.00 \\
\hline & & sub total & $\$$ & 723.32 \\
\hline \multirow{10}{*}{ Wall System } & 18 & 2"x6" @24"o.c. pneumatic w/ bot \& dbl top plates & $\$$ & 226.00 \\
\hline & 20 & $2 \times 6$ Window opening, 6 ' wide, header, bucks & $\$$ & 59.00 \\
\hline & 35 & $11 / 8^{\prime \prime}$ x $111 / 4 "$ composite rim board & $\$$ & 68.00 \\
\hline & 41 & R30 Floor insulation (rim joist) Batts & $\$$ & 20.80 \\
\hline & 42 & 7/16" OSB, pneumatic & $\$$ & 226.00 \\
\hline & 50 & blown cellulose $5.5^{\prime \prime}$ & $\$$ & 138.60 \\
\hline & 53 & 3050 vinyl clad, premium, dbl ins. glass & $\$$ & $1,080.00$ \\
\hline & 54 & window flashing & $\$$ & 25.00 \\
\hline & 55 & polyethylene v.b. $0.006 "$ & $\$$ & 28.80 \\
\hline & & sub total & $\$$ & $1,872.20$ \\
\hline \multirow{12}{*}{$\begin{array}{c}\text { Interior } \\
\text { Components }\end{array}$} & 57 & window extension jambs 4" & $\$$ & 86.40 \\
\hline & 59 & 1/2" drywall, skim coat & $\$$ & 282.60 \\
\hline & 60 & latex caulk & $\$$ & 63.84 \\
\hline & 61 & base molding & $\$$ & 55.00 \\
\hline & 62 & window trim & $\$$ & 68.20 \\
\hline & 63 & drywall compound sanding & $\$$ & 21.60 \\
\hline & 64 & window paint & $\$$ & 154.00 \\
\hline & 65 & trim paint & $\$$ & 55.02 \\
\hline & 66 & drywall paint - primer +2 coats & $\$$ & 127.80 \\
\hline & & sub total & $\$$ & 914.46 \\
\hline & & & & \\
\hline & & Total & $\$$ & $3,509.98$ \\
\hline
\end{tabular}

1. See Tables A1 and A2 "Detailed Cost" for the reference number. 


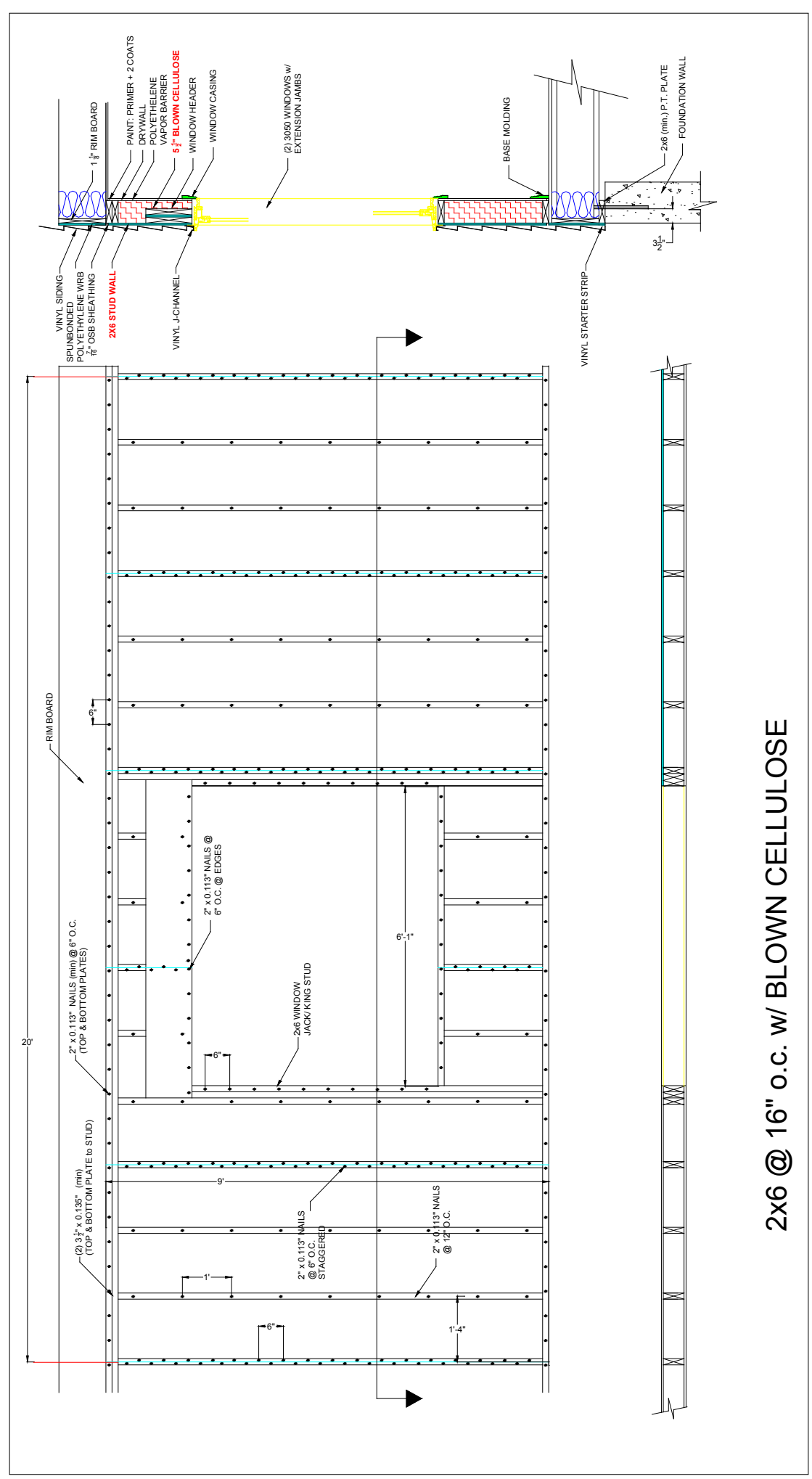

Figure B3. Configurations VS3 and FCS3-2 ×6 studs @ 16 in. o.c. 
Table B3. Costs for Configurations VS3 and FCS3-2 × 6 studs @ 16 in. o.c.

2x6 Studs @ 16" o.c.

\begin{tabular}{|c|c|c|c|c|}
\hline & Ref\# $^{1}$ & Component & Ins & alled Cost \\
\hline & 1 & vinyl siding, dbl 4", .048 thick & $\$$ & 564.00 \\
\hline & 2 & j channel, 3/4" pocket & $\$$ & 38.28 \\
\hline & 3 & starter strip & $\$$ & 35.60 \\
\hline Exterior & 4 & latex caulk & $\$$ & 33.44 \\
\hline & 14 & wrb housewrap, large roll & $\$$ & 52.00 \\
\hline & & sub total & $\$$ & 723.32 \\
\hline & 17 & 2"x6" @16"o.c. pneumatic w/ bot \& dbl top plates & $\$$ & 293.00 \\
\hline & 20 & $2 \times 6$ Window opening, 6 ' wide, header, bucks & $\$$ & 59.00 \\
\hline & 35 & $11 / 8^{\prime \prime}$ x $111 / 4$ " composite rim board & $\$$ & 68.00 \\
\hline & 41 & R30 Floor insulation (rim joist) Batts & $\$$ & 20.80 \\
\hline & 42 & 7/16" OSB, pneumatic & $\$$ & 226.00 \\
\hline Wall System & 50 & blown cellulose $5.5^{\prime \prime}$ & $\$$ & 138.60 \\
\hline & 53 & 3050 vinyl clad, premium, dbl ins. glass & $\$$ & $1,080.00$ \\
\hline & 54 & window flashing & $\$$ & 25.00 \\
\hline & 55 & polyethylene v.b. 0.006" & $\$$ & 28.80 \\
\hline & & sub total & $\$$ & $1,939.20$ \\
\hline & 57 & window extension jambs 4" & $\$$ & 86.40 \\
\hline & 59 & 1/2" drywall, skim coat & $\$$ & 282.60 \\
\hline & 60 & latex caulk & $\$$ & 63.84 \\
\hline & 61 & base molding & $\$$ & 55.00 \\
\hline & 62 & window trim & $\$$ & 68.20 \\
\hline Comnonents & 63 & drywall compound sanding & $\$$ & 21.60 \\
\hline & 64 & window paint & $\$$ & 154.00 \\
\hline & 65 & trim paint & $\$$ & 55.02 \\
\hline & 66 & drywall paint - primer +2 coats & $\$$ & 127.80 \\
\hline & & sub total & $\$$ & 914.46 \\
\hline & & & & \\
\hline & & Total & $\$$ & $3,576.98$ \\
\hline
\end{tabular}

1. See Tables A1 and A2 "Detailed Cost" for the reference number. 


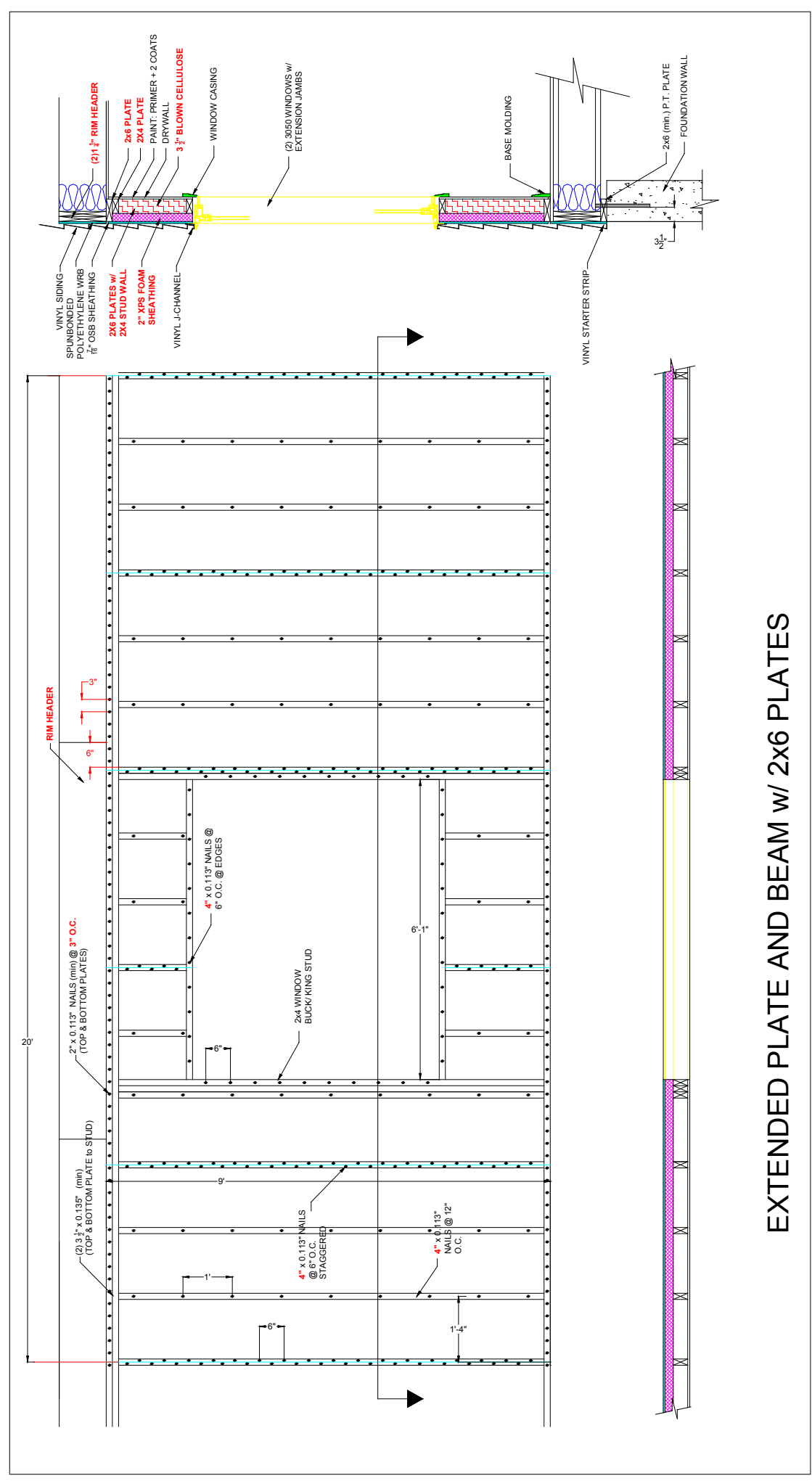

Figure B4. Configurations VS4 and FCS4-2 × 6 EP\&B 
Table B4. Costs for Configurations VS4 and FCS4-2 × 6 EP\&B

\section{2x6 Extended Plate \& Beam}

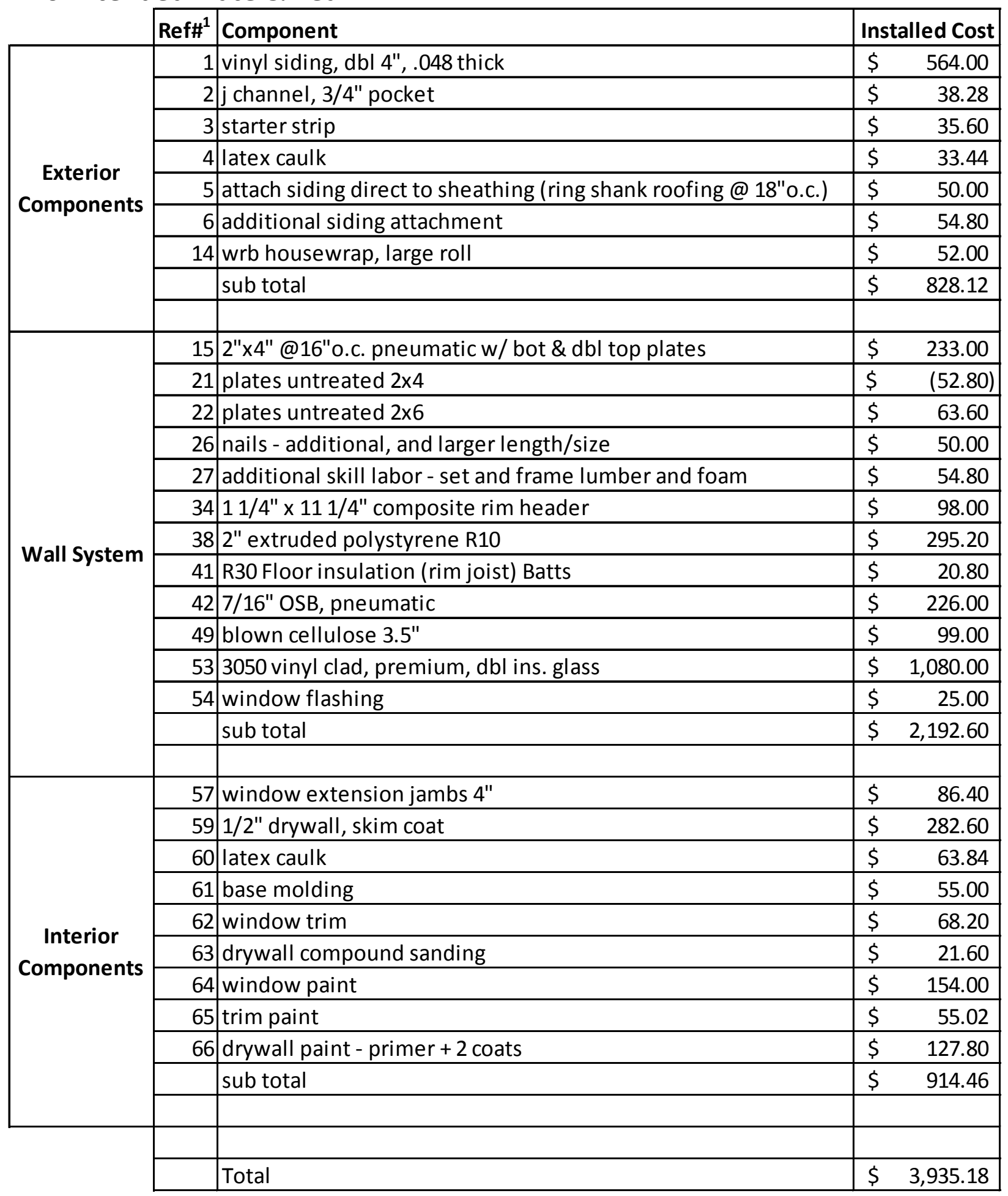

1. See Tables A1 and A2 "Detailed Cost" for the reference number. 


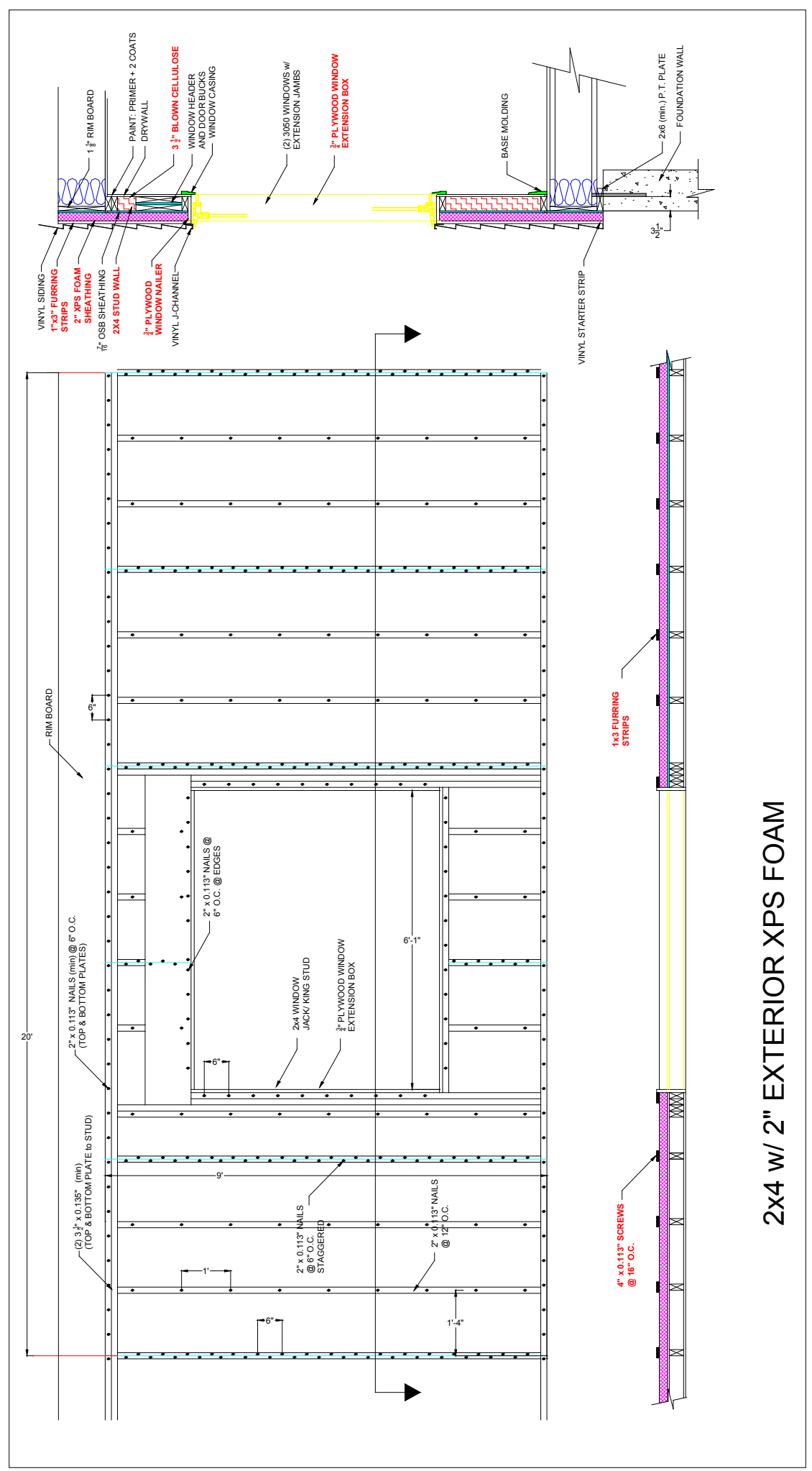

Figure B5. Configurations VS5 and FCS5-2 44 stud @16 in. o.c. with 2 in. + $1 / 2$ in. exterior XPS 
Table B5. Costs for Configuration VS5 andFCS5-2 $\times 4$ Stud @16 in. o.c.

With 2 in. $+1 / 2$ in. Exterior XPS

\section{2x4 @ 16" o.c. w/ 2" +1/2" Exterior XPS Rigid Foam Sheathing}

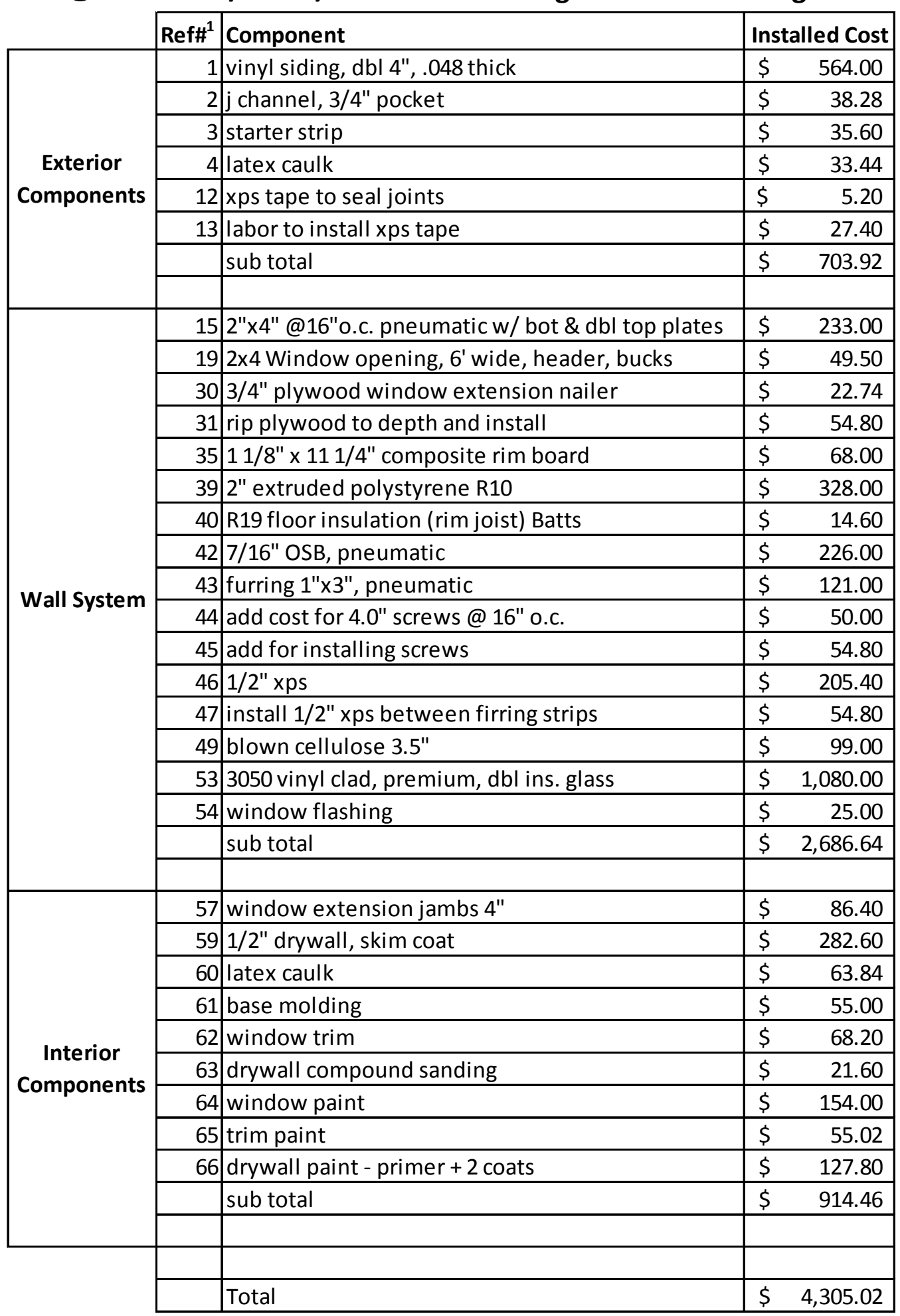

1. See Tables A1 and A2 "Detailed Cost" for the reference number. 


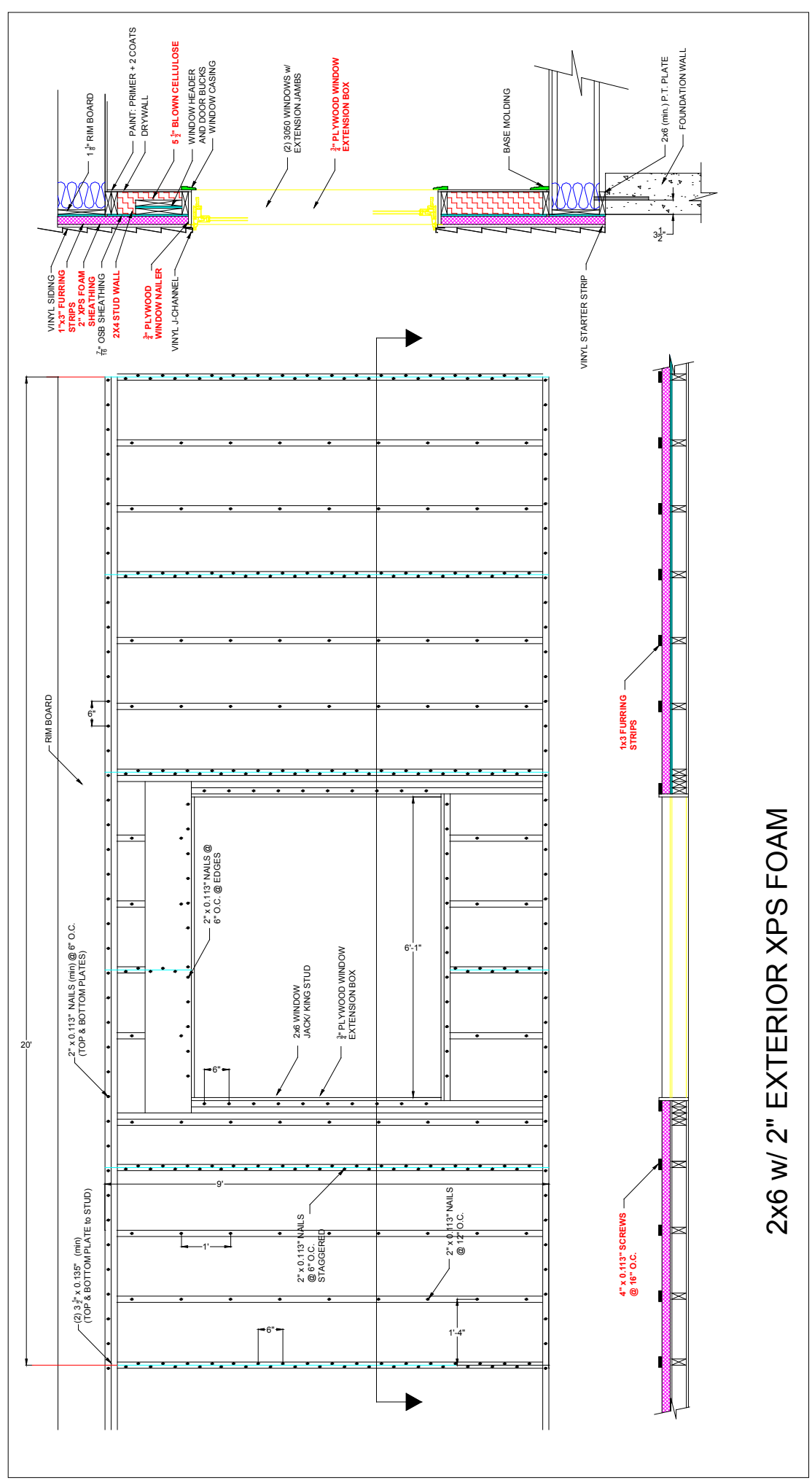

Figure B6. Configurations VS6 and FCS6-2 6 stud @16 in. o.c. with 2 in. + $1 / 2$ in. exterior XPS 
Table B6. Costs for Configurations VS6 and FCS6-2 $\times 6$ Stud @16 in. o.c. With 2 in. $+1 / 2$ in. Exterior XPS

\section{2x6 @ 16" o.c. w/ 2" +1/2" Exterior XPS Rigid Foam Sheathing}

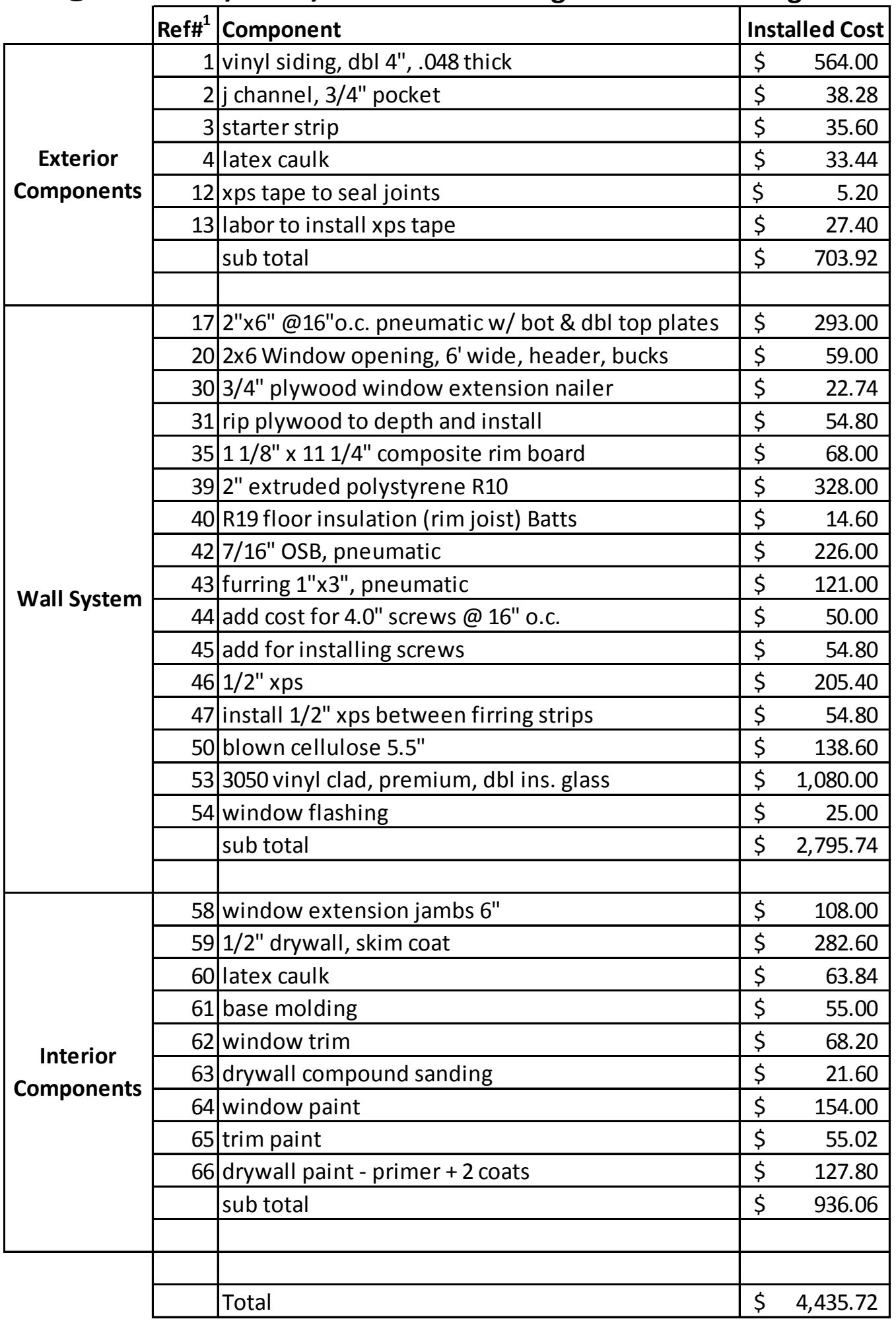

1. See Tables A1 and A2 "Detailed Cost" for the reference number. 


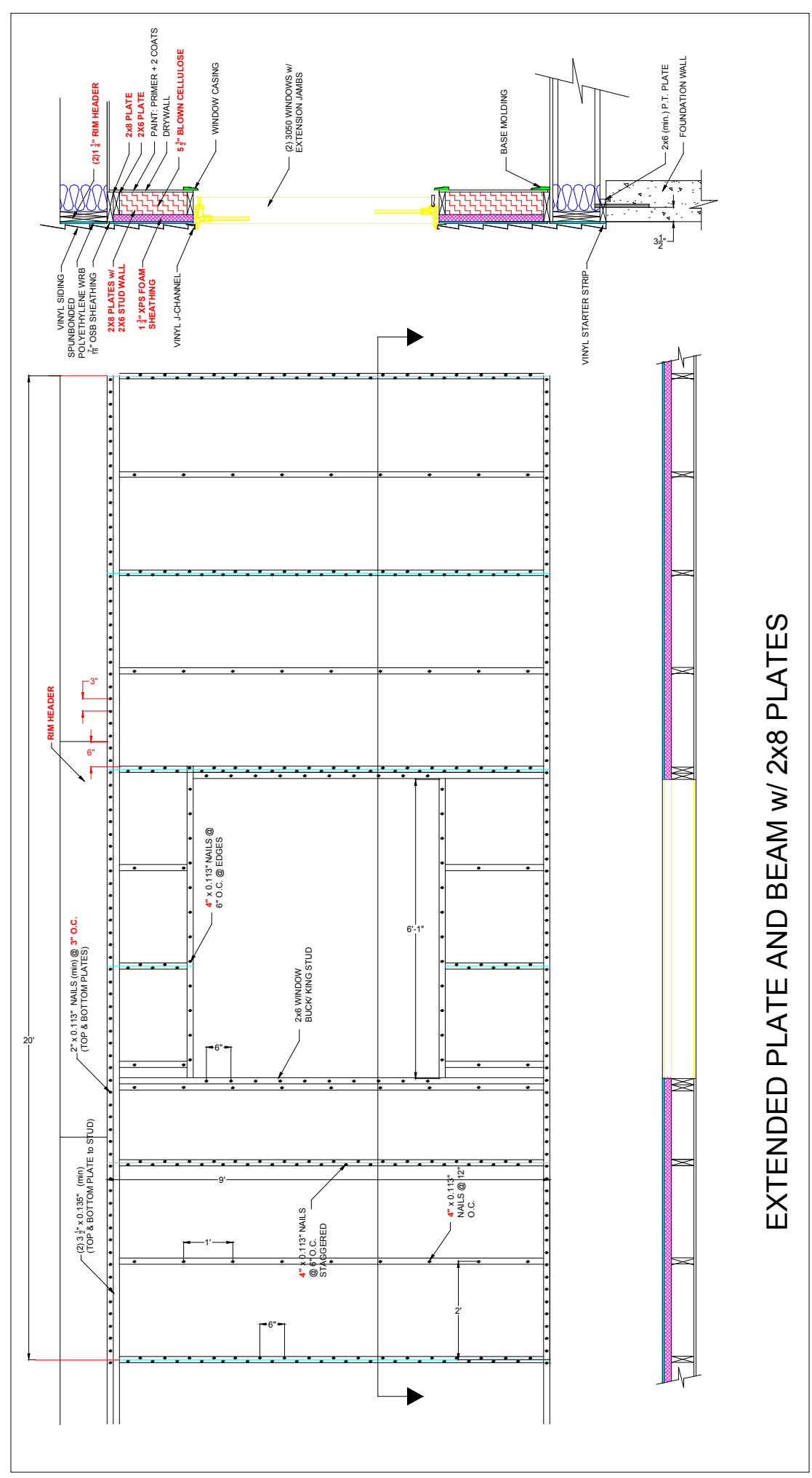

Figure B7. Configurations VS7 and FCS7-2 28 EP\&B 
Table B7. Costs for Configurations VS7 and FCS7-2 × 8 EP\&B

2x8 Extended Plate \& Beam

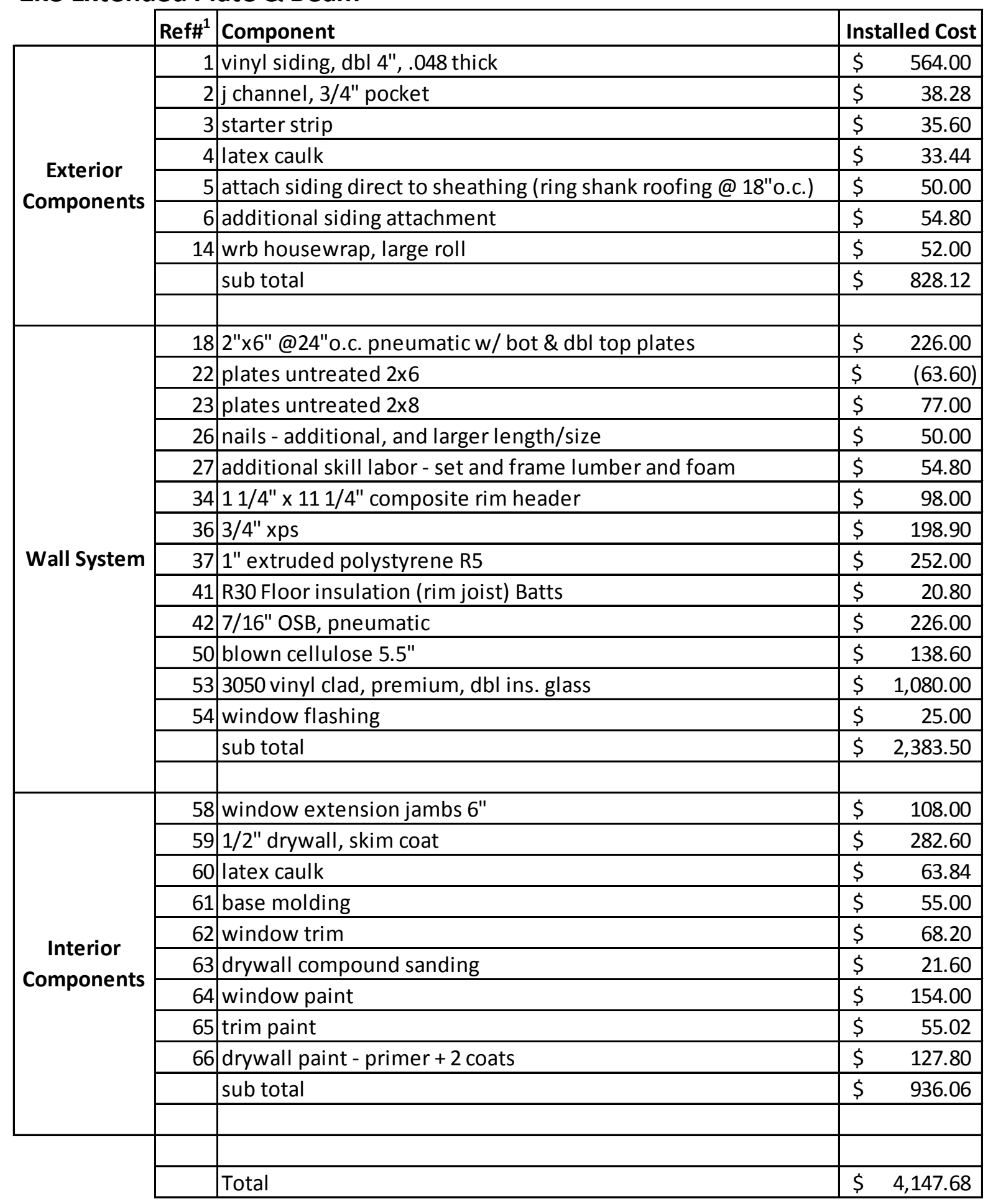

1. See Tables A1 and A2 "Detailed Cost" for the reference number. 


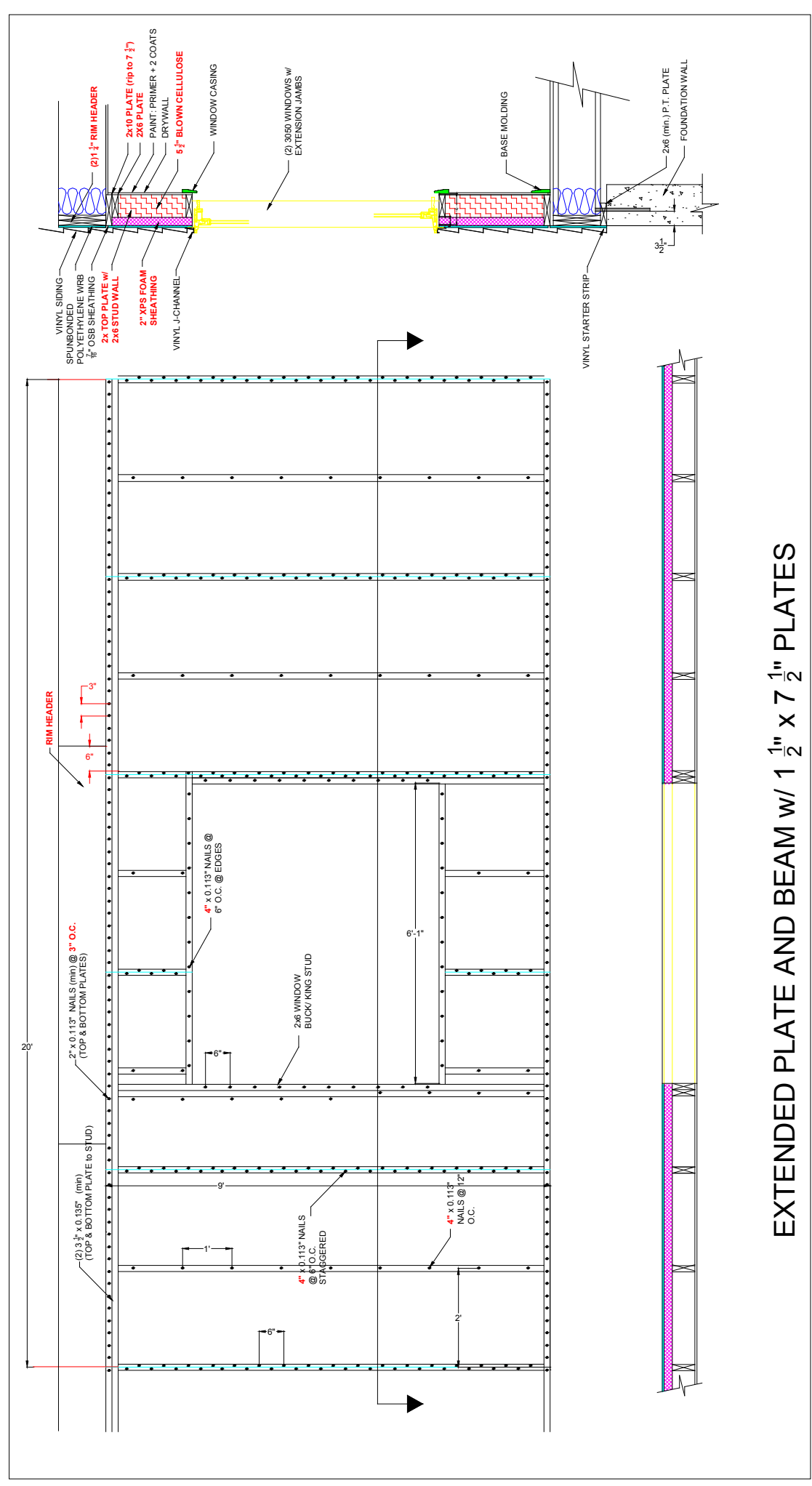

Figure B8. Configurations VS8 and FCS8-1.5 in. $\times 7.5$ in. EP\&B 
Table B8. Costs for Configurations VS8 and FCS8-1.5 in. $\times 7.5$ in. EP\&B

\section{5" x 7.5" Extended Plate \& Beam}

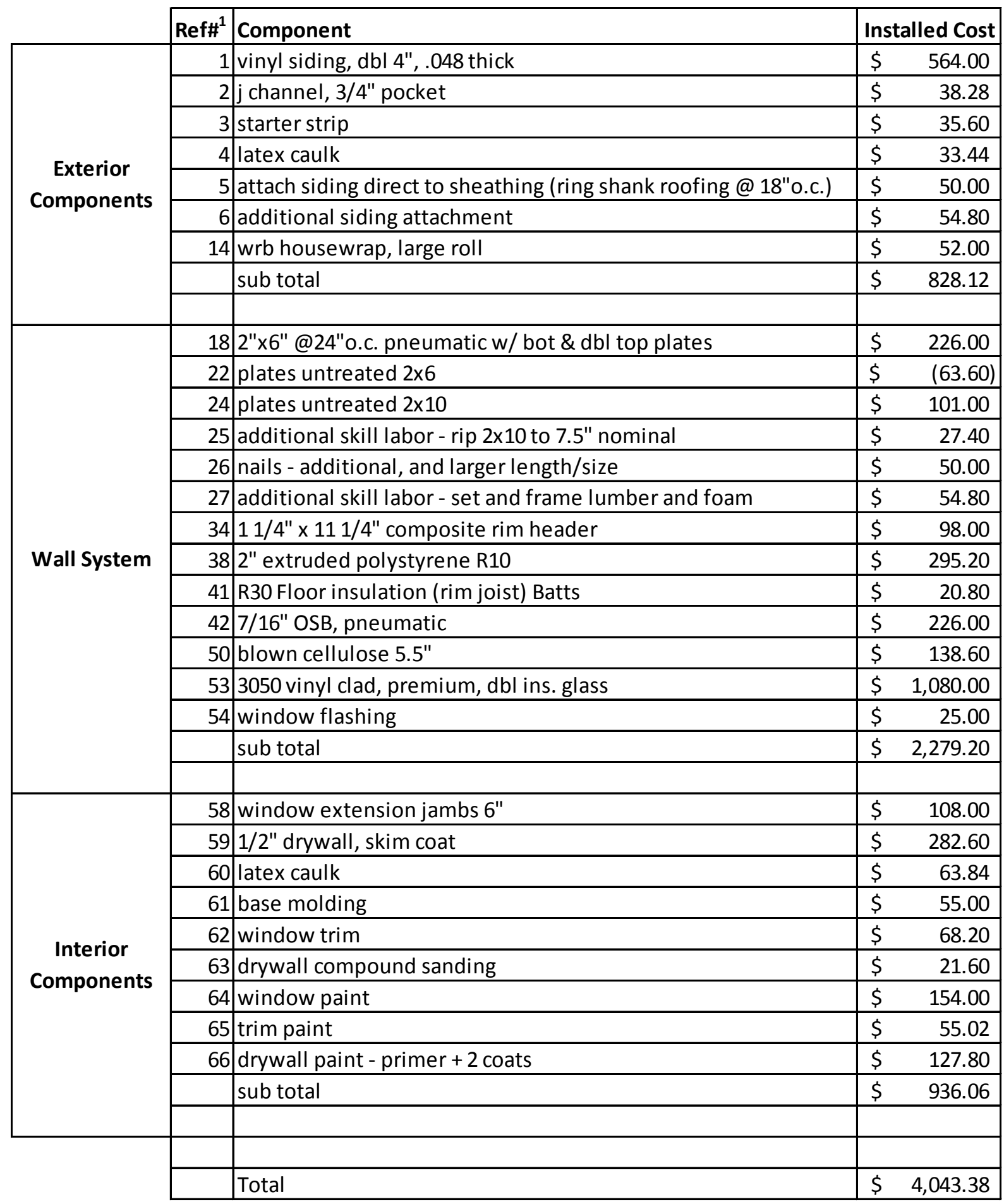

1. See Tables A1 and A2 "Detailed Cost" for the reference number. 


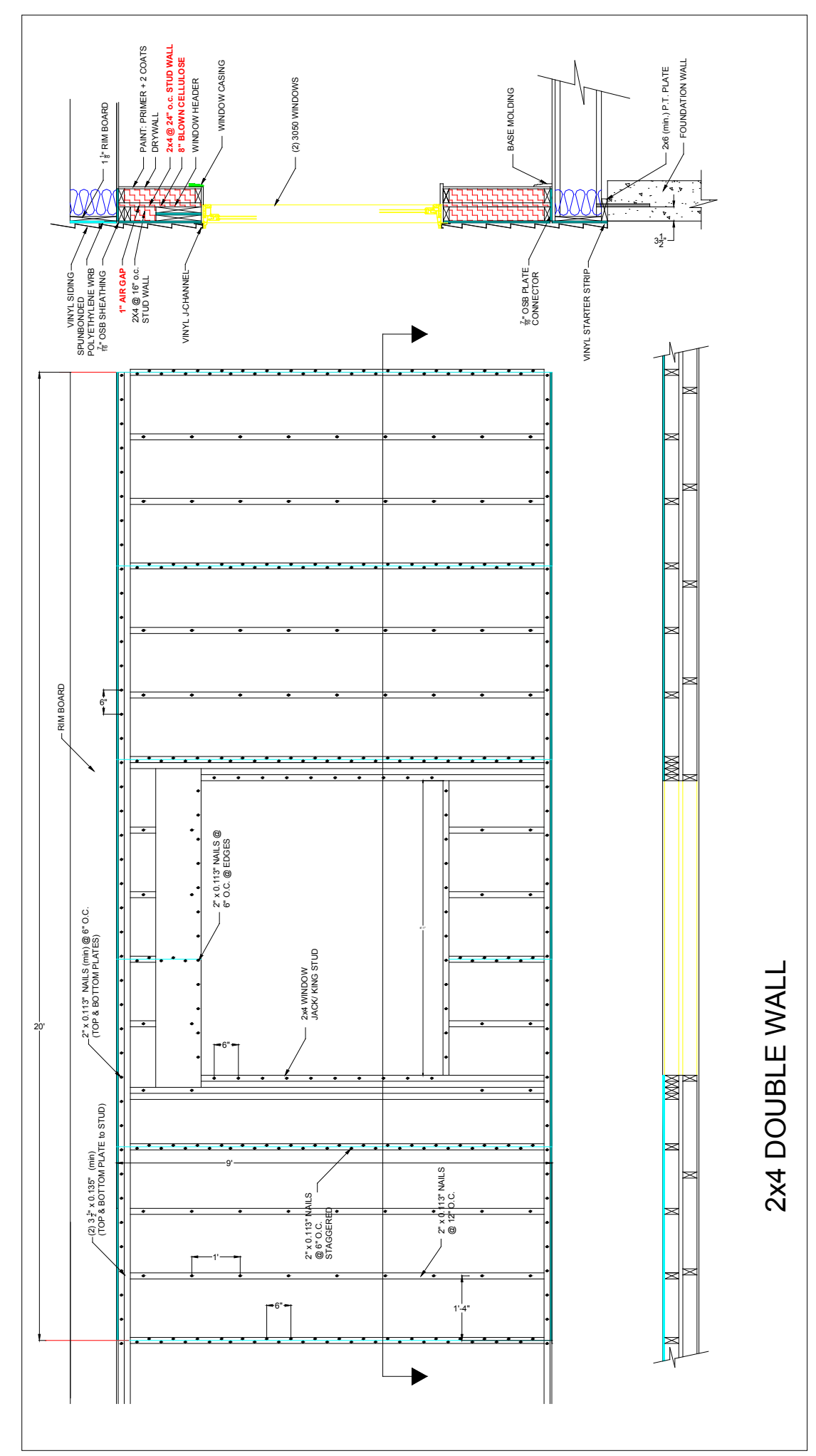

Figure B9. Configurations VS9 and FCS9-2 $\times 4$ double stud 
Table B9. Costs for Configurations VS9 and FCS9-2 $\times 4$ Double Stud

Double 2x4 stud wall w/ 1" Air Gap

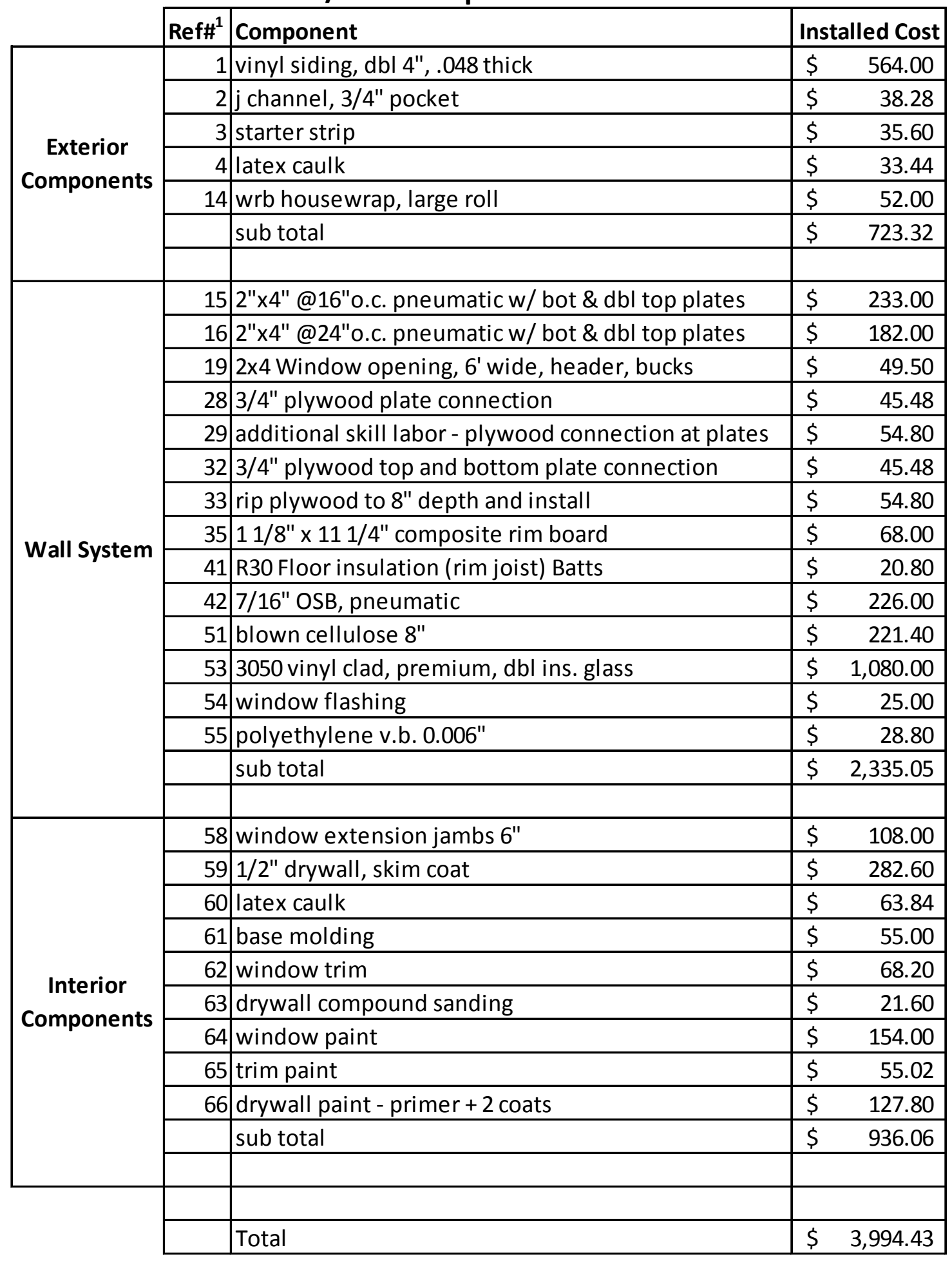

1. See Tables A1 and A2 "Detailed Cost" for the reference number. 


\section{Appendix C. Extended Plate and Beam Wall Details}

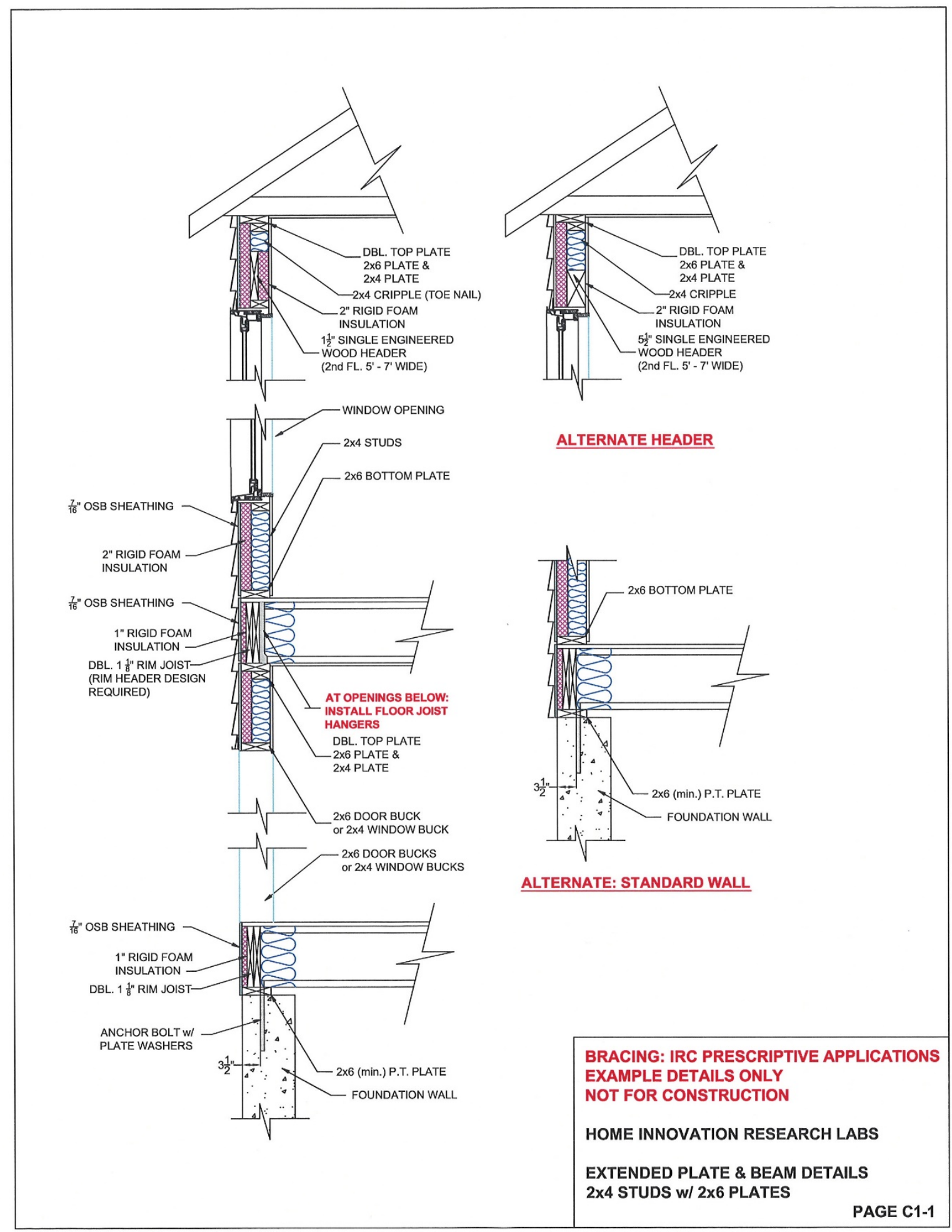




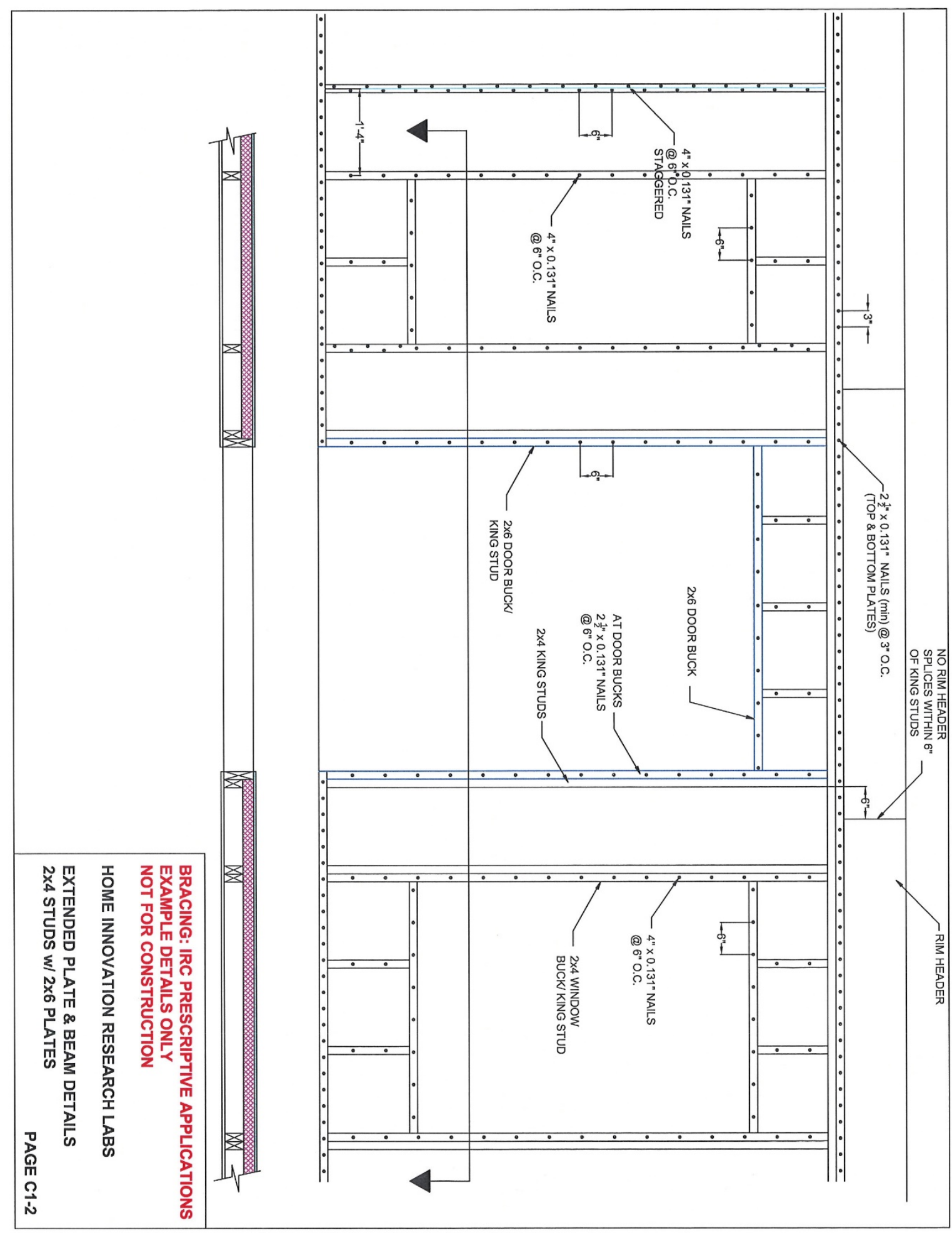




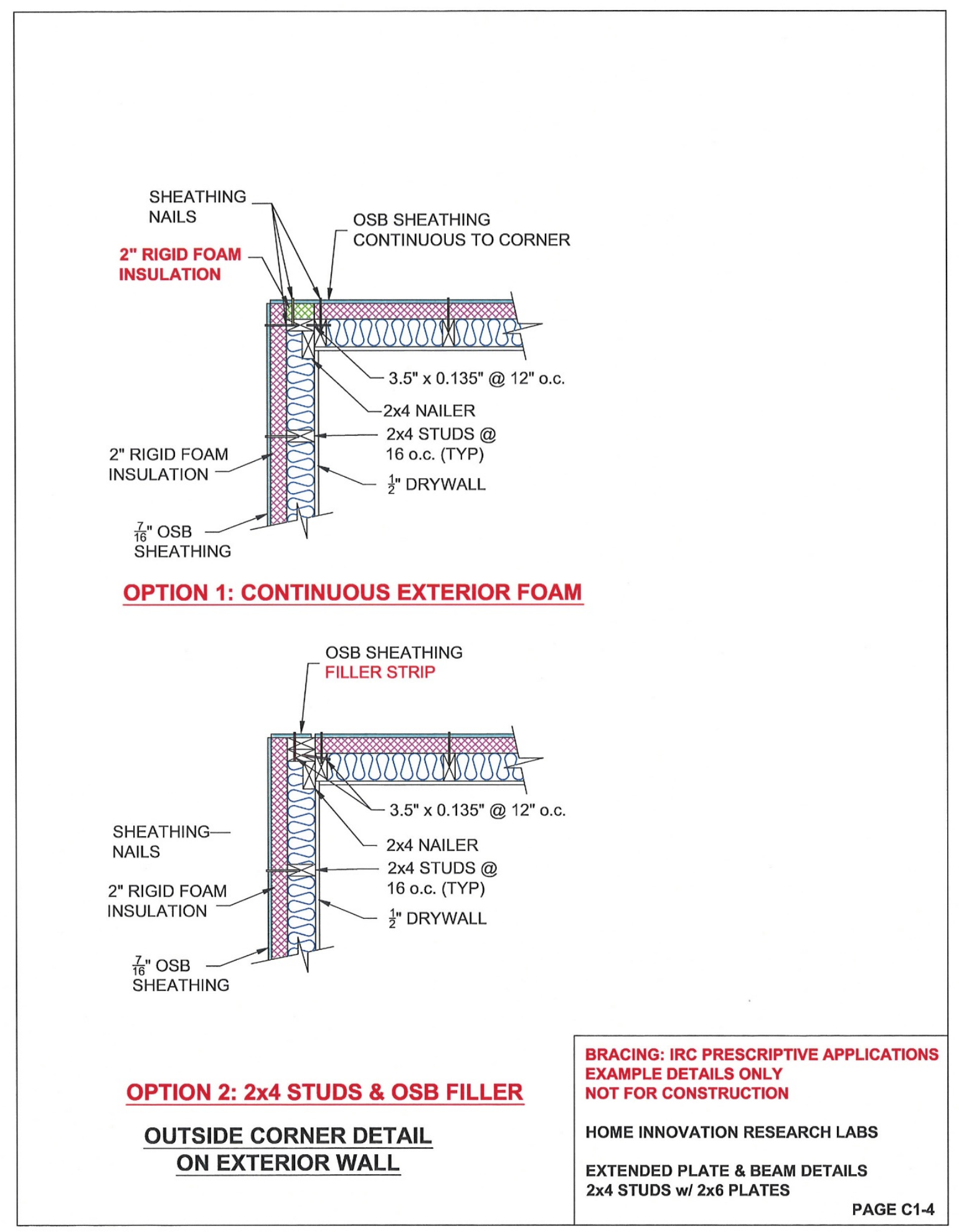




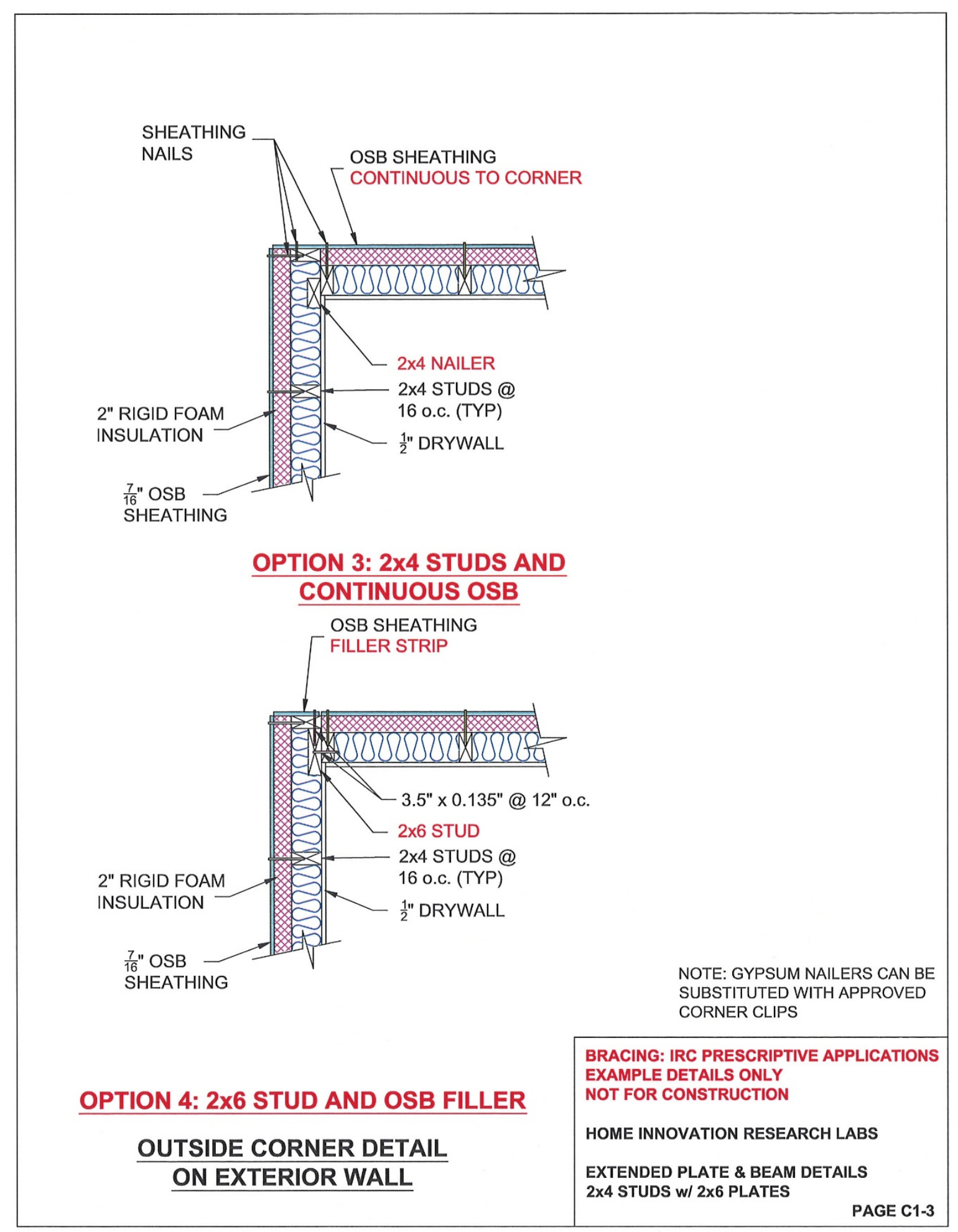




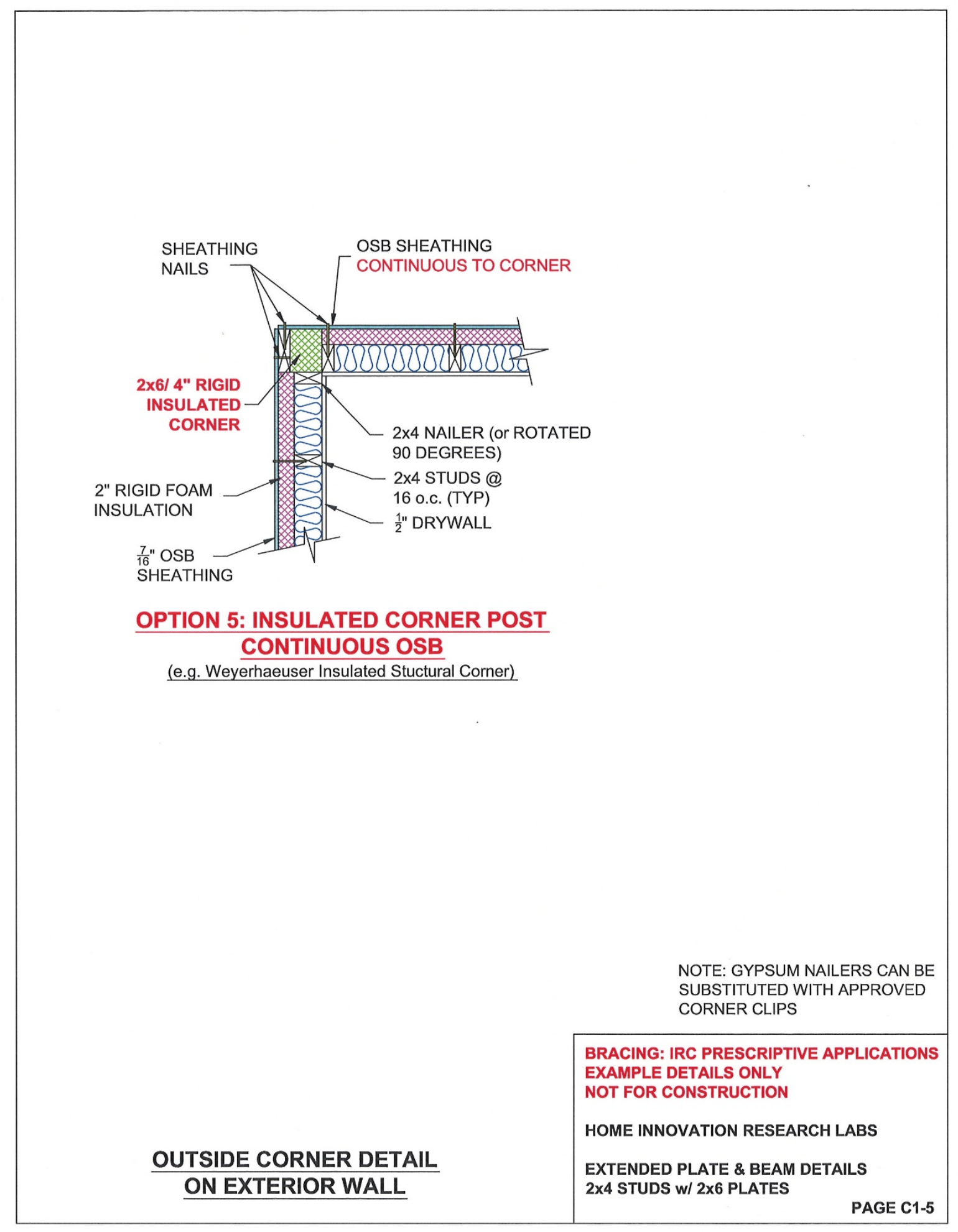




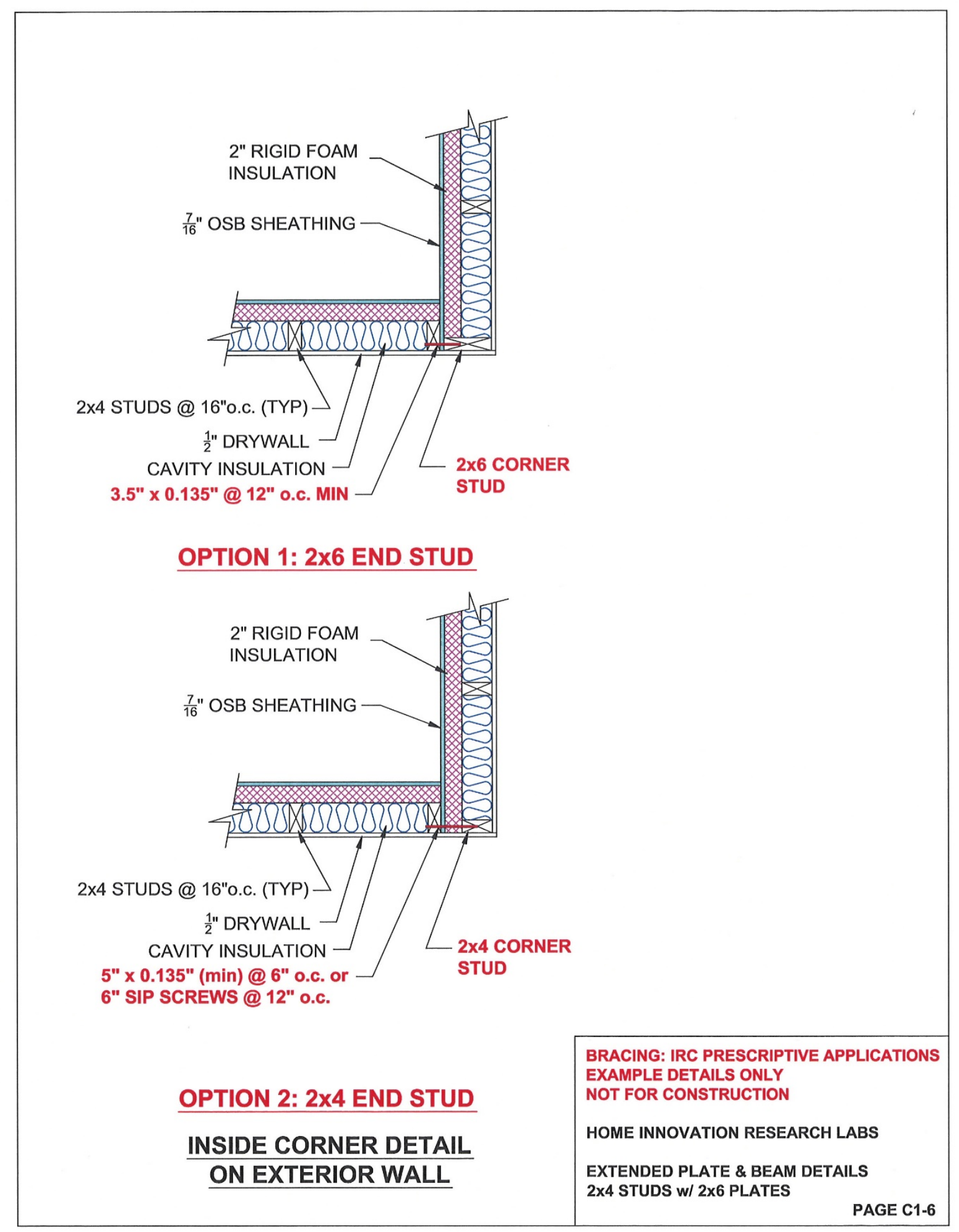




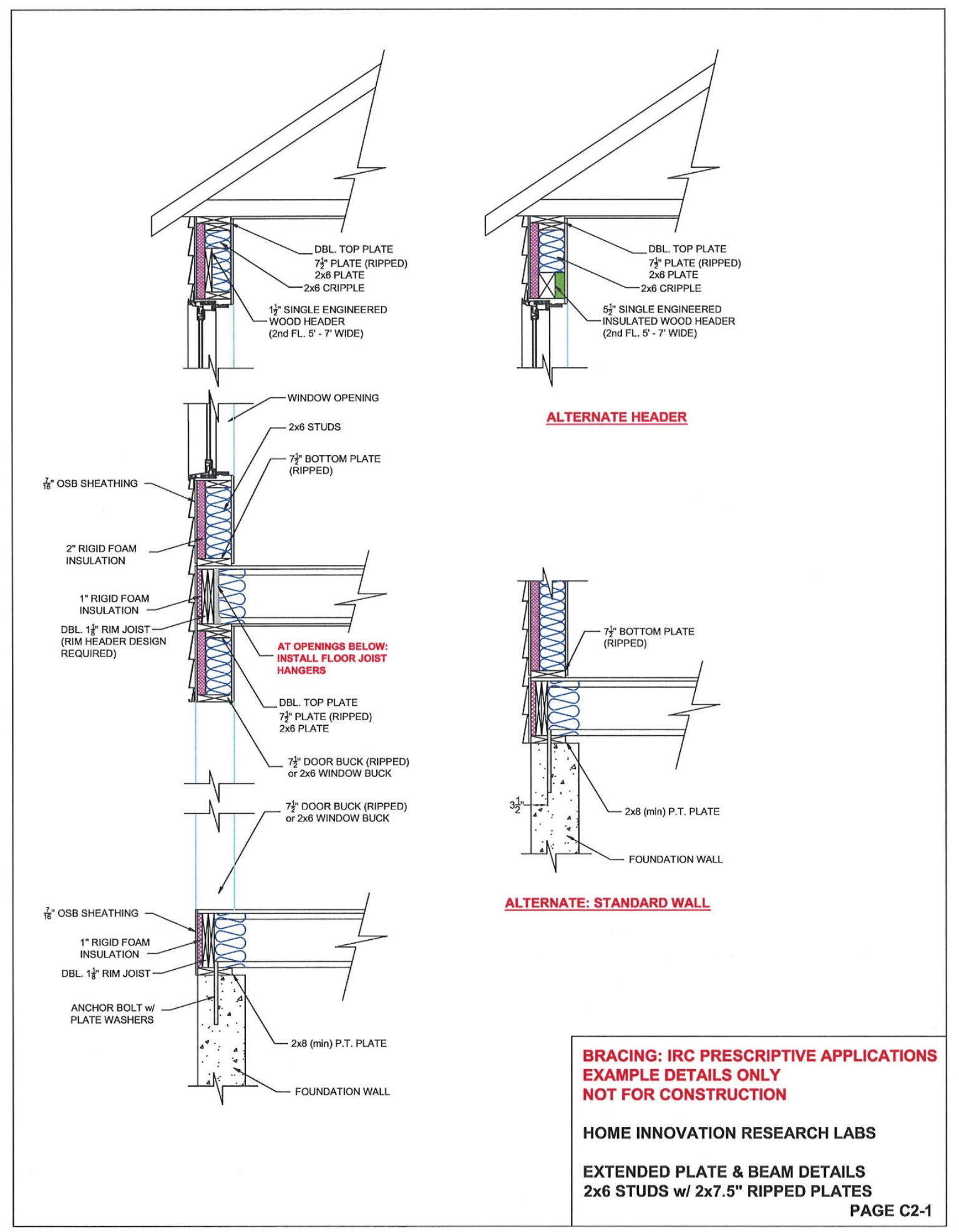




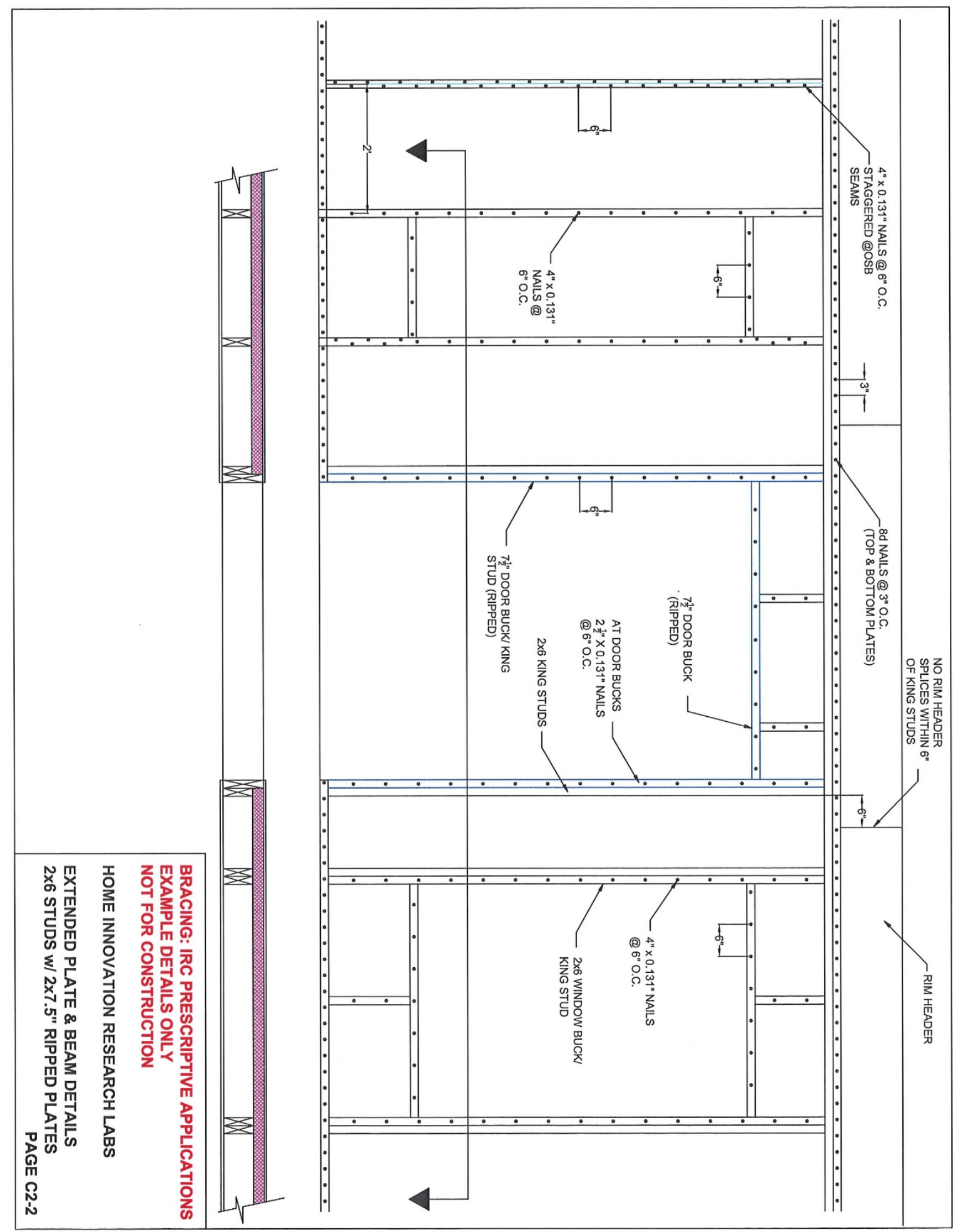




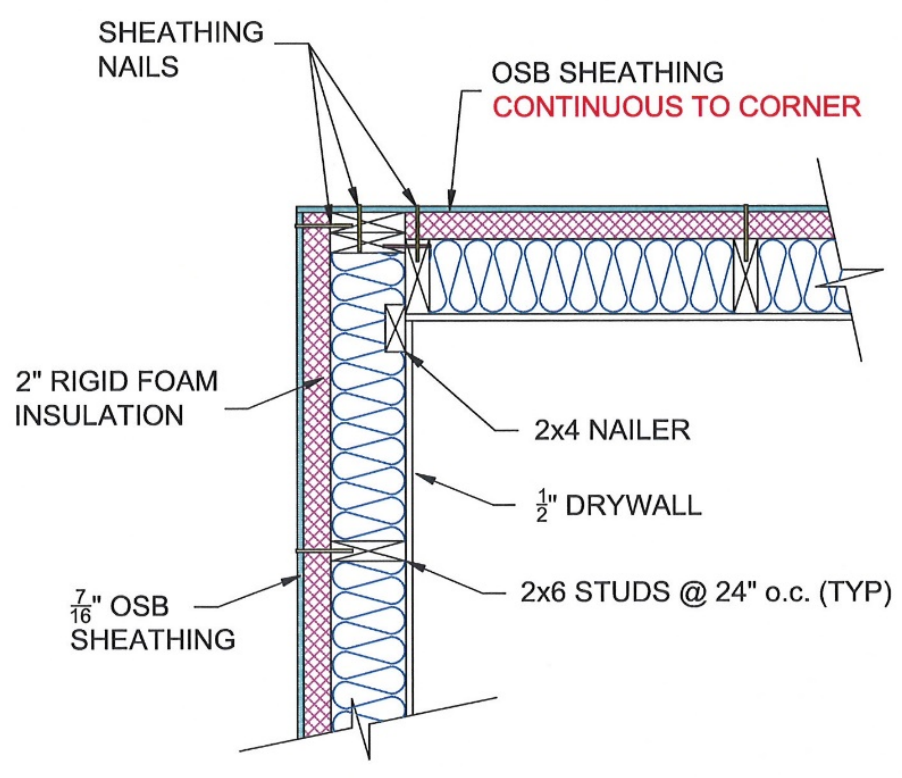

\section{OPTION 1: (2) $2 \times 6$ w/ CONTINOUS OSB}

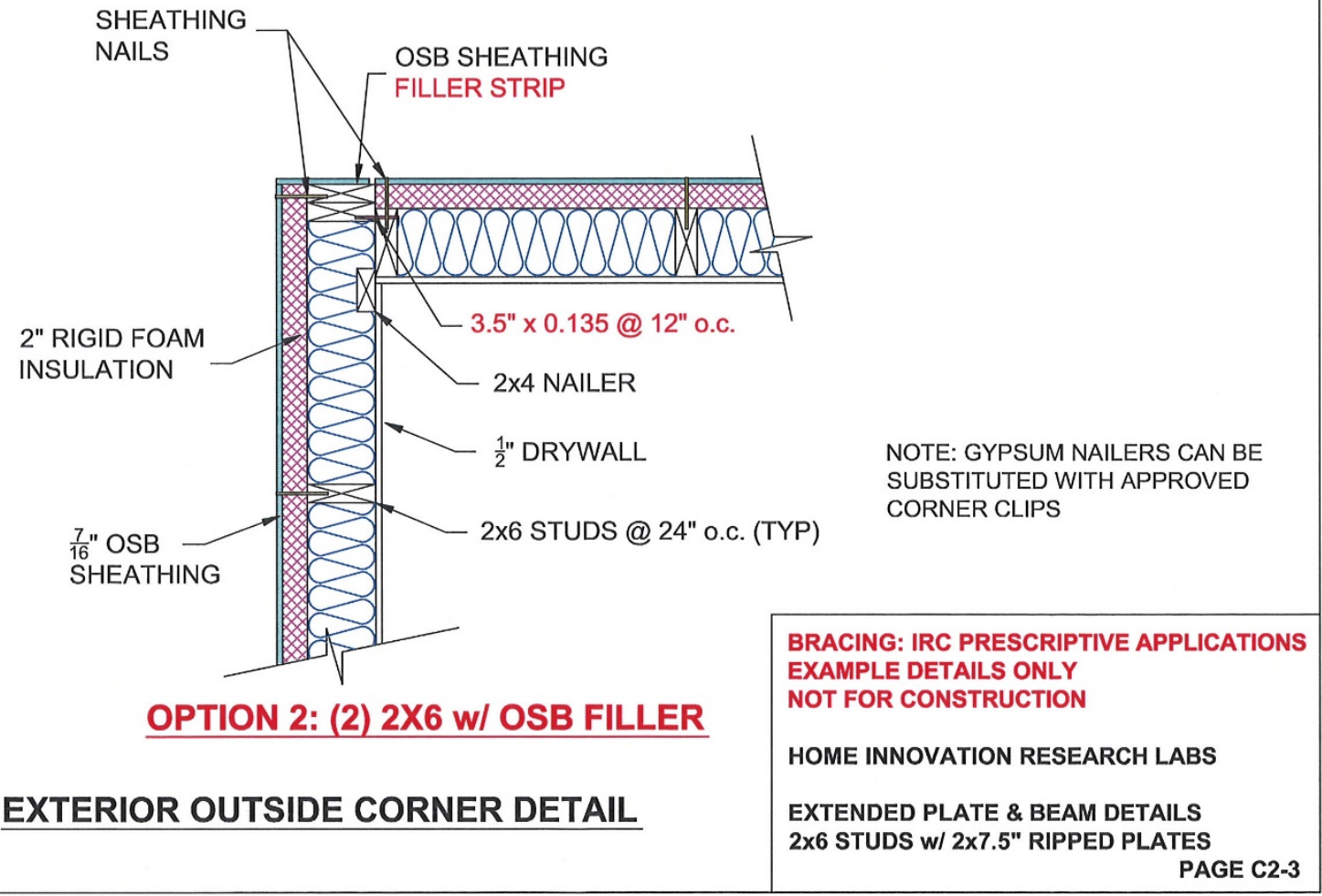




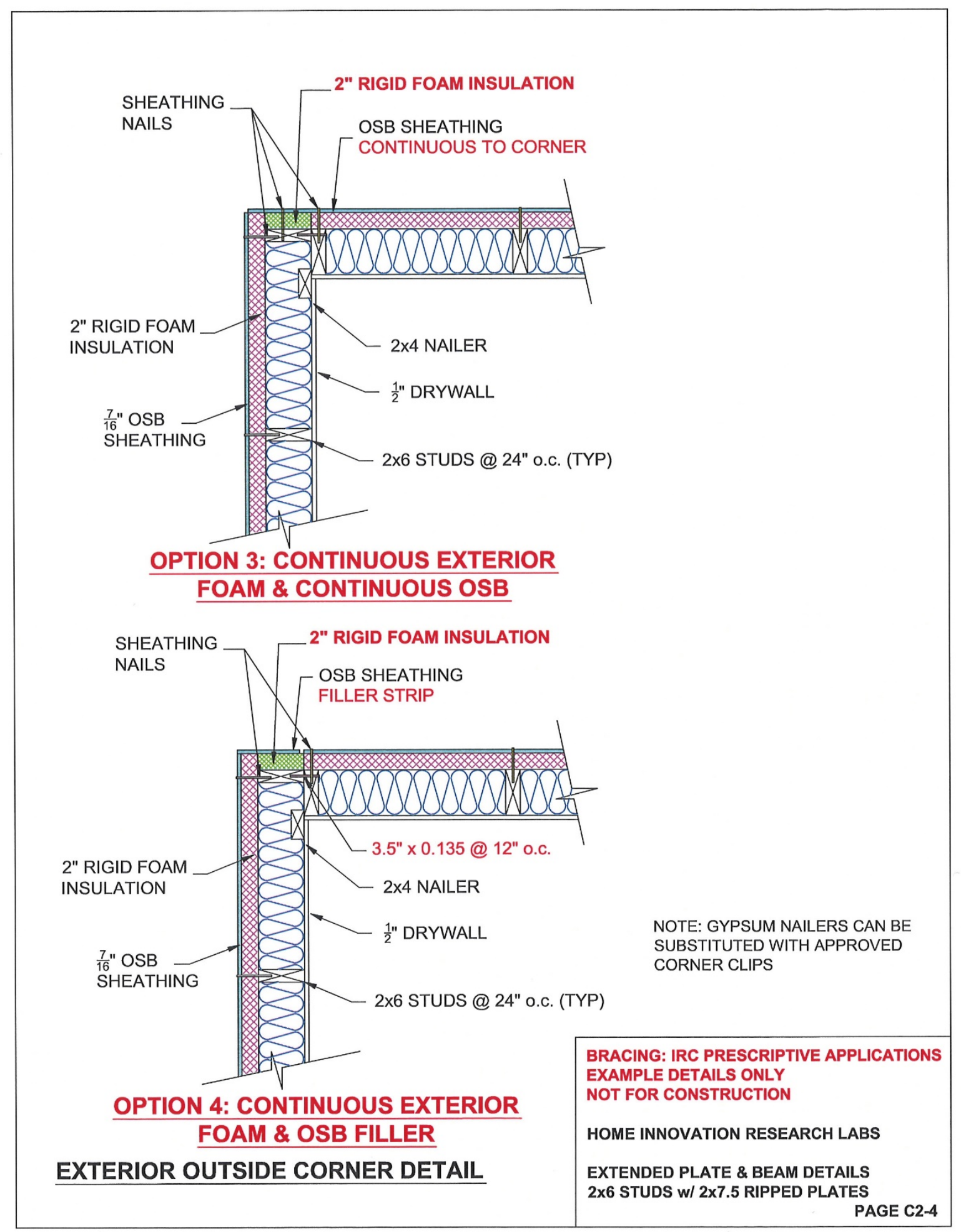




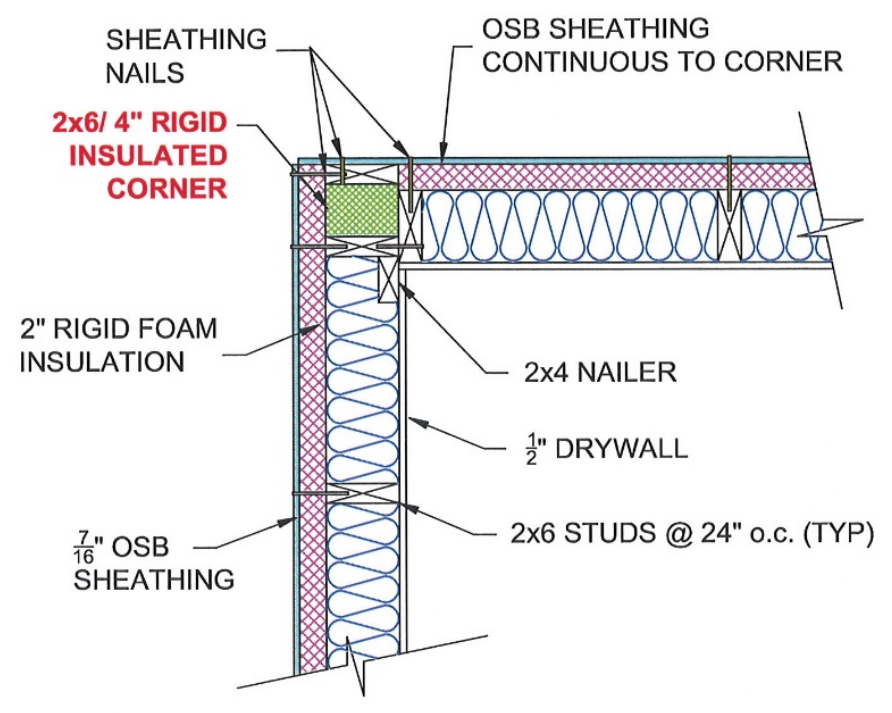

\section{OPTION 5: INSULATED CORNER POST}

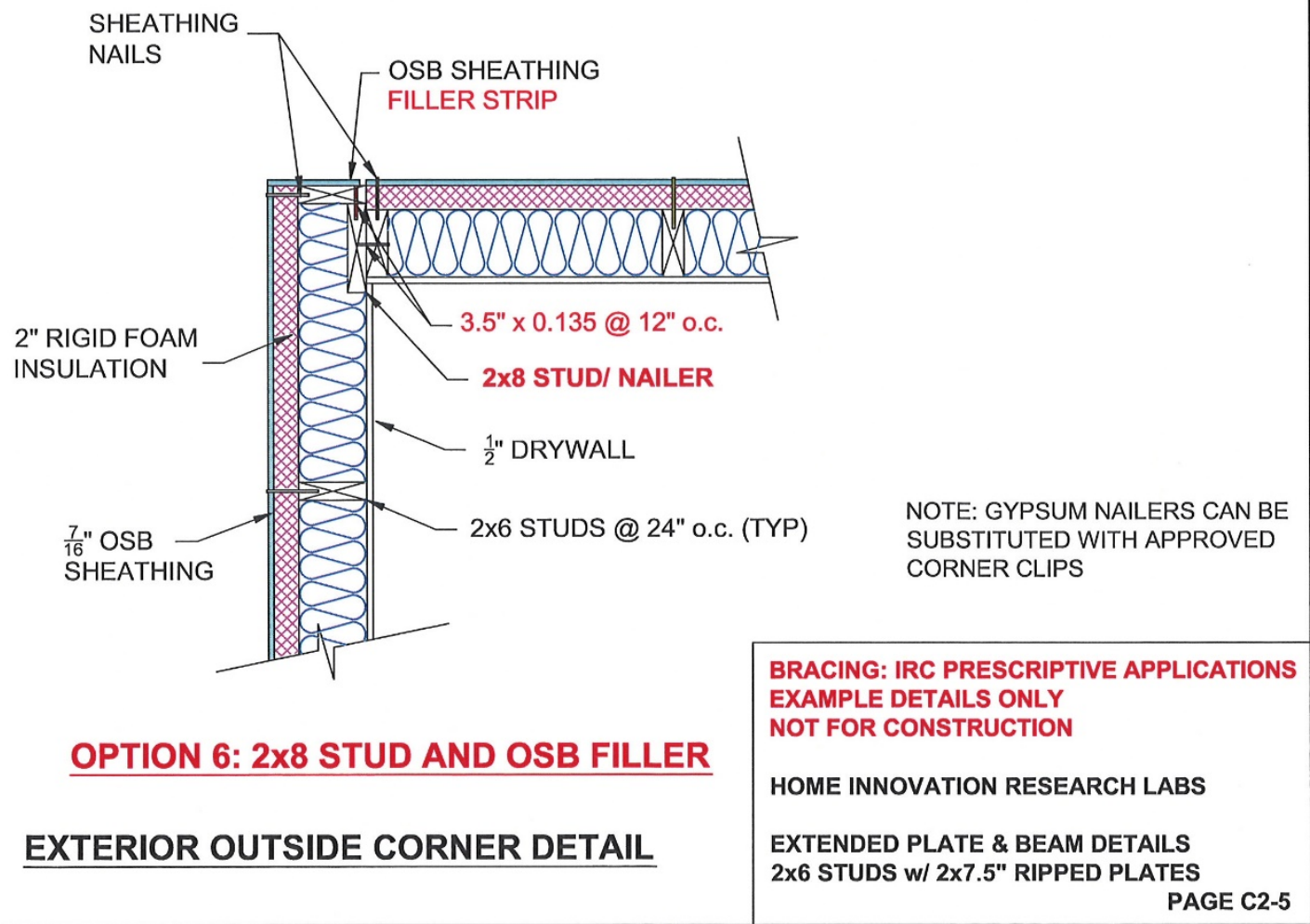




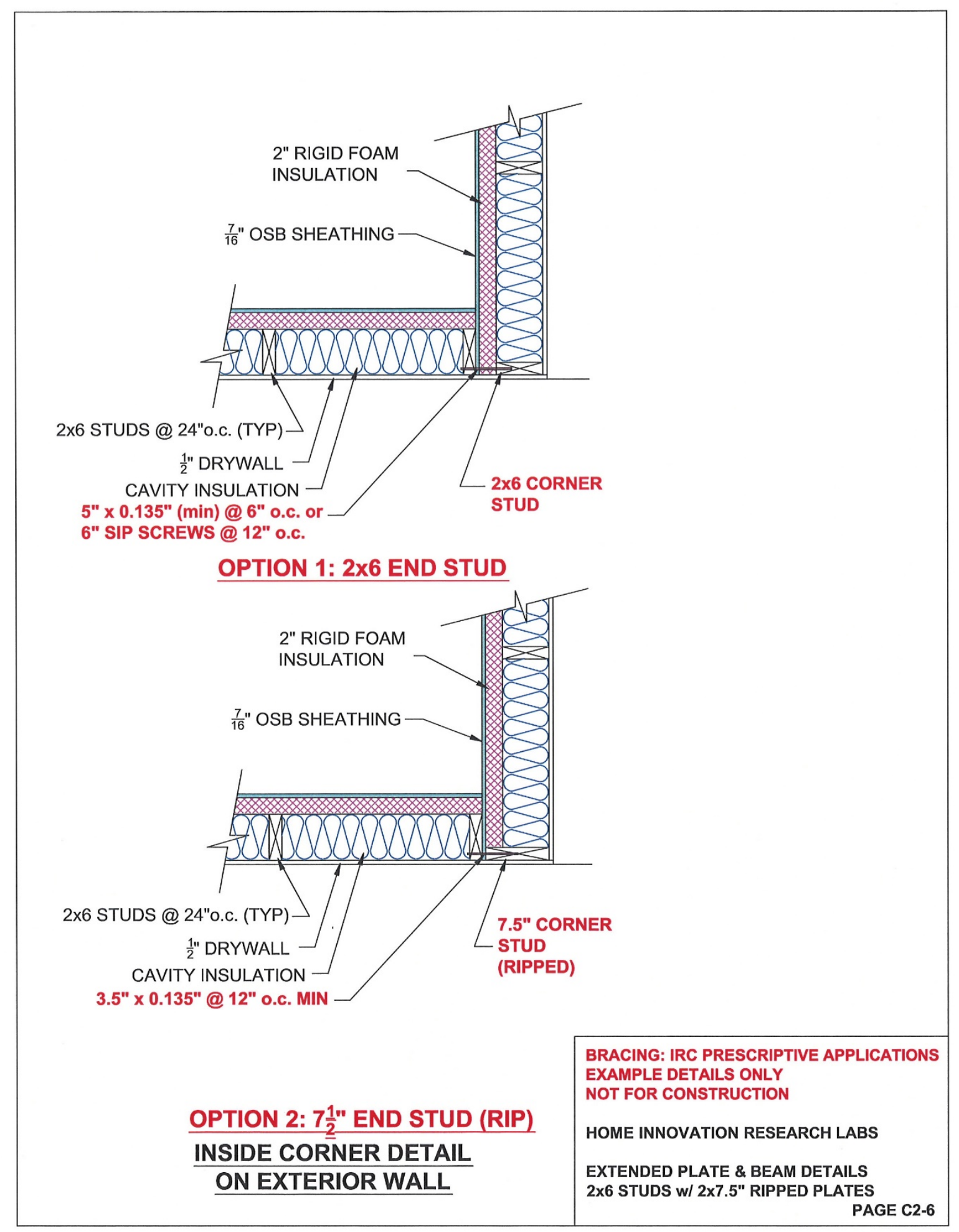




\section{Appendix D. Scope of Work, Field Framing of Extended Plate and Beam Walls}

EP\&B Configuration: $2 \times 4$ studs and $2 \times 6$ plates

\section{Introduction}

1.1. This scope of work addresses the construction procedure for field-framed EP\&B walls in a two-story building with a basement or a crawlspace.

1.2. This scope of work addresses the EP\&B configuration constructed using $2 \times 4$ stud and $2 \times 6$ plates (Configuration 1 ).

1.3. The construction procedure addresses framing and sheathing (including structural and foam sheathing).

1.4. The primary focus is on the methods and materials that are unique to the EP\&B system or impacted by the EP\&B system design. Where framing practices are not altered by the EP\&B design, typical construction methods and material shall be followed.

1.5. All headers shall be in accordance with building code or approved engineered design.

1.6. With exception of the wall structural sheathing nailing schedule that is unique to the EP\&B system, all fastening requirements are consistent with building code requirements for light-frame wood walls as applicable. Approved alternatives shall be permitted.

1.7. For additional information, refer to construction details provided with the Scope of Work.

\section{Material List}

2.1. Dimension lumber: Stud grade or higher

2.2. Wall sheathing: wood structural panels (WSP) - plywood or oriented strand board (OSB) with minimum 7/16 in. thickness

2.3. Engineered wood rim board

2.4. Metal joist hangers (at first-floor openings only - rim header application) per engineered design

2.5. Structural composite lumber (second-floor headers and rim joist application at first floor)

2.6. Insulating rigid board foam sheathing (XPS or Polyisocyanurate)

2.7. Fasteners per construction details

2.8. WSP floor sheathing and engineered floor joists per building plans

\section{Field-Framing Guidelines}

\subsection{Sill plate and First Floor Construction}

3.1.1. Verify sill plate anchor bolt size and spacing is in accordance with the house plans. The anchor bolt edge distance from exterior edge of the foundation wall should be approximately 3.5 in. to allow for the double rim joist installation.

3.1.2. Install minimum $2 \times 6$ pressure treated sill plate and secure using nuts over an appropriately-sized washer. 
3.1.3. Install a double 1-1/4 in. engineered wood rim joist faced-nailed at a nominal spacing of 24 in. on center at top and bottom edges and toe-nailed to sill plate on the exterior face with $8 \mathrm{~d}$ nails (2-1/2 in. $\times 0.113$ in.) at 6 in. on center.

3.1.4. Install engineered floor joists and floor sheathing in accordance with the building plans.

\subsection{Wall construction}

3.2.1. Layout $2 \times 6$ bottom (sole) plate.

3.2.2. Layout $2 \times 4$ studs @ 16 in. on center.

3.2.3. Layout first top plate $(2 \times 4$ framing $)$.

3.2.4. Attach bottom plate to studs and first top plate to studs using (2) $3 \frac{1}{2} \mathrm{in} . \times 0.135$ in. nails at each connection.

3.2.5. Attach second top plate $(2 \times 6$ framing) to the first top plate using $10 \mathrm{~d}$ nails $(3$ in. $\times 0.128$ in.) at 24 in. on center. End joints in double top plates shall be offset at least $24 \mathrm{in}$. and a minimum of eight (8) $10 \mathrm{~d}$ nails $(3 \mathrm{in} . \times 0.128 \mathrm{in}$.) shall be installed in the lapped area. In lieu of the offset, double top plates may be fastened to each other with an approved metal plate connector.

3.2.6. Mark the plates with the location of studs (will be needed for attaching WSP sheathing after foam sheathing is installed).

3.2.7. Install 2-in.-thick rigid foam sheathing over $2 \times 4$ studs between $2 \times 6$ top and bottom plates. The foam sheathing can consist of two layers of 1-in.-thick panels or a single 2-in.-thick layer. Rigid foam sheathing shall fill the entire space between the $2 \times 6$ top and bottom plates except at openings (see Sections 3.3 and 3.5 for framing at openings). The edge/end joints of foam sheathing panels shall be tight against each other and against $2 \times 6$ plate framing members. A rigid foam sheathing panel or a panel section shall span at least one stud bay. Where a double foam layer is used it is recommended that joints are offset between the two layers.

3.2.8. Install WSP sheathing over the insulating rigid foam sheathing. The WSP sheathing shall be oriented vertically and shall be continuous between top and bottom $2 \times 6$ plates. Horizontal WSP orientation or horizontal joints in WSP sheathing shall not be permitted (blocked or unblocked). WSP sheathing shall overlap top and bottom plates by a minimum of 1 in. to allow installation of sheathing nails. All vertical edges shall occur over studs. Use of elongated WSP panels that extend over the rim joists below and/or above the wall is permitted.

3.2.9. Allow 1/8-in. space at all WSP edges (or in accordance with WSP manufacturer's recommendations).

3.2.10. Attach WSP sheathing to $2 \times 6$ top and bottom plates and to $2 \times 4$ studs using nails in accordance with the following schedule:

- At $2 \times 6$ top and bottom plates: a minimum $2 \frac{1}{2}$ in. $\times 0.131$ in. at maximum 3 in. on center.

- At $2 \times 4$ studs through foam sheathing: a minimum 4 in. $\times 0.131$ in. at maximum 6 in. on center (at panel edges and in the field) to allow 1.5-in. penetration into the framing 
Note: 4-in.-long nails can be also used at plates to minimize the number of nail sizes at the job site.

\subsection{First Floor Openings}

3.3.1. Window bucks are framed using $2 \times 4$ studs.

3.3.2. Door bucks are framed using $2 \times 6$ studs to provide for direct attachment of WSP sheathing to achieve a greater stiffness of the door frame.

3.3.3. The space above all openings is framed as for a nonbearing wall (rim header design - see Section 3.4).

3.3.4. Horizontal door/window buck at the top of the opening shall be a continuous member and shall be attached to the exterior WSP sheathing using sheathing nails at 6 in. on center (to provide support for the horizontal buck member).

3.3.5. The number of king studs shall be determined based on the size of the opening in accordance with Table 1 or approved engineered design. (Note: a window or door buck continuous from bottom to top plate is a king stud.)

Table D1. Number of King Studs at First Floor Openings (Rim Header) ${ }^{a}$

\begin{tabular}{|c|c|c|}
\hline Opening Width, ft & At Window Opening & At Door Opening $^{\mathbf{b}}$ \\
\hline 3 & 1 & 1 \\
\hline 4 & 2 & 1 \\
\hline 6 & 3 & 2 \\
\hline 8 & 3 & 2 \\
\hline 10 & 4 & 3 \\
\hline 12 & 5 & 4 \\
\hline
\end{tabular}

a. The number of king studs at each side of the opening.

b. Number of king studs is reduced at door opening because the first stud (buck) is a $2 \times 6$ member.

3.3.6. WSP sheathing is connected to window or door bucks using $4 \mathrm{in} . \times 0.131 \mathrm{in}$. nails at 6 in. on center $\left(2 \frac{1}{2}\right.$ in. $\times 0.131$ in. nails are permitted for use with $2 \times 6$ door bucks where sheathing is applied directly to framing.)

\subsection{Rim Headers and Second Floor Construction}

3.4.1. Install double 1-1/4 in. engineered wood rim joist along the entire perimeter of the wall.

3.4.2. Rim joists shall not have splice joints over an opening and the first splice joint to each side of the opening shall occur a minimum of 6 in. away from the opening edge and past the outermost king studs (rim header application).

3.4.3. Double rim joist shall be faced-nailed at top and bottom edges at a nominal spacing of $24 \mathrm{in}$. on center and at $16 \mathrm{in}$. on center over openings with minimum 2.5 in. $\times 0.131$ in. nails. The exterior rim shall be toe-nailed to top plate with $8 \mathrm{~d}$ nails (2-1/2 in. $\times 0.113$ in.) at 6 in. on center. 
3.4.4. The maximum rim joist span shall be verified by a licensed professional. (Note: A double 1-1/4 X11.875 structural composite lumber member is sufficient for most openings up to $8 \mathrm{ft}$ wide).

3.4.5. Install engineered wood floor joists in accordance with the floor plans.

3.4.6. Floor joists located above an opening shall be supported by a metal joist hanger selected by a licensed professional based on design loads.

3.4.7. Install WSP floor sheathing in accordance with the building plans.

\subsection{Top Floor Openings}

3.5.1. Top floor openings are conventionally framed using single $1 \frac{1}{4}-$ to $1 \frac{1}{2}$-in.-thick engineered wood headers (up to 5-7 ft) or double engineered wood headers (for larger openings).

3.5.2. Where single header is used, it is insulated with 2 -in. rigid foam sheathing on the interior face of the header.

3.5.3. Headers are supported by jack studs. The number of jack studs and king studs is determined based on standard practice in accordance with building code or engineered design.

\subsection{Corner Details (Exterior Walls)}

3.6.1. Construct wall corners at intersecting exterior walls using one of the details provided with this Scope of Work.

3.6.2. Framing members at the corners are arranged in a manner to minimize thermal bridging and allow for increased quality and level of insulation installation. Rigid foam sheathing insulation is installed at the corners as provided on the details.

3.6.3. The intersecting walls shall be connected to each other at the corner using one of the options:

- Adjacent framing members are nailed directly to each other using $3.5 \mathrm{in} . \times$ 0.135 in. nails at 12 in. on center.

- Adjacent framing members that are separated by up to 2 in. of rigid foam sheathing insulation are nailed to each other using 5 in. $\times 0.135$ in. nails at 6 in. on center or using 6 in. $\times 0.190$ in. SIP screws at 12 in. on center.

- Exterior WSP sheathing from both intersecting walls is nailed directly to a common $2 \mathrm{x}$ framing member using minimum 2.5 in. $\times 0.131$ in. nails spaced a maximum of 6 in. on center (for each wall).

- Other approved fastening methods.

3.6.4. Double top plates are overlapped at corners and intersections and two (2) 3 in. $\times$ 0.128 in. nails installed at each lap (face-nailed). Alternatively, the intersecting walls are fastened to each other with an approved metal plate connector. 


\section{Appendix E. Instrumentation Accuracy}

\begin{tabular}{|l|l|r|}
\hline \multicolumn{1}{|c|}{ Sensor } & \multicolumn{1}{c|}{ Test } & Uncertainty of Measurement \\
\hline UTM load cell & Vertical Load & $8 \mathrm{lb}$ \\
\hline Racker load cell & Shear Wall & $51 \mathrm{lb}$ \\
\hline Racker string pot & Shear Wall & $0.0017 \mathrm{inch}$ \\
\hline Racker LVDTs & Shear Wall & $0.0142 \mathrm{inch}$ \\
\hline
\end{tabular}


buildingamerica.gov

U.s. DEPARTMENT OF Energy Efficiency \& Nㅡㄹㅡ Renewable Energy 